\title{
IntechOpen
}

\section{Evaluation of Health Services}

Edited by Sandeep Reddy and Aida Isabel Tavares 



\section{Evaluation of Health Services}

Edited by Sandeep Reddy and Aida Isabel Tavares 

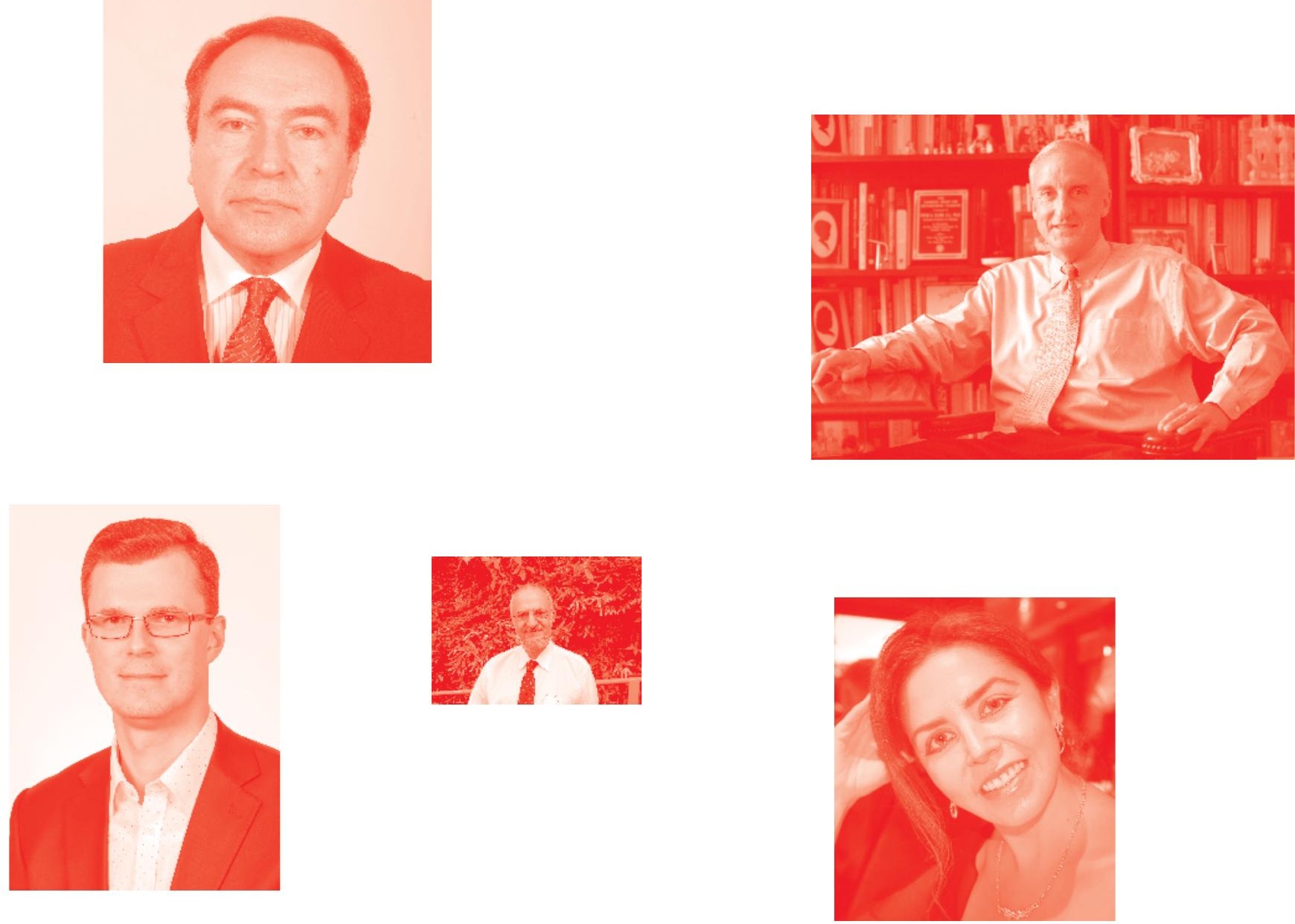

Supporting open minds since 2005
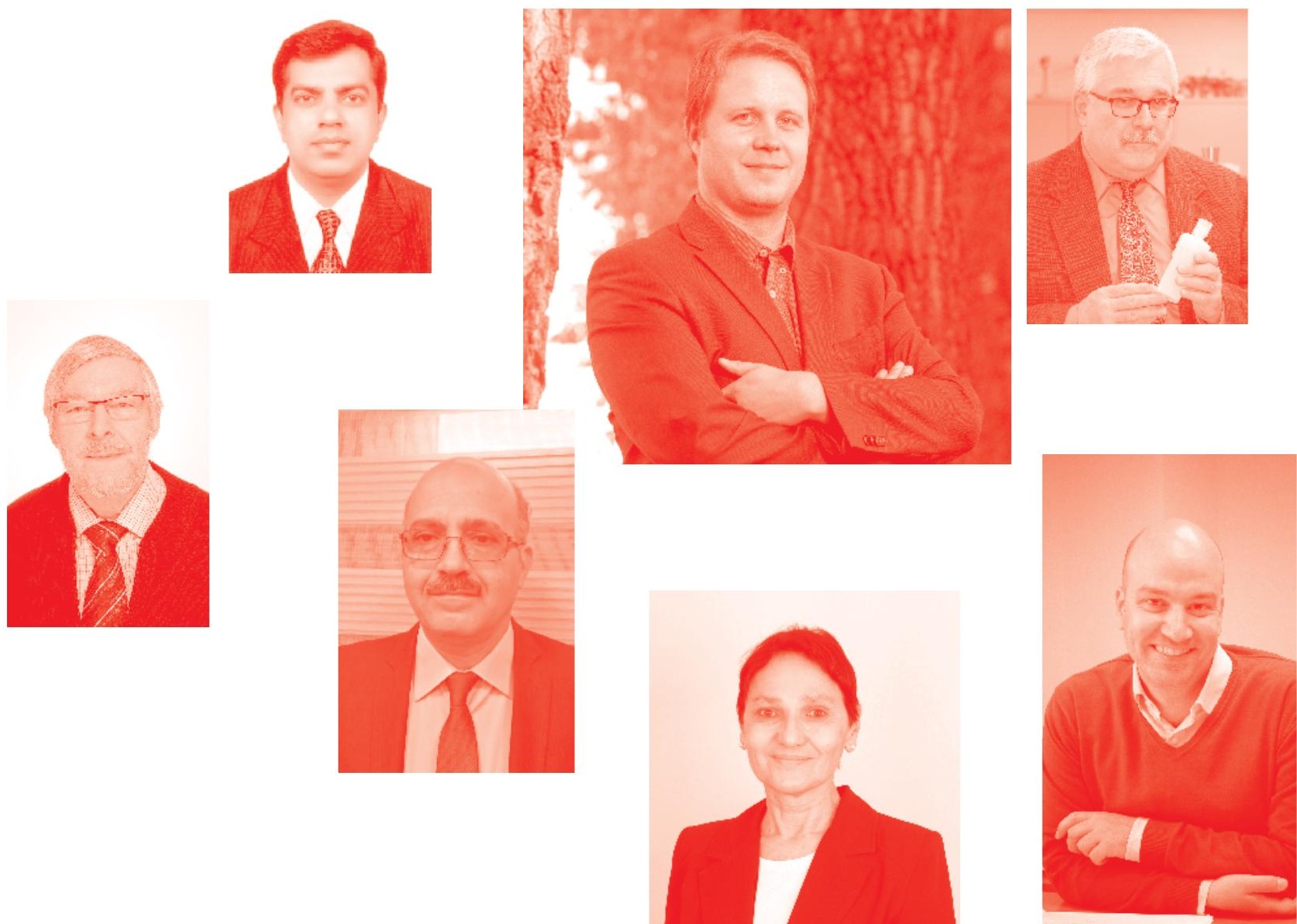
Evaluation of Health Services

http : //dx. doi. org/10.5772/intechopen. 79149

Edited by Sandeep Reddy and Aida Isabel Tavares

Contributors

Anke-Peggy Holtorf, Shanlian Hu, Diana Brixner, Kalman Wijaya, Jiangijang He, Anunchai Assawamakin, Nikolaos Maniadakis, John Mellor-Clark, Scott Steen, Sandeep Reddy, Ajit Yadav, Akansha Singh, Edgar Cambaza, Edson Mongo, Robina Nhambire, Jacinto Singo, Edsone Machava, Eun-Whan Lee, Hyeon-Jin Choi, Aida Isabel Tavares

( ) The Editor(s) and the Author(s) 2020

The rights of the editor(s) and the author(s) have been asserted in accordance with the Copyright, Designs and Patents Act 1988. All rights to the book as a whole are reserved by INTECHOPEN LIMITED . The book as a whole (compilation) cannot be reproduced, distributed or used for commercial or non-commercial purposes without INTECHOPEN LIMITED's written permission. Enquiries concerning the use of the book should be directed to INTECHOPEN LIMITED rights and permissions department (permissions@intechopen.com).

Violations are liable to prosecution under the governing Copyright Law .

\section{(cc) BY}

Individual chapters of this publication are distributed under the terms of the Creative Commons Attribution 3. 0 Unported License which permits commercial use, distribution and reproduction of the individual chapters, provided the original author(s) and source publication are appropriately acknowledged. If so indicated, certain images may not be included under the Creative Commons license. In such cases users will need to obtain permission from the license holder to reproduce the material. More details and guidelines concerning content reuse and adaptation can be found at http : //www . intechopen . com/copyright-policy . html.

\section{Notice}

Statements and opinions expressed in the chapters are these of the individual contributors and not necessarily those of the editors or publisher. No responsibility is accepted for the accuracy of information contained in the published chapters. The publisher assumes no responsibility for any damage or injury to persons or property arising out of the use of any materials, instructions, methods or ideas contained in the book.

First published in London, United Kingdom, 2020 by IntechOpen

IntechOpen is the global imprint of INTECHOPEN LIMITED, registered in England and Wales,

registration number: 11086078, 7th floor, 10 Lower Thames Street, London,

EC3R 6AF, United Kingdom

Printed in Croatia

British Library Cataloguing-in-Publication Data

A catalogue record for this book is available from the British Library

Additional hard and PDF copies can be obtained from orders@intechopen.com

Evaluation of Health Services

Edited by Sandeep Reddy and Aida Isabel Tavares

p. cm.

Print ISBN 978-1-83880-154-0

Online ISBN 978-1-83880-163-2

eBook (PDF) ISBN 978-1-83880-164-9 


\section{We are IntechOpen, \\ the world's leading publisher of Open Access books}

Built by scientists, for scientists

\section{$4,700+$}

Open access books available

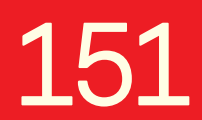

Countries delivered to
$120,000+$

International authors and editors

Our authors are among the

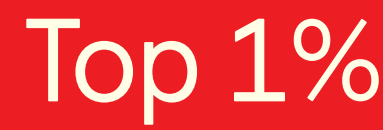

most cited scientists

Contributors from top 500 universities
$135 \mathrm{M}+$

Downloads

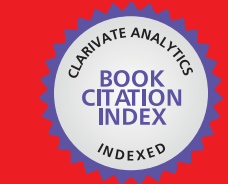

WEB OF SCIENCE ${ }^{\mathrm{MM}}$

Selection of our books indexed in the Book Citation Index in Web of Science ${ }^{\mathrm{TM}}$ Core Collection (BKCI)

\section{Interested in publishing with us? \\ Contact book.department@intechopen.com}

Numbers displayed above are based on latest data collected.

For more information visit www.intechopen.com 



\section{Meet the editors}

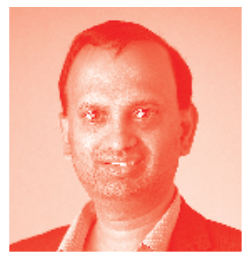

Associate Professor Sandeep Reddy is the Director of the MBA (Healthcare Management) program and Course Chair of the Graduate Certificate of Hospital Administration in the School of Medicine, Deakin University, Australia. Sandeep has a background in health service management, public health and medicine. Following some years in clinical practice and medical education, Sandeep attained extensive experience managing various health service projects and formulating high-level policy in Australia, New Zealand, and Europe. Sandeep is currently focusing on teaching and research in healthcare management, medical informatics, and health program evaluation. Sandeep is a certified health informatician and also has a Ph.D., which involved a realist evaluation of emergency department access in the context of health reforms.

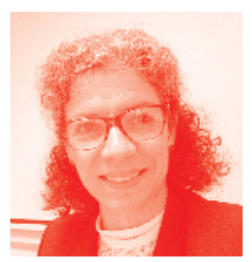

Aida Isabel Tavares holds a PhD in Economic Analysis awarded by the Autónoma University of Barcelona in 2008. Her research focus has been on health economics, and policy and management and she has published several articles in international peer-reviewed journals. She has also published a book on Public Economics. Prof. Tavares has taught several courses including microeconomics, health economics, and public economics. Currently she collaborates with the Centre of Studies and Research in Health of the University of Coimbra and she is Assistant Professor in the Lisbon School of Economics and Management, University of Lisbon. 



\section{Contents}

Preface

Section 1

Introduction

Chapter 1

Introductory Chapter: Evaluation of Health Services

by Sandeep Reddy

Section 2

Health Service Evaluation

Chapter 2

Value-Based Evaluation of Chinese Provincial Health Insurance

Policy Schemes

by Shanlian Hu, Anke-Peggy Holtorf, Kalman Wijaya, Jiangjiang He

and Diana Brixner

Chapter 3

Age- and Sex-Specific Burden of Morbidity and Disability in India:

A Current Scenario

by Ajit Kumar Yadav and Akansha Singh

Chapter 4

Evaluating the Efficiency of a Collaborative Learning Network in

Supporting Third Sector Organisations in the UK

by Scott Steen and John Mellor-Clark

Chapter 5

Outbreak of Cholera Due to Cyclone Idai in Central Mozambique (2019)

by Edson Mongo, Edgar Cambaza, Robina Nhambire, Jacinto Singo

and Edsone Machava

Section 3

Economic Evaluation

Chapter 6

Weighing Price and Performance for Decisions for Multisource

Pharmaceutical Bidding in Public Hospitals in Thailand

by Anunchai Assawamakin, Anke-Peggy Holtorf and Nikolaos Maniadakis 
Chapter 7

The Burden of Informal Caregivers of Alzheimer's Patients:

An Estimation to Portugal

by Aida Isabel Tavares and Carolina Freitas

Chapter 8

Methodology of Estimating Socioeconomic Burden of Disease

Using National Health Insurance (NHI) Data

by Hyeon-Jin Choi and Eun-Whan Lee 


\section{Preface}

As the costs and resources of delivering health services have increased over the years, the importance of evaluating in the health sector has become essential. Evaluation includes assessing health services, interventions, and burden of disease comprising the measurement of death, disability, and loss of health due to diseases, injuries, and risk factors.

An evaluation provides a systematic process of assessing the efficacy and efficiency of health services, including an assessment of their impact on beneficiaries, whether it be individuals or communities. The methods of evaluating health services and disease burden, including data collection and analysis, have evolved in line with the complexity of delivering health care and health interventions. The rich picture that different evaluation methods derive has become critical in informing stakeholders and policy makers about the value of a particular program or intervention. Evaluation allows the improvement of disease prevention, control of disease outbreaks, and helps in addressing health inequities.

In this book, various evaluation studies are detailed, providing an excellent resource for both evaluation practitioners and academics alike. The book mainly focuses on exemplifying how and where evaluation is used rather than the methodology as such. However, a collection of economic evaluation focused chapters presents a comprehensive resource for readers who are interested in this area. Added to this is a discussion of novel evaluation approaches that can be used to assess the quality of programs, and burden of diseases. The evaluation of burden of disease is taken in a broad perspective so that different analyses are described in this book. The contributions go from estimating the cost of illness in Korea, the burden of morbidity in India, to the cost of malaria and cholera outbreaks in Mozambique.

The geographical range and variety of case studies showcase how evaluation has become integral for health service planning and assessment and assists public health policy makers to decide how to use limited resources to minimize burden and inequity. This book will act as a ready resource for both experienced workers and those intending to learn about health service evaluation.

Sandeep Reddy Associate Professor, School of Medicine, Deakin University, Victoria, Australia 
Aida Isabel Tavares

Assistant Professor,

Lisbon School of Economics and Management,

Lisbon University,

Lisbon, Portugal 
Section 1

\section{Introduction}





\title{
Introductory Chapter: Evaluation of Health Services
}

\author{
Sandeep Reddy
}

\section{Introduction}

While health services intend to address the healthcare needs of their respective populations, many a time, they are unclear as to how to expend their resources to attain optimal outcomes [1]. In times of financial constraints and increasing burden of chronic diseases, it is essential to maximise available resources to ensure sustainable healthcare delivery [2]. As funds will always be scarce in relation to growing need, appropriate choices have to be made [3]. Decision-makers need to prioritise resources for options that derive maximum benefit-public health or economic. With the growth of health service data based on technological improvements in collecting data, availability of information to make these choices has not been an issue [1]. It is rather the need for an appropriate framework, which can guide decisionmakers as to what needs to be prioritised. In this regard, evaluation, in particular, evaluation of health outcomes, as a framework has been shown to be useful to guide appropriate health service planning and implementation $[1,4,5]$.

\section{Evaluation}

Program evaluation has been described as a systematic process that examines the value of a program or project in light of its efficiency, effectiveness and appropriateness [4]. Appropriate evaluation supports accountability and enables a robust evidence base to guide health service planning and delivery. While there are various forms of evaluation approaches, commonly, many of these approaches fit under formative, process and summative types depending on the implementation phase. Evaluators need to consider the context of the program they are assessing, stakeholder needs and the resources available and use discretion to choose the type of evaluation approach [5]. In instances, where there is not enough clarity about the link between the interventions and outcomes, other parameters such as appropriateness and progress of the intervention can be considered in the evaluation process [1].

A type of evaluation termed economic evaluation is increasingly becoming popular. It is a technique initially developed by economists but now widely adopted by other practitioners too [3]. Basically, it compares the benefits and costs associated with an intervention and informs options that could be adopted. While there are various forms of economic evaluation including cost-effectiveness analysis, cost-utility analysis and cost-minimisation analysis, the 'cost-benefit' framework is common to all these forms [3]. Economic evaluation, however, assesses only one aspect of a healthcare intervention and should be complemented by other forms of assessment including clinical evaluation. Ideally, economic evaluation should be supported by clinical trials, so appropriate data can inform decision-making. 


\section{Innovative approaches}

Many evaluation types being used to assess healthcare interventions have been in use for many years. However, this does not mean they are appropriate for all the healthcare interventions or programs they are assessing [6]. There may be in certain instances requirement of customised evaluation approaches. One such innovative model is the integrated model of evaluation (IMoE) [6]. This model is a hybrid of traditional evaluation approaches that focus on before-after and input-output aspects of programs and theory-driven evaluation approaches that consider the context in which the program operates and formulates a program theory as to how the intervention leads to anticipated outcomes. While considering both approaches, it also presents a more practical version by utilising realistic elements that can be pursued in a timely manner. Besides, the model aligns with the health program context by measuring quality improvement and change that are critical to many health interventions [6]. The key components of the IMoE are outlined in Figure 1 and described below.

a. Program theory is a causal statement of how the program outcomes are to be achieved as a result of the program intervention in the relevant context presented.

b.Intervention comprises the resources and inputs being introduced through the program or project.

c. Change considers the variations that emerge as a result of the intervention.

d.Outcomes relate to the program objectives or results.

The IMoE implementation approach involves formulating a preliminary program theory and then testing it through collection and analysis of data [6]. The model is a neutral method and favours ways that are appropriate to the context and objectives being assessed. This approach allows for before-after intervention assessment but with a robust theoretical underpinning. Further, the evaluation of

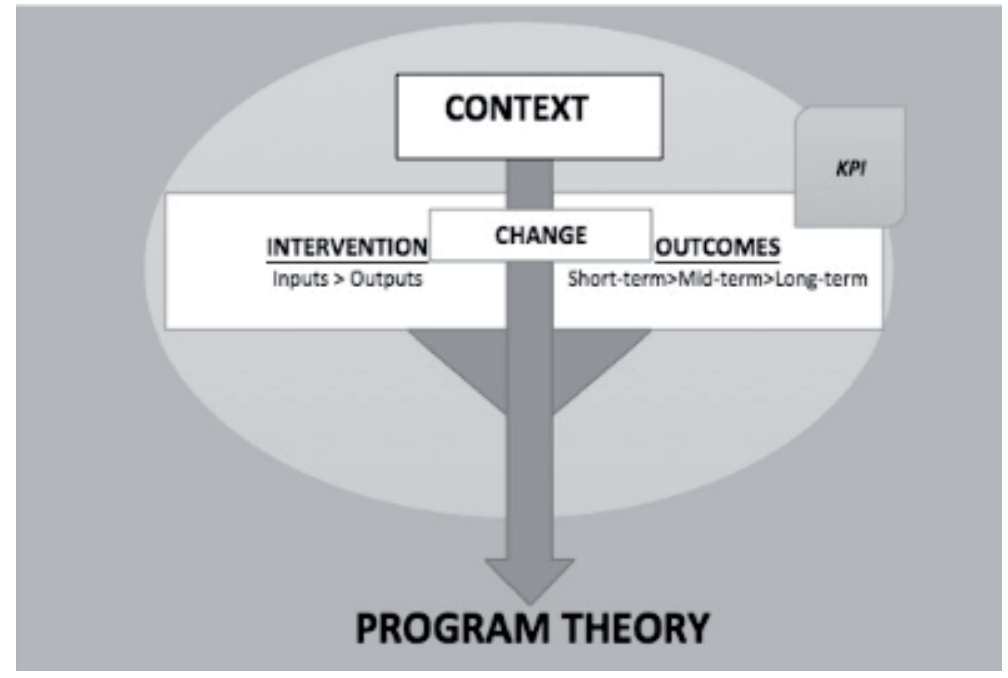

Figure 1.

Integrated model of evaluation. Source: Reddy et al. [6]. 
change that has occurred provides a comprehensive picture of the effects of the intervention. Thus, the hybrid approach of the IMoE enables stakeholders to gain more value from commissioning evaluation than relying either on traditional or theory-driven approaches alone.

\section{Conclusion}

In an era of scarce resources, budgetary pressures and increasing burden of diseases, it is crucial that stakeholders plan and implement healthcare programs appropriately $[2,3]$. Evaluation is not just for assessment of the efficacy of an intervention or program; it can be used to guide planning too $[1,6]$. Appropriate forms of evaluation can benefit not only the funders but also the community by ensuring the sustainability of health programs and realisation of better outcomes.

\section{Author details}

Sandeep Reddy

School of Medicine, Deakin University, Victoria, Australia

*Address all correspondence to: sandeep.reddy@deakin.edu.au

\section{IntechOpen}

(C) 2020 The Author(s). Licensee IntechOpen. This chapter is distributed under the terms of the Creative Commons Attribution License (http://creativecommons.org/licenses/ by/3.0), which permits unrestricted use, distribution, and reproduction in any medium, provided the original work is properly cited. (cc) BY 


\section{References}

[1] Irwig L. An approach to evaluating health outcomes. New South Wales Public Health Bulletin. 1993;4(12):135

[2] Reeve C, Humphreys J, Wakerman J. A comprehensive health service evaluation and monitoring framework. Evaluation and Program Planning [Internet] . 2015;53:91-98. DOI: 10.1016/j.evalprogplan.2015.08.006

[3] Robinson R. Economic evaluation and health care. What does it mean? BMJ. 1993;307(6905):670-673

[4] ACI. Understanding Program Evaluation-An ACI Framework. Agency for Clinical Innovation, NSW. May 2013. Available from: https://www. aci.health.nsw.gov.au/_data/assets/ pdf_file/0008/192437/FrameworkProgram-Evaluation.pdf

[5] Ukoumunne OC, Gulliford MC, Chinn S, Sterne JAC, Burney PGJ, Donner A. Evaluation of health interventions at area and organisation level. British Medical Journal. 1999;319(7206):376-379

[6] Reddy S, Namara KM, Malakellis M, Denton T, McDonald C, Opie J, et al. Evaluation of clinical quality improvement interventions: Feasibility of an integrated approach. Pilot and Feasibility Studies. 2019;5(1):1-9 
Section 2

\section{Health Service Evaluation}





\title{
Value-Based Evaluation of Chinese Provincial Health Insurance Policy Schemes
}

\author{
Shanlian Hu, Anke-Peggy Holtorf, Kalman Wijaya, \\ Jiangjiang He and Diana Brixner
}

\begin{abstract}
Since 2011, an international group of health policy experts has been working on a value-framework to be used for pharmaceutical policy decisions based on multicriteria decision analysis (MCDA). This tool can be easily adapted to a local decision-making context through a facilitated workshop format. Several workshops have been conducted in emerging markets to test the acceptance and feasibility of using MCDA in local decision-making. In China, national policy goals for expanding health-care coverage pressure the provincial governments to implement more comprehensive coverage schemes. This chapter demonstrates the adaptation of a global value-framework to the local policy environment. In September 2018, nine leaders from provincial health insurance bureaus responsible for the urban employee basic medical insurance (UEBMI) participated in a 1-day workshop to build a consensus on the most important objectives for the health-care reform and to translate these into measurable criteria. The participants ranked the criteria by importance and MCDA methodology was used for weighing the importance of each criterion in the final decision. The model driving this process will be presented and discussed by comparing two policy options for health-care reform.
\end{abstract}

Keywords: China, multicriteria decision analysis, MCDA, insurance policy, decision-making, stakeholder engagement, medical savings account

\section{Introduction}

\subsection{Provincial insurance schemes in China}

In 1998, the State Council of China issued a decision on establishing the basic medical insurance system for urban employees [1].

As a consequence, a universal medical insurance system (UMIS) was designed to improve access to medical services and reduce out-of-pocket (OOP) costs for all Chinese citizens [2]. By 2014, 97.5\% of the population had some form of insurance coverage. The key options are the urban employee basic medical insurance (UEBMI), the new rural cooperative medical scheme (NRCMS), or the urban resident basic medical insurance (URBMI). The differences are in the type of population covered (e.g., in 2014, 283.3 million urban employees, 736 million rural citizens, or 314.5 million urban residents), in the annual premium per capita 
(in 2014, 2841 RMB for UEBMI, 411 RMB for NRCMS, or 409 RMB for URBMI) and consequently, the scope of available funds and coverage [2].

All employing units (employers) and their employees in cities and towns are intended to participate in the UEBMI. The expenses of basic medical insurance shall be shared by employers and employees. The basic system includes the combination of social coordination funds and individual medical saving accounts (MSAs).

The basic medical insurance premiums are paid by individual employees with a $2 \%$ payroll tax and by employers with $6 \%$ payroll tax. About $30 \%$ of the contributions of employers are paid into the personal MSAs, while the remaining $70 \%$ of the basic medical insurance premiums are collected as coordination funds. Individual MSAs are used for outpatient payment, the coordination funds are used for hospitalization and to provide for coverage of some special diseases with high medical costs in outpatient departments [3]. The maximum ceiling payment is limited at four to six times the average annual wage of local employees. The excess cost can be insured by commercial medical insurance or government medical assistance. In 2010, these basic medical insurance principles were included in the Social Insurance Law of the People's Republic of China [4].

\subsection{Why is change needed?}

Although all provinces have implemented provincial solutions for the basic medical insurance for employees, a few shortcomings have been observed over the years. These include the risk that the funds in the MSAs are not always used efficiently and may not suffice to cover a comprehensive outpatient care. In consequence, patients may prefer to use inpatient care facilities, which however, lead to higher overall costs $[3,5]$. Simply put, individual choices on use of health-care funds are done with the short-term individual or family advantage in mind, whereas with pooled HC funds, decisions can be made based on overall health outcome of the population, and supply cost can be negotiated or managed accordingly. Not every individual owner of an MSA has the capability to invest in that HC service, which maximizes health outcomes with the available funds, and there is a risk that individual choices favor delayed treatments at more advanced stages of disease and to worse outcomes. An international study on the efficiency of MSA across different countries (China, Singapore, South Africa, and the United States of America) concluded that "the available evidence suggests that MSA schemes have generally been inefficient and inequitable and have not provided adequate financial protection" [6].

In addition, many healthy people or high-income employees do not use the savings in the personal accounts and therefore, they accumulate over time in the personal MSAs and are not available for the financing of current health-care services [7]. For example, in the Liaoning Province, the recent average proportion of health-care funds accumulated in individual accounts reached $40 \%$, resulting in almost half of medical insurance funds being accumulated as surplus held in the MSAs. The same situation as was observed in Shanghai in 2015, with $40.3 \%$ of premium surplus accumulated in medical savings accounts [8]. In a model with a pooled fund administered across the whole membership, the entire budget could be allocated for health-care services across the members as needed. Thus, at any time, the money which is not spent by healthy people can be used for the treatment of sick people.

In terms of equity, a high variation in scope of coverage is also observed [9]. For access to medicines, distorted funding mechanisms create financial barriers for access to medicine in China [10,11]. Research in 2014 on the impact of the UEBMI on equity revealed improved equity for inpatient services, but inequity growth for outpatient services [12]. 
Affordability of medicines, a major part of outpatient care, is also still of concern [13]. There is a high regional variability in the scope of coverage and reimbursement methods [13]. For example, in some cities, the coverage for pharmaceuticals lies within the general outpatient coverage scheme; in others a range of "regulated diseases" are defined for coverage, whereas in other cities, a secondary drug reimbursement lists exist.

Due to these challenges and shortcomings, provincial insurance authorities want to improve their insurance policies for UEBMI by raising reimbursement for outpatient care services and products. This will in turn improve utilization of all available funds to increase the overall efficiency of healthcare.

\subsection{A format to facilitate policy decisions}

In China, the responsibility for transferring nationally formulated policy objectives into the provinces is decentralized and lies with the provincial administration. There are many options on how the provincial policies can be formulated and applied. Alignment of the overall central policy is important to ensure consistency and equity in health-care access for the Chinese population. However, new policies are in the responsibility of the provincial insurance authorities, and therefore, the policy decision has to be made in each province under consideration of the national policy priorities and the provincial political and health-care context. In such complex situations, decision support tools may help the provincial authorities to prioritize possible insurance options.

Among the plethora of decision support tools, multiple criteria decision analysis (MCDA) was chosen because this method can help to assess multiple, and sometimes conflicting, criteria to evaluate alternatives [14-16]. It originates from operational research supporting single decision-makers [17] but is increasingly also used to structure decision alternatives, to prognose their consequences, and to facilitate dialog on the benefits and harms of decisions in a multistakeholder context in order to enhance procedural quality in the decision-making process [18]. MCDA methods are used across many branches of science and policy-making including environmental, infrastructural, and health-care policies, prioritization, and planning $[15,19,20]$.

Next to MCDA, other methods are existing to inform strategic decisions between alternative option and much can be learned from the world of business management [21]. Some of these lead to increasing complexity such as strategic options development and analysis (SODA), a comprehensive cognitive mapping of individual stakeholder views. Others, such as a "strengths, weakness, opportunity, and threat" (SWOT) analysis, structure the thinking and accumulate facts and data, but the interpretation and weighing is left to the decision-makers. Pure deliberation of the alternatives in the discussion among decision-makers and experts often lead to decisions of low transparency and may lack consistency. Simulating the impact of a new policy in a health economic models or trade-off models would limit the factors to be considered.

MCDA is an umbrella term for decision support tools which can be used in situations like presented here for the Chinese insurance policies, where (1) there are one or several clearly stated objectives that stakeholders groups and/or decisionmakers value differently [20], (2) there are several alternative options how to fully or partially reach these objectives, and (3) there multiple criteria, which can be integrated into a calculable composite measure of the benefit or worth of the various alternatives [21]. Among the MCDA methods are the analytic hierarchy process, weighed sum and weighed product models, or ranking and simple multiattribute rating techniques (SMART) as described below [22, 23]. 
A taskforce of the International Society of Pharmacoeconomics and Outcomes Research (ISPOR) has described the MCDA process for the use in health-care decisions $[24,25]$. Generally, the process includes six steps, and is adapted based on the specific decision problem, objective, and context. The definition of the decision problem is the first step. Subsequently, agreement needs to be reached among the stakeholders to determine which criteria are useful to determine the alternative option that will best solve the decision problem. If the importance of these defined criteria differs, the stakeholders also should agree on the weight (relative importance) of each criterion in the assessment of the alternative options.

Finally, in the assessment of the alternatives, each criterion is scored separately and contributes with the predetermined weight, to the composite score that reflects the overall performance of each alternative. As decisions in healthcare often impact a wide range of stakeholders, the criteria may also be chosen to accommodate different stakeholder perspectives [26]. MCDA is being used widely across health-care systems to inform decision-making in healthcare, including benefit-risk assessment of medicines, formulary listings, purchasing, or reimbursement decisions [25, 27-29]. MCDA has specifically been suggested as an evidence-based health technology assessment (HTA) tool for evaluating off-patent pharmaceuticals in developing countries [30]. Examples for using MCDA in decision-making for off-patent medicines in developing countries are emerging in several countries such as China, Thailand, Indonesia, or Egypt [31-34].

A short explanation of MCDA in lay language (English) can be viewed in the online material to this book and via the Internet (https://www.youtube.com/ watch?v=7OoKJHvsUbo).

\subsection{Policy initiative in China}

The objective of this initiative was to collaborate among provincial insurance policy leaders in China to create an MCDA tool to evaluate insurance policy options across China. This collaborative process was intended to provide a transparent prioritization of insurance models to guide provinces in the decision process. A secondary objective was to adapt a globally validated MCDA in a local environment to address a specific decision problem.

\section{Process for adaptation of a global format}

MCDA is a method to support decision-making, while allowing for adaptation to a specific decision problem. The methodology, framework, and process applied in the workshop followed a previously developed and validated model (Figure 1) $[30,33]$ for adaptation to a new decision problem and context. Each of the phases will be described in detail below.

\subsection{Workshop preparation}

To achieve broad buy-in and acceptance for the tool, many of the important stakeholders should be included. Through participation in an interactive workshop, individual stakeholders will be able to see exactly how the tool was developed and can contribute their perspective to shape the new tool. In order to limit the workshop to less than 1-day preparation prior to the workshop is important. Ideally, the definition of the decision problem should occur prior to the workshop. For the initiative described here, decision problem was the assessment of health-care policy options across China (see Section 1.4). 


\begin{tabular}{|c|c|c|}
\hline $\begin{array}{l}\text { Planning \& } \\
\text { Preparation }\end{array}$ & Workshop & Post-Workshop \\
\hline $\begin{array}{l}\text { - Definition of } \\
\text { Objective } \\
\text { - Stakeholder } \\
\text { Mapping } \\
\text { - Desk Research } \\
\text { - Draft Criteria } \\
\text { - Draft Scoring } \\
\text { - Preliminary } \\
\text { model adaptation }\end{array}$ & $\begin{array}{l}\text { - Consensus on } \\
\text { objectives } \\
\text { - Consensus on } \\
\text { criteria } \\
\text { - Scoring review } \\
\text { - Ranking of } \\
\text { criteria } \\
\text { - Weighting of } \\
\text { criteria }\end{array}$ & $\begin{array}{l}\text { - Test application } \\
\text { - Piloting } \\
\text { - Revision of } \\
\text { instrument }\end{array}$ \\
\hline
\end{tabular}

Figure 1.

Process applied for adapting a previously developed MCDA tool and framework to the decision problem of developing new insurance policies in China.

\subsubsection{Stakeholder engagement}

One of the core principles of designing and implementing change is that the key stakeholders are considered throughout the process according to their respective position in the context of the change. The design and implementation of the new insurance policies will be the responsibility of the provincial insurance authorities under the conditions outlined by the national policy framework. They will not only have to be convinced by the new insurance model and its feasibility, but they will also have to defend any new design versus the outside stakeholders such as provincial policy-makers, provincial urban employers, and provincial urban employees, and toward the inside stakeholders who will be charged with the implementation.

In this initiative, the analysis started by listing all impacted stakeholders who hold influence over the proposed change in program. Each of the stakeholders was rated by their level of interest in the insurance policy and the level of influence (power) they have in relation to the new policies.

For the development of the decision tool, these medical insurance representatives were invited to participate in the workshop. In addition, academic policy influencers and public health experts participated in the presentations and discussions.

In the subsequent steps of piloting, validation, and full implantation (beyond the described workshop), a broader range of stakeholders has to be involved or managed to ensure that their interests are represented, and the decision principles are accepted by expanded stakeholders.

\subsubsection{Adaptation of global format to the decision problem}

As outlined in the introduction (see Sections 1.1 and 1.2), the national policies could benefit by improvements in the insurance coverage scheme for urban employees. To accommodate the comparison of alternative insurance policies a multicriteria decision tool was created to test how well each insurance option addressed national and provincial requirements.

For this, a set of requirements was identified through desk research and discussion with policy-makers and academic health policy experts before the workshop by the core team, which led to the base set of evaluation criteria. 


\subsubsection{Proposed decision criteria}

Preliminary criteria were identified in the five domains presented in Figure 2: (1) funding and finance, (2) access, (3) policy priority (access), (4) equity, and (5) likelihood of change. Each of the domains contained two or three criteria as defined below with a total number of 11 criteria. Of the five domains, two ((2) access and (3) policy priority) were related to access. While more criteria had been considered, it was important to manage the number of criteria. The relevance and feasibility of the proposed criteria was further challenged in the workshop by the participating stakeholders.

Under the domain of "funding and finance," two criteria were proposed. The criterion "financial impact for insurance" should help to roughly estimate the financial risk of a potential future health policy on health-care expenditure to be covered by the insurance scheme in comparison to the current insurance expenditure. To estimate the impact of a future insurance model on overall extent of insurance expenditure would be available as funding for healthcare, a criterion "mobilization of funding for outpatient healthcare (HC)" was proposed.

To assess the impact of a future policy on overall "access" for patients to healthcare, three criteria were predefined. With the criterion "access to pharmaceuticals," the impact of a new insurance model on patient access to ambulatory pharmaceutical therapies as compared to the current system should be assessed. As most of the ambulatory care is made up by pharmaceuticals, which currently are to a large extent paid by the patients out-of-pocket, improvement in this area would be a major achievement. To compare the expected impact of the new model on overall coverage for healthcare in the outpatient setting, the second criterion "outpatient coverage" was suggested. The third criterion "economic burden for patients" was introduced to assess the impact of the potential future health policy on the patients' finances in comparison to the current system.

A separate domain named "access/policy priority" was put forward for discussion in the workshop to emphasize the need of meeting the policy priorities set by the national government policy. The first priority to be addressed is "timely interventions" (care when it is needed) to assess the impact of the future model on time to care (initiated by patient, family member, or insurance model). The intent here is to decrease the hurdles or improve the motivation for searching for healthcare early in the disease process instead of waiting until reaching more severe disease states before seeking care. The second criterion in this domain, "primary care utilization" is meant to help determine the impact of the future policy on the use of primary care in comparison to the current system. The policy objective emphasized

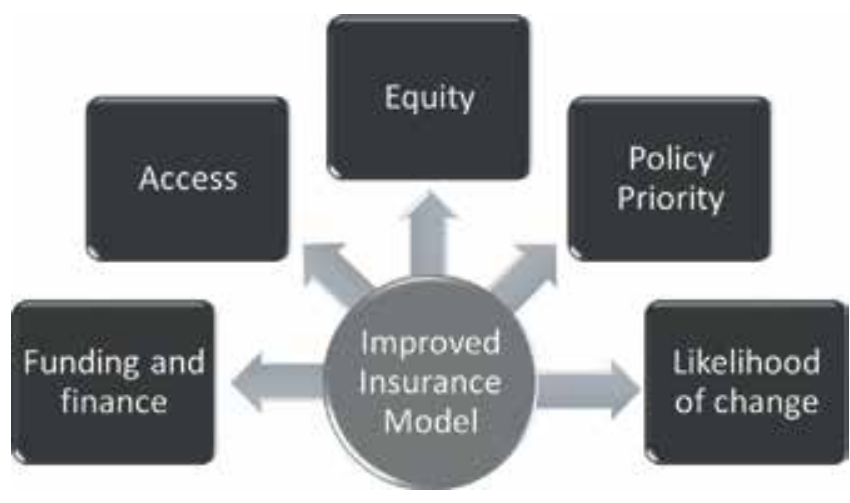

Figure 2.

Five domains for assessing the impact of insurance policy options on the intended outcomes of the policy changes. 
by this criterion is to shift care more toward the primary care level with much lower hurdles for patients as opposed to the current practice of accessing care mostly through specialized hospital services.

Two criteria were attributed to the domain of "equity." "Solidarity for outpatient $\mathrm{HC}^{\prime}$ " appeared an important criterion to compare the impact of the new policy system on the solidarity principle. Full solidarity would mean equal health-care cost to everybody independent from personal health status. Furthermore, the impact of the future insurance model on health-care equity as compared to the current situation should be captured under the criterion of "equity." This could potentially also imply higher contributions for people with higher income.

An important aspect to look at is the feasibility of introducing a new insurance policy model. This was to be addressed by the domain of "likelihood of change." The criterion "ease of transition," required an estimate of the smoothness of transitioning from the current to the future model. A specific criterion "acceptability to stakeholders" was proposed to account for the resistance of key stakeholders toward changing from the current to the potential future system. The final domains and their related criteria are presented in Table 2.

\subsubsection{Proposed scoring for the decision criteria}

For each of the proposed criteria, a scoring scale was developed. The scoring definitions were mostly qualitative assessments and nonlinear. For example, the possible outcomes and related scores for "financial risk for insurance" were high risk of nonmanageable cost increase (exclusion), increased but manageable cost increase (25\%), minimal cost increase expected (50\%), same cost as current (75\%), decreased cost to insurance expected (100\%). In this example, exclusion means that an insurance option would be immediately excluded which can, with reasonable certainty, be expected to lead to massive financial impact to a degree which may bankrupt the insurance. Another example of a proposed scoring is the criterion of "equity" with the possible outcomes of "high degree of HC differences within population" (0\%), "limited improvement of HC equity" (25\%), "(limited) improvement of HC equity" (50\%), "HC equity is mostly satisfied" (75\%), "HC is the same for everybody" (100\%).

Except for the score "exclusion," all scores are expressed in percentages. This method provides for a normalization within the scoring system even if each score does not have the same number of scoring levels. This also allows for differentiation between the importance of the possible outcomes. The final score for each criterion will be calculated from the score (in percentage) and the maximum score achievable by this criterion (described in Section 2.3).

\subsection{Interactive stakeholder workshop}

The interactive stakeholder workshop took place in Beijing, China, on September 14, 2018 under the leadership of Professor Shanlian Hu (Fudan University). The agenda started with introductory presentations on the policy changes which triggered the initiative. The view on the initiative from different perspectives (e.g., academic, policy, industry) was presented through a moderated discussion of participants' expectations and viewpoints on upcoming changes and the expected improvements in health insurance schemes. This was followed by an interactive component to develop a common general decision model following a validated MCDA calculation model and process for local adaptation $[30,35]$. This portion of the workshop was moderated by two international health-policy advisors. 


\begin{tabular}{|c|c|c|c|c|c|}
\hline $\begin{array}{l}\text { (I) } \\
\text { Delining current short- } \\
\text { Comings and expectutions } \\
\text { for future policies }\end{array}$ & $\begin{array}{l}\text { (2) } \\
\text { Choice and } \\
\text { definition } \\
\text { of criteris: }\end{array}$ & $\begin{array}{l}\text { (3) } \\
\text { Gitaria } \\
\text { scorine }\end{array}$ & $\begin{array}{c}\text { (4) } \\
\text { Ranking } \\
\text { of criteria }\end{array}$ & $\begin{array}{l}\text { (5) } \\
\text { Weighting } \\
\text { of cnteria }\end{array}$ & $\begin{array}{l}\text { (6) } \\
\text { Testingl } \\
\text { Revicwing } \\
\text { the model }\end{array}$ \\
\hline
\end{tabular}

Figure 3.

Six-step process for developing the MCDA tool in a workshop with key decision-makers for prioritizing insurance policy options in China.

Because the workshop facilitators spoke English, the entire workshop was supported by simultaneous translation to ensure involvement, understanding, and contribution of all participants. All materials were made available in the both languages.

The flow of the interactive part of the workshop is depicted in Figure 3.

\subsubsection{Discussion change objectives}

Each insurance representative had the opportunity to address shortcomings of the current system and their expectations for an improved insurance scheme. The key statements resulting from this discussion are summarized in Table 1. These shortcomings and expectations were well aligned with those proposed by the core team during the workshop preparation. Overall, there was high concordance among the participants.

Finally, participants shared a common voice that the workshop would yield a tool to choose the most rational insurance system to meet the needs of their provincial environments, while still maintaining national consistency.

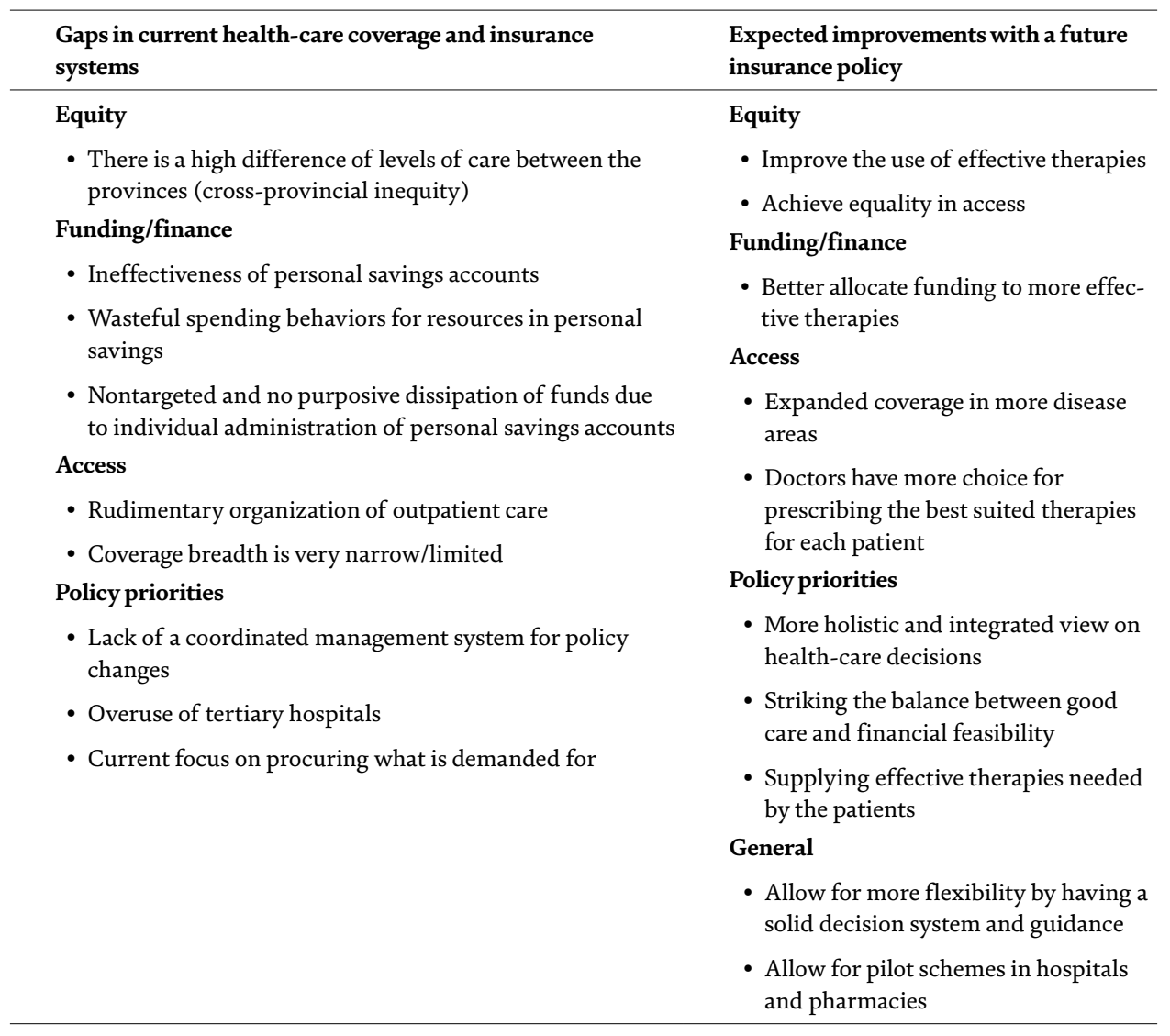

Table 1.

Summary of current insurance system shortcomings and expected improvements for future policies. 


\subsubsection{Discussion and refinement of criteria}

Each domain and their related preliminary criteria were presented and discussed with workshop participants. The participants confirmed the relevance of all proposed domains and criteria except under the domain funding and finance. The criterion "mobilization of funding for outpatient HC" was dropped as participants stated that concept was covered by the "financial impact for insurance" criterion. Thus, these 2 criteria were merged into one and that resulted in 10 criteria across 5 domains as listed in Table 2.

\subsubsection{Discussion and refinement of scoring}

The proposed scoring for all criteria was reviewed and general agreement was reached that the scoring should systematically apply the same number, levels, and results of possible scores. A consistent five-level scoring for each criterion was developed, whereby the first criterion would always result in exclusion of that insurance option. The scoring is defined in Table 3.

\subsection{Model construction}

A multicriteria decision analysis was demonstrated in Excel (Microsoft ${ }^{\mathrm{TM}}$ ). Although the model was programmed before the workshop based on the predefined

\begin{tabular}{|c|c|c|}
\hline Domain & Criterion & Definition \\
\hline $\begin{array}{l}\text { Funding and } \\
\text { finance }\end{array}$ & $\begin{array}{l}\text { Financial impact and } \\
\text { funding for insurance }\end{array}$ & $\begin{array}{l}\text { To estimate the financial impact of a potential future } \\
\text { health policy on health-care expenditure to be covered } \\
\text { by the insurance scheme in comparison to the current } \\
\text { expenditure }\end{array}$ \\
\hline \multirow[t]{3}{*}{ Access } & Access to pharmaceuticals & $\begin{array}{l}\text { To estimate the impact of a new insurance model on } \\
\text { patient access to ambulatory pharmaceutical therapies as } \\
\text { compared to the current system }\end{array}$ \\
\hline & $\begin{array}{l}\text { Coverage for outpatient } \\
\text { HC }\end{array}$ & $\begin{array}{l}\text { To compare the expected impact of the new model on } \\
\text { overall coverage for ambulatory care }\end{array}$ \\
\hline & $\begin{array}{l}\text { Affordability: economic } \\
\text { burden for patients }\end{array}$ & $\begin{array}{l}\text { To assess the financial impact on out-of-pocket cost for } \\
\text { the patients or family }\end{array}$ \\
\hline \multirow[t]{2}{*}{ Policy priority } & Timely interventions & $\begin{array}{l}\text { To assess the impact of the future model on time to care } \\
\text { (initiated by patient, family member, or insurance model) }\end{array}$ \\
\hline & Primary care utilization & $\begin{array}{l}\text { To estimate the impact of the future policy on the use of } \\
\text { primary care in comparison to the current system }\end{array}$ \\
\hline \multirow[t]{2}{*}{ Equity } & $\begin{array}{l}\text { Solidarity for outpatient } \\
\text { HC }\end{array}$ & $\begin{array}{l}\text { To compare the impact of the new policy system on the } \\
\text { solidarity principle. Full solidarity = equal HC cost to } \\
\text { everybody independent from personal health status }\end{array}$ \\
\hline & Equity & $\begin{array}{l}\text { To estimate the impact of the future insurance model } \\
\text { on health-care (HC) equity as compared to the current } \\
\text { situation }\end{array}$ \\
\hline \multirow[t]{2}{*}{$\begin{array}{l}\text { Likelihood of } \\
\text { change }\end{array}$} & Ease of transition & $\begin{array}{l}\text { To estimate the smoothness of transitioning from the } \\
\text { current to the future model }\end{array}$ \\
\hline & $\begin{array}{l}\text { Acceptability to } \\
\text { stakeholders }\end{array}$ & $\begin{array}{l}\text { To estimate the resistance of key stakeholders toward } \\
\text { changing from the current to the potential future system }\end{array}$ \\
\hline
\end{tabular}

Table 2.

Domains and criteria with definitions as determined in the workshop. 
Citeria name

Possible outcomes

Score (\%)

\begin{tabular}{|c|c|c|}
\hline \multirow{5}{*}{$\begin{array}{l}\text { Financial Impact and } \\
\text { Funding for Insurance }\end{array}$} & High risk of non-manageable increase & $0 \%$ \\
\hline & Cost Increased without improved funding & $25 \%$ \\
\hline & Cost Increased but manageable & $50 \%$ \\
\hline & Same cost, without improved funding & $75 \%$ \\
\hline & Decreased cost to insurance, improved funding & $100 \%$ \\
\hline \multirow{5}{*}{$\begin{array}{l}\text { Access to } \\
\text { pharmaceuticals }\end{array}$} & Reduced & $0 \%$ \\
\hline & Same as now & $25 \%$ \\
\hline & More people have access than now & $50 \%$ \\
\hline & Greatly reduced barrier to access & $75 \%$ \\
\hline & Free access without barrier & $100 \%$ \\
\hline \multirow{5}{*}{$\begin{array}{l}\text { Coverage for outpatient } \\
\text { HC }\end{array}$} & Coverage reduced versus today & $0 \%$ \\
\hline & Same as now & $25 \%$ \\
\hline & Limited to medical savings & $50 \%$ \\
\hline & Improvement over current & $75 \%$ \\
\hline & High degree of coverage for all & $100 \%$ \\
\hline \multirow{5}{*}{$\begin{array}{l}\text { Affordability: Economic } \\
\text { burden for patients }\end{array}$} & Affordability for patients reduced & $0 \%$ \\
\hline & Same as now & $25 \%$ \\
\hline & Affordability for patients slightly improved & $50 \%$ \\
\hline & Affordability for patients much improved & $75 \%$ \\
\hline & Solid foundation for tiered healthcare system & $100 \%$ \\
\hline \multirow{5}{*}{$\begin{array}{l}\text { Timely interventions: } \\
\text { care when care is } \\
\text { needed }\end{array}$} & Reduced versus current & $0 \%$ \\
\hline & Same as current & $25 \%$ \\
\hline & Partially improved & $50 \%$ \\
\hline & Greatly improved & $75 \%$ \\
\hline & Foundation for political steering mechanisms & $100 \%$ \\
\hline \multirow{5}{*}{ Primary care utilization } & Increases use of high tier hospitals & $0 \%$ \\
\hline & Unchanged & $25 \%$ \\
\hline & Increased primary care utilization compared to now & $50 \%$ \\
\hline & Efficiently guide more orderly tiered system & $75 \%$ \\
\hline & Builds foundation for tiered system & $100 \%$ \\
\hline \multirow{5}{*}{$\begin{array}{l}\text { Solidarity for outpatient } \\
\text { HC }\end{array}$} & No incentives for solidarity (below $20 \%$ of cost) & $0 \%$ \\
\hline & Solidarity $20-40 \%$ of cost & $25 \%$ \\
\hline & Solidarity $41-60 \%$ of cost & $50 \%$ \\
\hline & Solidarity $60-80 \%$ of cost & $75 \%$ \\
\hline & Solidarity $>80 \%$ of cost & $100 \%$ \\
\hline \multirow{5}{*}{ Equity } & Very high HC differences within population & $0 \%$ \\
\hline & Limited improvement of HC equity & $25 \%$ \\
\hline & Much improvement of HC equity & $50 \%$ \\
\hline & HC equity is mostly satisfied & $75 \%$ \\
\hline & $\mathrm{HC}$ is the same for everybody & $100 \%$ \\
\hline \multirow{5}{*}{ Ease of transition } & Not feasible & $0 \%$ \\
\hline & High degree of system-change; large investments required & $25 \%$ \\
\hline & High degree of system change & $50 \%$ \\
\hline & Some minor changes required & $75 \%$ \\
\hline & Easy, no system or behavior change required & $100 \%$ \\
\hline \multirow{5}{*}{$\begin{array}{l}\text { Acceptability to } \\
\text { stakeholders }\end{array}$} & High resistance to be expected & $0 \%$ \\
\hline & Resistance expected from a few stakeholders groups & $25 \%$ \\
\hline & Minor resistance expected from few stakeholders & $50 \%$ \\
\hline & Highly acceptable & $75 \%$ \\
\hline & Fully acceptable & $100 \%$ \\
\hline
\end{tabular}

Table 3.

Outcomes definitions and scoring for each decision criterion. 
domains, criteria, and scoring, there was continuous adaptation throughout the workshop to reflect the input of the participants. The final model integrated all results from the workshop.

Once agreement had been reached on the domains, criteria, and scoring functions, the participants were guided through the process of ranking the criteria and subsequently weighing them for their relative importance.

This involved an anonymous voting with an audience response system (Ombea ${ }^{\circledR}$ with OMBEA ResponsePad ${ }^{\mathrm{TM}}$ ) for defining the decision priorities among the list of 10 criteria (step 4 in Figure 3) and the relative importance of each of the criteria in the overall decision (step 5 in Figure 3 ) following the modified simple multiattribute rating technique (SMART) method for ranking and swing weighing of the criteria [29]. For each vote, the result was computed as a median value. The resulting model was tested and reviewed using two test cases (step 6).

\section{Testing the model}

The first step in validating a decision model is testing the model with either known or extreme alternatives. During the workshop, there was limited time for testing; therefore, we will present two high-level insurance policy options to compare using the resulting model from the workshop.

\subsection{Potential insurance scheme options}

A concern raised during the introduction was that the insurance funds allocated to medical savings accounts (MSAs) are not used efficiently. Therefore, a key component of health-care reform should include a more effective use of MSA funding.

The goals of a future reform would be to (1) increase the population solidarity and foster a more rational use of medical insurance premiums both from the perspective of the employee and the employer and thus (2) increase the efficiency of how the funds are utilized. In addition, the new policies should support key government (national) health-care policy priorities such as (3) a shift health-care utilization from tertiary to primary care services, and thus (4) incentivize earlier use of health-care services instead of delaying until more expensive inpatient services are required (timely interventions).

\subsubsection{Insurance model option 1}

The scope of payment for personal MSAs would be expanded to include additional services such as deductible (user fees) of hospitalization medical expenses, or for the medical expenses of other family members, paying the premiums of commercial medical insurance participation. Thus, insured employees would have more options for MSA spending and would still make individual decisions on when and how the money would be spent. This option would not provide an incentive to increase the use of outpatient care.

\subsubsection{Insurance model option 2}

A pooled outpatient funding system for the urban employees' medical insurance would be established, similar to how current inpatient service is funded. This 
would create a gradual transition of payments into the coordinated population fund instead of the MSA and ultimately absorb the remaining funds in current MSAs. In this option, the decision on funding allocation would be made by the insurance authority or government across the entire insured population for both outpatient and inpatient care. Proactive funding of outpatient care would be intended to decrease inpatient care down the road.

\subsection{Comparison of options}

Four members of the project team and two additional Chinese health-care experts used the MCDA model to independently rate the two insurance policy options. Their answers were evaluated using the following rules:

a. If three or four of the raters answered identically, this was taken as the result for that attribute;

b.If the answers were distributed, the median result was used;

c. If the median was between two scores, the answers from the Chinese respondents were given a higher weight;

d.If the result was between two scores, the more conservative response was chosen.

Following this approach, insurance option 2 was rated with a total of 78.0 points as the superior policy as compared to insurance option 1 with a total of 53.95 points. The detailed results are shown in Table 4. Insurance option 1 scored better for the attributes relating to "financial impact and funding for the insurance," "access to pharmaceuticals," coverage for outpatient healthcare, "affordability/economic burden to patients," "timely interventions," "primary care utilization," "solidarity," and "equity." In the final two attributes "ease of transition" and "acceptability to stakeholders," insurance option 1 was rated higher.

This example shows that there is a trade-off in any decision-making process-in this case between the domain "likelihood of change" where option 1 scored higher and for the other four domains, where option 2 scored higher. The model highlighted these trade-offs and made them more transparent. Once policy-makers agree on their final decisions, they are also more aware of what resistance may be expected and therefore may be better prepared to consider preventive measures to minimize such resistance.

\subsection{Model observations}

The intention of model testing was to understand (A) ease of use of the model for those using the model and (B) to see how consistent the answers are between different users.

To answer the first question, the users were specifically asked about their experience. The model was rated to be very easy (1) or easy (2) and neutral by two raters.

The interrater consistency varied depending on both the attributes and the insurance option. For most questions, there was a clear preference for one score. The highest response variability was observed for option 1 in relation to "financial impact and funding for insurance," "primary care utilization," "ease of transition," and "acceptability to stakeholders." The responses for option 2 had less variability.

In order to improve the interrater variability, two improvements were suggested: (1) provide the raters with a more detailed description of the meaning of 
Value-Based Evaluation of Chinese Provincial Health Insurance Policy Schemes DOI: http://dx.doi.org/10.5772/intechopen.84373

an attribute and a score and (2) provide more a more detailed description of the two insurance models. An additional step of deliberation where a discussion could be led between the raters could give the rational for their individual ratings and consensus could be developed in the process. The latter approach would help to

\begin{tabular}{|c|c|c|c|c|}
\hline \multirow[b]{2}{*}{ Criterion } & \multirow[b]{2}{*}{$\begin{array}{c}\text { Weight of } \\
\text { criterion }\end{array}$} & \multicolumn{3}{|c|}{ Option 1} \\
\hline & & Assessment & Attribute Score $(\%)$ & $\begin{array}{c}\text { Weighted } \\
\text { score } \\
\text { (points) }\end{array}$ \\
\hline $\begin{array}{l}\text { Financial Impact and Funding } \\
\text { for Insurance }\end{array}$ & 26.88 & Cost Increased but manageable & $50 \%$ & 13.44 \\
\hline Access to pharmaceuticals & 3.35 & $\begin{array}{l}\text { More people have access than } \\
\text { now }\end{array}$ & $50 \%$ & 1.68 \\
\hline Coverage for outpatient HC & 13.71 & Improvement over current & $75 \%$ & 10.28 \\
\hline $\begin{array}{l}\text { Affordability: Economic } \\
\text { burden for patients }\end{array}$ & 10.55 & $\begin{array}{l}\text { Affordability for patients } \\
\text { slightly improved }\end{array}$ & $50 \%$ & 5.27 \\
\hline $\begin{array}{l}\text { Timely interventions: care } \\
\text { when care is needed }\end{array}$ & 4.83 & Same as current & $25 \%$ & 1.21 \\
\hline Primary care utilization & 4.02 & $\begin{array}{l}\text { Increased primary care } \\
\text { utilization compared to now }\end{array}$ & $50 \%$ & 2.01 \\
\hline Solidarity for outpatient HC & 8.11 & Solidarity $20-40 \%$ of cost & $25 \%$ & 2.03 \\
\hline Equity & 6.76 & $\begin{array}{l}\text { Limited improvement of HC } \\
\text { equity }\end{array}$ & $25 \%$ & 1.69 \\
\hline Ease of transition & 2.58 & Some minor changes required & $75 \%$ & 1.94 \\
\hline Acceptability to stakeholders & 19.20 & Highly acceptable & $75 \%$ & 14.40 \\
\hline Overall score & & & & 53.946 \\
\hline
\end{tabular}

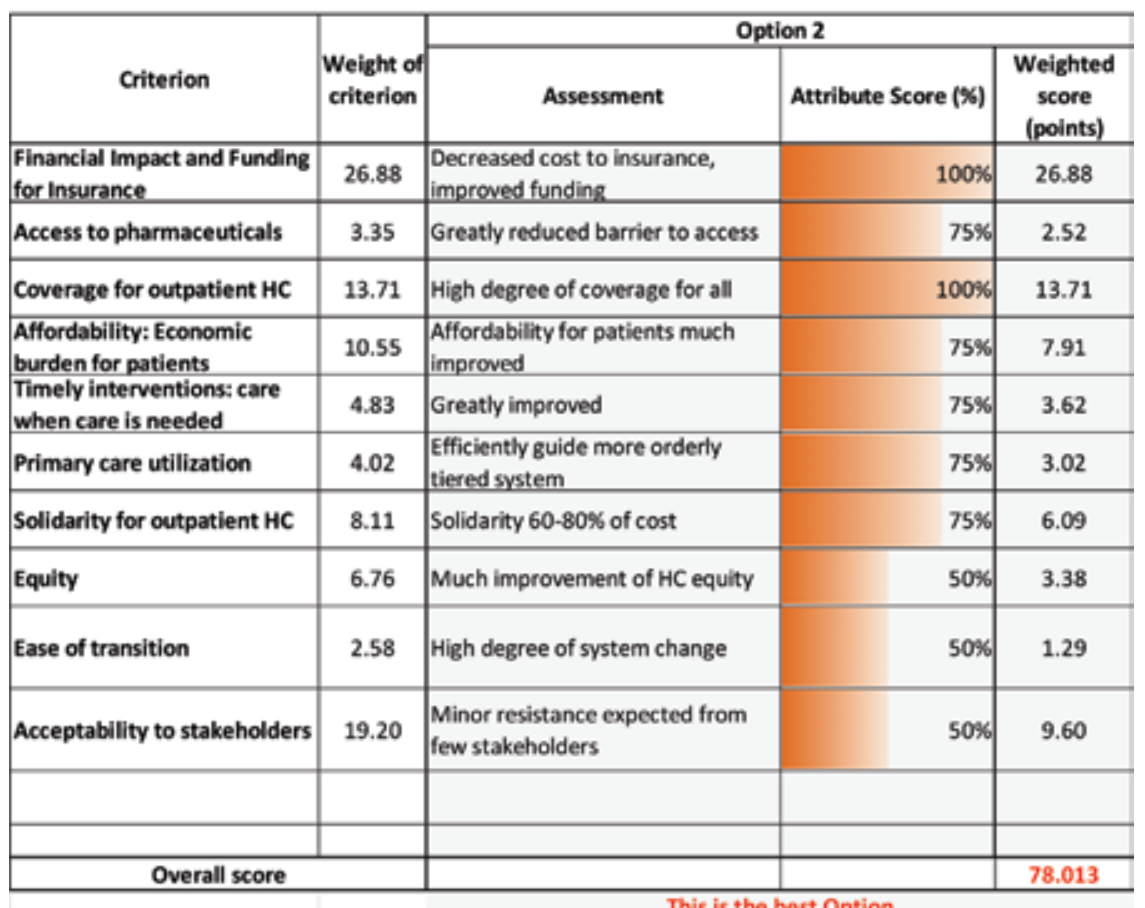

This is the best Option

Table 4 .

Scoring of option 1 and option 2 in the MCDA model for the comparison of insurance models in China as rated by six test persons (four Chinese, two international). 
improve the cross-rater understanding as a part of the implementation and training process and enhance the consistent use of the model over time.

Two raters proposed to reduce the numbers of criteria for some of the options, because it may be difficult to determine the exact response if the gradual differences between the possible answers become too small.

We would propose when applying this model to a decision problem the interrater variability should be monitored throughout the introduction phases. The results of these evaluations will help to improve the model over time.

\section{Implementation process}

Before releasing the model to provincial insurers, further pilot testing would be recommended. Ideally, a selected group of insurance experts would be asked to use the model in the assessment of their own insurance options and, in parallel, the two "standard" options as described above.

After the evaluation, the pilot users should be interviewed for their experience in the process and suggestions for improvement. This feedback could be used for building a next version tool, which could then be presented to the State Medical Insurance Bureau and released to a broader user group. In addition, guidance and training material should be developed to support interrater consistency in the application of the model. Dissemination could happen via various channels such as the State Medical Insurance Bureau or presentations and workshops at provincial or national conferences where insurance policy experts come together.

As mentioned above, the use of the model should be accompanied by an ongoing collection for user feedback (e.g., in an online survey format) and regular revision of the tool for further adaptation to new application requirements.

\section{Discussion}

\subsection{Transferability within China}

At the end of the first workshop, participants found high value in the MCDA approach toward building a criteria-based decision tool. In particular, they appreciated the experience with the MCDA methodological approach which can be applied to decisions in technology assessment based on predefined requirements.

Yu et al. warned in a recent publication that "if supply-induced demand is not effectively controlled, a universal and uniform social health insurance may be more harmful than beneficial in China" [36]. By substituting the existing fee-for-service design with bundled provider payment policies, there can be more integrated approaches for smaller population groups that exist in China [37]. However, this is only possible, if allocation of funds for outpatient services is made by health-care decision-makers, guided by considerations of equity, access, and efficiency in public healthcare. Tools such as MCDA will improve transparency and consistency in health-care decision-making. Although the decision on the future UEBMI policy will be made on a provincial level, the evaluation tool will assist the decision-makers to go through a set of rational decision considerations (criteria) before selecting the most appropriate option. A consensus process, validated through a pilot testing phase, will provide a high level of legitimacy to the decision-making process.

UEBMI is the insurance system for urban employees. The other insurance options for urban residents (URBMI) or for rural citizens (NRCMS) could use similar tools for further developing their insurance options or to design a merged 
insurance policy [38]. However, it should be noted that the three systems vary in terms of financing mechanisms, funding extent, and coverage policies and would require a full adaptation of the model. In addition, the stakeholders involved in the process might differ. For example, consumers or patients could be included as important stakeholders, because URBMI and NRCMS are voluntary systems and not mandatory by employment.

The described methodology could also be transferable to other types of decisions in China, such as which products should be listed or reimbursed, or which of the available alternatives should be purchased [30]. Such an application is presented in another chapter of this book at the example of purchasing off-patent pharmaceuticals in hospitals in Thailand [39]. However, successful adaptation of the methodology for each new type of application requires a thorough process described in Figure 1 of this report, including preparation, involvement of the decision stakeholders, and phased implementation [33].

\subsection{Country transferability}

Many countries moving toward Universal Healthcare Coverage are building up their health-care systems and coverage policies. They will face similar decisions throughout this process. Although the instrument described here has been developed for the needs of the Chinese stakeholders in the context of the current insurance policies, the process and the principles can be transferred to other countries. This structured and transparent approach for planning and implementation can provide learnings for improvement of health-care insurance policies.

\subsection{Key learnings, challenges, and limitations}

By using a structured and previously validated process for developing a decision support tool [33], we were able to work with key stakeholders from several provinces in China during a 1-day workshop to apply the tool to a decision problem. The resulting MCDA spreadsheet model can be used by UEBMI insurance policy-makers in the provinces of China to compare new options of insurance policies.

A few key components in the process are essential for successful implementation. The most important is the engagement of the stakeholders impacted by the decision. Through the engagement of all stakeholders, a variety of factors can be considered and an open exchange is possible through a workshop format to incorporate all perspectives [40]. In addition, stakeholders, who are part of the "inner circle," or the guiding coalition, can further to convey the momentum for change. This becomes of utmost importance once full implementation is realized [37, 40, 41]. In our example, the decision to limit the stakeholders to insurance experts and academic health policy leaders was purposeful to reflect the current decision-makers. However, a broader range of stakeholders may be involved in the testing phase of individuals' provinces or countries.

Another key success factor is to clearly define the decision problem at the outset of the stakeholder collaboration. If there is a general agreement on the objective of the new policy, and on the criteria, which help to measure whether the objectives can be achieved, the MCDA tool offers an opportunity for increasing transparency of the decision process. Increased transparency may also contribute to a higher trust in the policies by the public in China [42].

The participants in the workshop cautioned that it may be necessary to adapt such a model in their respective provinces to address provincial health-care priorities, which may differ from province to province. A practical implication was use of the domains and criteria as a checklist for the design of new insurance policy options. 
Finally, for the long-term success of any future policy change, measurement of outcomes is important. The criteria used in the selection process could become key performance indicators around population health and economics as used in other evaluations $[2,5,43]$.

Some limitations or pitfalls of using MCDA as a decision support tool need to be considered. First, there is a risk of bias in the MCDA when the criteria overlap and therefore overemphasize certain aspects of the evaluation. In our example, the participants felt this to be the case with the two finance-related criteria which were originally proposed. They, therefore, decided to merge the two criteria into one. Second, the ranking and weighing methodologies can have a high impact on the "resolution" capability of the decision support tool. In this chapter, we have used a modified SMART approach to MCDA which has been recognized broadly as practicable $[23,39]$. It should also be emphasized that decision-makers may be tempted to use the summary score as "the decision argument." Instead, decisionmakers should deliberate and compare the entire rating profile to confirm, that the instrument and the summary score have validity in the specific comparison. This will allow a more differentiated argumentation and documentation why a specific decision has been taken and which preventive measures should be taken to overcome the areas of weaknesses of the chosen option, which are those criteria, where it scored low.

There are also a few limitations to our proposed process. In our workshop, only a limited number of stakeholders were represented. Future programs should aim to achieve a good balance between all relevant stakeholders to maintain an active dialog during the workshop and manage the number of participants to avoid limitation of discussion. Preparation through stakeholder research, including mapping and assessment of appointments, is important to strike this balance.

Another limitation was the need to work with translators during the entire process, which was due to the international composition of the project management and moderating team. To minimize the risk for misunderstanding, the workshop was simultaneously translated and all materials, including the model, were available in both English and Chinese language.

\section{Conclusions}

In this report, we have demonstrated how an internationally developed and validated process based on MCDA methods was adapted to decide which funding model should be selected for the future UEBMI insurance policy in the provinces of China. The processes included extensive stakeholder analysis and engagement as well as an interactive workshop for building consensus on objectives of the reforms, the criteria for success, and the measures for scoring such criteria.

The advantage of combining stakeholder driven cocreation with the principles of multicriteria decision analysis was to build a model with the input and final consensus of key stakeholders that still allows for local adaptation of criteria, weighing, and scoring. Using such a structured decision model fosters consistency and transparency across all decisions and allows for documentation of the decision process and evaluation of the impact.

We would like to end this report with a specific concluding comment of one of the workshop participants: "It is hard to predict the future; but using a rational method to approximate the future needs for insurance models will help me to convince my constituents." 


\section{Conflict of interest}

This initiative has been funded by Abbott Products Operations AG in Switzerland: DB received funding for moderating the workshop and for the travel expenses; APH received funding for planning and facilitating the workshop and for writing the manuscript. The open access fees for the book chapter were also paid by the company.

\begin{tabular}{ll}
\multicolumn{2}{l}{ Abbreviations } \\
HC & healthcare \\
HTA & health technology assessment \\
ISPOR & $\begin{array}{l}\text { International Society of Pharmacoeconomics and Outcomes } \\
\text { Research }\end{array}$ \\
MCDA & multicriteria decision analysis \\
MSA & medical saving accounts \\
NRCMS & new rural cooperative medical scheme \\
OPP & out-of-pocket costs \\
RMB & Renminbi, Yuán (currency of the People's Republic of China) \\
UEBMI & urban employee basic medical insurance \\
UMIS & universal medical insurance system \\
URBMI & urban resident basic medical insurance
\end{tabular}

\section{Author details}

Shanlian $\mathrm{Hu}^{1}$, Anke-Peggy Holtorf ${ }^{2 *}$, Kalman Wijaya ${ }^{3}$, Jiangjiang $\mathrm{He}^{4}$ and Diana Brixner ${ }^{5}$

1 School of Public Health, Fudan University, Shanghai, China

2 Health Outcomes Strategies GmbH, Basel, Switzerland

3 Abbott Product Operations AG, Allschwil, Switzerland

4 Shanghai Health Development Research Center, Shanghai, China

5 College of Pharmacy, University of Utah, Salt Lake City, USA

*Address all correspondence to: anke.holtorf@health-os.com

\section{IntechOpen}

(C) 2019 The Author(s). Licensee IntechOpen. This chapter is distributed under the terms of the Creative Commons Attribution License (http://creativecommons.org/licenses/ by/3.0), which permits unrestricted use, distribution, and reproduction in any medium, provided the original work is properly cited. (cc) BY 


\section{References}

[1] The State Council. The Decision on Establishing the Basic Medical Insurance System for Urban Employees. No. 44. China; 1998

\section{[2] Xiong X, Zhang Z, Ren J, Zhang J,} Pan X, Zhang L, et al. Impact of universal medical insurance system on the accessibility of medical service supply and affordability of patients in China. PLoS One. 2018;13(3):e0193273. Available from: https://journals.plos. org/plosone/article?id=10.1371/journal. pone. 0193273 [cited: 05 December 2018]

[3] Miao Y, Gu J, Zhang L, He R, Sandeep $\mathrm{S}, \mathrm{Wu}$ J. Improving the performance of social health insurance system through increasing outpatient expenditure reimbursement ratio: A quasiexperimental evaluation study from rural China. International Journal for Equity in Health. 2018;17. Available from: https:// www.ncbi.nlm.nih.gov/pmc/articles/ PMC6019724/ [cited: 05 December 2018]

[4] Social Insurance Law of People's Republic of China. Approved by 11th People's Congress, signed by Jintao $\mathrm{Hu}$, the Chairman of the People's Republic of China, on October 28, 2010. Chairman of the People's Republic of China; 2010

[5] Huang F, Gan L. The impacts of China's urban employee basic medical insurance on healthcare expenditures and health outcomes. Health Economics. 2017;26(2):149-163. Available from: https://onlinelibrary. wiley.com/doi/abs/10.1002/hec.3281 [cited: 20 April 2018]

[6] Wouters OJ, Cylus J, Yang W, Thomson S, McKee M. Medical savings accounts: Assessing their impact on efficiency, equity and financial protection in health care. Health Economics, Policy, and Law. 2016;11(03):321-335. Available from: http://www.journals.cambridge. org/abstract_S1744133116000025 [cited: 17 December 2018]
[7] Zheng Y. On the Equity Issues of Medical Savings Accounts of China's Urban Health Insurance. Journal of Shanghai University of Finance and Economics. 2012;01:368. http://en.cnki. com.cn/Article_en/CJFDTOTALSCJB201201011.htm. [Accessed: 17 December 2018]

[8] Hu S, He J, Wang L, editors. A study on Improving Medical Saving Accounts in Health Insurance. Shanghai: Fudan University Press; 2017. 209 p. (China Library CIP data; No. 109014). Available from: http://www.fudanpress.com

[9] Dou G, Wang Q, Ying X. Reducing the medical economic burden of health insurance in China: Achievements and challenges. Bioscience Trends. 2018;12(3):215-219. Available from: https://www-jstage-jst-go-jp. ezproxy.lib.utah.edu/article/ bst/12/3/12_2018.01054/_article [cited: 05 December 2018]

[10] Chen Y, Yin Z, Xie Q. Suggestions to ameliorate the inequity in urban/rural allocation of healthcare resources in China. International Journal for Equity in Health. 2014;13:34

[11] Sun J, Hu CJ, Stuntz M, Hogerzeil H, Liu Y. A review of promoting access to medicines in China-Problems and recommendations. BMC Health Services Research. 2018;18(1):125. Available from: https://bmchealthservres. biomedcentral.com/articles/10.1186/ s12913-018-2875-6 [cited: 20 April 2018]

[12] Zhou Z, Zhu L, Zhou Z, Li Z, Gao J, Chen $G$. The effects of China's urban basic medical insurance schemes on the equity of health service utilisation: Evidence from Shaanxi Province. International Journal for Equity in Health. 2014;13:23. Available from: https://www.ncbi.nlm.nih.gov/pmc/ articles/PMC4016277/ [cited: 17 December 2018] 
[13] Huang Y, Jiang Y, Zhang L, Mao W, van Boven JFM, Postma MJ, et al. Availability, use, and affordability of medicines in urban China under universal health coverage: an empirical study in Hangzhou and Baoji. BMC Health Serv Res. 2018;18:1-10 (online). DOI: 10.1186/s12913-018-2993-1

[14] Keeney RL, Raiffa H. Decisions with Multiple Objectives: Preferences and Value Trade-Offs. Cambridge, UK: Cambridge University Press; 1993. p. 596

[15] Köksalan MM, Wallenius J, Zionts S. Multiple Criteria Decision Making from Early History to the 21st Century. Singapore; Hackensack, N.J: World Scientific Pub. Co; 2011

[16] Regier DA, Peacock S. Theoretical foundations of MCDA. In: Marsh K, Goetghebeur M, Thokala P, Baltussen R, editors. Multi-Criteria Decision Analysis to Support Healthcare Decisions. Cham: Springer International Publishing; 2017. pp. 9-28. DOI: 10.1007/978-3-319-47540-0_2

[17] Mendoza GA, Martins H. Multicriteria decision analysis in natural resource management: A critical review of methods and new modelling paradigms. Forest Ecology and Management. 2006;230(1):1-22. Available from: http://www.sciencedirect.com/ science/article/pii/S0378112706002258 [cited: 07 January 2019]

[18] Fish R, Burgess J, Chilvers J, Footitt A, Turner K. Participatory and Deliberative Techniques to Support the Monetary and Non-monetary Valuation of Ecosystem Services: An Introductory Guide. London, UK: Defra; 2011. Available from: https://ueaeprints.uea. ac.uk/38123/ [cited: 07 January 2019]

[19] Kujawski E. Multi-Criteria Decision Analysis: Limitations, Pitfalls, and Practical Difficulties; 2003. Available from: https://escholarship.org/uc/ item/0cp6j7sj [cited: 07 January 2019]
[20] Saarikoski H, Barton DN, Mustajoki J, Keune H, Gomez-Baggethun E, Langemeyer J. Multi-criteria decision analysis (MCDA) in ecosystem service valuation. In: OpenNESS Ecosystem Services Reference Book. 2016. p. 6. (EC FP7 Grant Agreement no. 308428). Available from: http://www.opennessproject.eu/library/reference-book

[21] IfM. Decision Support Tools [Internet]. University of Cambridge. Available from: https://www.ifm.eng. cam.ac.uk/research/dstools/ [cited: 07 January 2019]

[22] Velasquez M, Hester PT. An analysis of multi-criteria decision making methods. International Journal of Operations Research. 2013;10(2):11

[23] Communities and Local Government. Multi-Criteria Analysis: A Manual. Wetherby, Great Britain: Department for Communities and Local Government; 2009. Available from: http://www.communities.gov.uk/ documents/corporate/pdf/1132618.pdf [cited: 24 March 2018]

[24] Marsh K, Ijzerman M, Thokala P, Baltussen R, Boysen M, Kalo Z, et al. Multiple criteria decision analysis for health care decision making-Emerging good practices: Report 2 of the ISPOR MCDA emerging good practices task force. Value in Health. 2016;19(1):1-13. Available from: http://linkinghub.elsevier. com/retrieve/pii/S1098301515051359 [cited: 07 September 2016]

[25] Thokala P, Devlin N, Marsh K, Baltussen R, Boysen M, Kalo Z, et al. Multiple criteria decision Analysis for health care Decision Making-An introduction: Report 1 of the ISPOR MCDA Emerging Good Practices Task Force. Value in Health. 2016;19(1):1-13. Available from: http://linkinghub.elsevier. com/retrieve/pii/S1098301515051359 [cited: 07 September 2016]

[26] Phelps CE, Madhavan G. Using multicriteria approaches to assess the 
value of health care. Value in Health. 2017;20(2):251-255. Available from: http://www.sciencedirect.com/science/ article/pii/S1098301516341195 [cited: 24 November 2017]

[27] Jaramillo HEC, Goetghebeur M, Moreno-Mattar O. Testing multi-criteria decision analysis for more transparent resource-allocation decision making in Colombia. International Journal of Technology Assessment in Health Care. 2016:1-8. Available from: https:// www.cambridge.org/core/journals/ international-journal-of-technologyassessment-in-health-care/article/ testing-multi-criteria-decision-analysisfor-more-transparent-resourceallocation-decision-making-in-colombia/ F845945DC1DB7231AC51B20DF1C65728 [cited: 03 November 2016]

[28] Kolasa K, Zah V, Kowalczyk M. How can multi criteria decision analysis support value assessment of pharmaceuticals?-Findings from a systematic literature review. Expert Review of Pharmacoeconomics \& Outcomes Research. 2018;18(4):379-391

[29] Mühlbacher AC, Kaczynski A. Making good decisions in healthcare with multi-criteria decision analysis: The use, current research and future development of MCDA. Applied Health Economics and Health Policy. 2016;14(1):29-40

[30] Brixner D, Maniadakis N, Kaló Z, $\mathrm{Hu}$ S, Shen J, Wijaya K. Considering multicriteria decision analysis (MCDA) simple scoring as an evidence-based HTA methodology for evaluating off-patent pharmaceuticals (OPPs) in emerging markets. Value in Health Regional Issues. 2017;13c:1-6. Available from: http:// www.valuehealthregionalissues.com/ article/S2212-1099(17)30001-8/fulltext [cited: 18 August 2017]

[31] Brixner D, Maniadakis N, Kaló Z, Kim K, Wijaya K. An evidence framework for off-patent pharmaceutical review (EFOR) for health technology assessment in emerging markets. Value in Health Regional Issues. 2018;16c:9-13.

Available from: http://www. valuehealthregionalissues.com

[32] Hu S, Zhang Y, He J, Du L, Xu M, $\mathrm{Xie} \mathrm{C}$, et al. A case study of pharmaceutical pricing in China: Setting the price for off-patent originators. Applied Health Economics and Health Policy. 2015;13(1):13-20. Available from: http://link.springer.com/article/10.1007/ s40258-014-0150-5

[33] Inotai A, Nguyen HT, Hidayat B, Nurgozhin T, Kiet PHT, Campbell JD, et al. Guidance towards the implementation of multi-criteria decision analysis framework in developing countries. Expert Review of Pharmacoeconomics \& Outcomes Research. 2018

[34] Tuan PL, Tuan Kiet PH, Brixner DI, Ngo VH. Development of Multiple Criteria Decision Analysis Framework for Off-Patent Pharmaceuticals Decision Making in Vietnam. Hanoi, Vietnam: European Chamber of Commerce Vietnam; 2017. Available from: https:// www.eurochamvn.org/node/16937

[cited: 23 March 2018]

[35] Inotai A, Brixner D, Maniadakis N, Dwiprahasto I, Kristin E, Prabowo A, et al. Development of multi-criteria analysis (MCDA) framework for offpatent pharmaceuticals - an application on improving tender decision making in Indonesia. BMS Health Services Research. 2018;18:(online)

[36] Yu J, Qiu Y, He Z. Is universal and uniform health insurance better for China? Evidence from the perspective of supply-induced demand. Health Economics, Policy, and Law. 2018;1:-16. Available from: http:// www.cambridge.org/core/journals/ health-economics-policy-and-law/ article/is-universal-and-uniform- 
health-insurance-better-for-chinaevidence-from-the-perspective-ofsupplyinduced-demand/16A329720B EA09E5B347F81F77FC84D2 [cited: 05 December 2018]

[37] Wang X, Sun X, Gong F, Huang Y, Chen L, Zhang Y, et al. The Luohu model: A template for integrated urban healthcare systems in China. International Journal of Integrated Care. 2018;18(4). Available from: https:// www.ncbi.nlm.nih.gov/pmc/articles/ PMC6199563/ [cited: 05 December 2018]

[38] Meng Q, Fang H, Liu X, Yuan B, $\mathrm{Xu}$ J. Consolidating the social health insurance schemes in China: Towards an equitable and efficient health system. The Lancet. 2015;386(10002):14841492. Available from: http://www. sciencedirect.com/science/article/ pii/S0140673615003426 [cited: 05 December 2018]

[39] Assawamakin A, Holtorf A-P, Maniadakis N. Weighing price and performance for decisions for multisource pharmaceuticals bidding in public hospitals in Thailand. In: Evaluation of Health Programs. London, UK: INTECH Open Access Publisher; 2019

[40] Rittenhouse J. Improving Stakeholder Management using Change Management Tools. Orlando, USA: Project Management Institute; 2015. Available from: https://www. pmi.org/learning/library/improvestakeholder-management-9901 [cited: 06 November 2018]

[41] Kotter JP. Leading Change. 1R ed. Boston, Mass: Harvard Business Review Press; 2012. 208 p

[42] Zhao D, Zhao H, Cleary PD. Understanding the determinants of public trust in the health care system in China: an analysis of a cross-sectional survey. J Health Serv Res Policy. 2018; [Epub ahead of print]:1-7 (online). DOI: $10.1177 / 1355819618799113$
[43] Gao C, Xu F, Liu GG. Payment reform and changes in health care in China. Social Science \& Medicine. 2014;111:10-16. Available from: http:// www.sciencedirect.com/science/article/ pii/S0277953614002147 [cited: 05 December 2018] 



\title{
Chapter 3
}

\section{Age- and Sex-Specific Burden of Morbidity and Disability in India: A Current Scenario}

\author{
Ajit Kumar Yadav and Akansha Singh
}

\begin{abstract}
India is the second most populous country in the world with a population of 1.3 billion; any change in its morbidity and disability pattern is bound to bring change at the Asia level, which is a matter of concern for the developing countries. Disability-free life expectancy (DFLE) and disability-adjusted life years (DALYs) provide summary measures of health across characteristics. The assessments of epidemiological patterns and health system performance of any place and time period display its progress towards the goal of sustainable development goals (SDGs). The main aim of this study is to assess the age and sex pattern of the burden of diseases (mortality and morbidity) and disability in India. The information on disease and deaths was extracted from the 71st round of the National Sample Surveys (NSS) conducted in 2014 (NSS 2014) and the Causes of Deaths Study conducted in the 2010-2013 (RGI 2010-2013) and disability from Census of India 2011 (ORG 2011).
\end{abstract}

Keywords: morbidity, disability, age, sex and India

\section{Introduction}

The main aim of the Millennium Development Goal was to remove poverty and improve health. With the end of MDG goals in 2015, a new set of sustainable development goals (SDGs) were proposed to be achieved by the year 2030. The third goal of SDG is to ensure healthy lives and promote well-being at all ages. Reducing the prevalence of non-communicable disease (NCD) is one of the targets of SDG Goal 3. According to Global Burden of Disease Study 2015, DALYs due to communicable disease fell from 1200 million in 1990 to 7416 million in 2015, whereas total DALYs due to non-communicable diseases increased from 1.1 billion to 1.5 billion in 2015. In 2015, communicable accounted for $30.1 \%$ of the global DALYs; non-communicable disease accounts for $59.7 \%$ and injuries $10.1 \%$. Since 2005, DALYs for the major communicable causes have declined substantially except for a few subsets of infectious diseases [1]. The life expectancy at birth in India has increased from 49.7 years in 1970-1975 to 68.3 years in 2011-2015 [2]. The life expectancy has increased from 23.7 years in 1881 to 66.9 years in 2011-2015 for males and from 25.6 to 70.0 years for females during this period [2, 3]. Further, infant mortality rates reduced from 130 to 37 deaths per 1000 live births from 1970 to 2015 [4, 5]. Child and adult mortality 


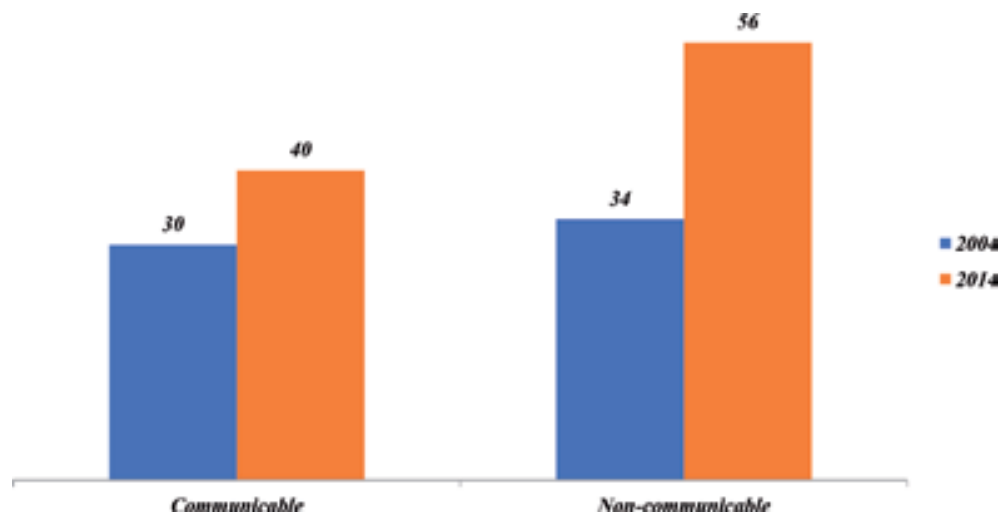

Figure 1.

Change in morbidity prevalence in India from 2004 to 2014.

rates have also declined significantly $[6,7]$, and there has been a significant increase in the probabilities of surviving to age 60 and $70[8,9]$.

With the significant improvement in life expectancy [10], there has been a gradual shift in the age distribution of deaths and disease pattern [11]. The numbers of DALY and DALY rates dropped substantially for communicable disease group between 1990 and 2016. By contrast, numbers of DALYs increased substantially for NCDs. The all-age prevalence of the most leading NCDs increased substantially in India from 1990 to 2016 [12]. Communicable diseases were the major causal agent of mortality in the early 1970s. However, mortality and disease burden are gradually moving towards non-communicable diseases. The premature deaths are shifted to the years lived with disability [13]. The communicable diseases are more concentrated in the people of the lower socio-economic group, and non-communicable diseases are on the rise due to current changes in India's population age structure and improved economic status and lifestyles $[13,14]$. In this transition period, studies to understand the relationship between mortality and morbidity has become imperative for giving useful feedback to programme and policy planners who are involved in the public health management.

Studies on mortality and morbidity at the country level have taken central place in the social research domain from several decades (Figure 1). Studies addressing the pattern and cause of mortality and morbidity are scarce in India due to paucity of data. This issue has already been studied in the developed countries exhaustively. India is recently going through a phase of both demographic and epidemiological transitions. Health condition has improved along with increasing life expectancy. However, increase in life expectancy is accompanied with the loss of healthy life years. There is a need to examine the recent levels and age pattern of morbidity and its relation to the mortality in the context of India. The main aim of the paper is to see the age pattern of self-reported morbidity by sex in India and to estimate the burden of reported morbidities with a special focus on communicable and noncommunicable diseases and disability by age and sex. This paper aims to provide an overall picture of the disease burden on the context of health and social development and throws light for policy investment and future research.

\section{Data and methods}

We have used 71st round of the National Sample Survey (NSS) data conducted in the year 2014. The 71st round was conducted in two subrounds of 6 months each. 
The NSS provides information about the different communicable and non-communicable diseases on any person in surveyed household who were found ill during the last 15 days from the date of survey. Causes of Death data were extracted from the Causes of Death report published by the Registrar General of India (RGI), New Delhi, during 2010-2013. We used cause-specific proportion of deaths for communicable and non-communicable diseases by age and sex. The 2011 census, which covers the entire population of India, provides reported information on seven types of disability and one category for multiple disabilities. The prevalence of disability by age and sex is taken from the 2011 census. The proportion of total deaths by age was extracted from the report of Sample Registration System 2006 [15].

Self-reported ailments were classified into three categories: communicable disease, non-communicable disease, disability and 'other'. The main independent variables considered in this study are age and sex. The other individual socio-demographic factors considered in the analysis are residence, educational attainment and monthly per capita expenditure quintiles. Descriptive statistics and bivariate analysis are used for description of prevalence of diseases and disability and its association with age group. Logistic regression analysis is used for multivariate analysis.

The prevalence of disease was calculated with information from the survey on any person who had fallen ill during the last 15 days from the date of survey:

$$
\text { Prevalence }=\frac{\text { Number of diseased persons during the reference period }}{\text { Total population during the same time period }} \times 1000
$$

Summary measures of the health of a population are calculated by combining data on mortality and non-fatal health outcomes into a single number - disabilityadjusted life years (DALYs) and disability-free life expectancy (DFLE) are calculated by age for male and female population in India.

Disability-adjusted life year measures health gaps as opposed to health expectancies. It measures the difference between a current situation and an ideal situation where everyone lives up to the age of the standard life expectancy in perfect health. The DALY combines in one measure the time lived with disability and the time lost due to premature mortality:

$$
\mathrm{DALY}=\mathrm{YLL}+\mathrm{YLD}
$$

where YLL is the years of life lost due to premature mortality and YLD is the years lived with disability.

The computation formula for YLL is given by:

$$
\mathrm{YLL}=(\mathrm{N} / \mathrm{r}) \times\left(1-\mathrm{e}^{-\mathrm{rL}}\right)
$$

where $\mathrm{N}$ is the number of deaths, $\mathrm{L}$ is the standard life expectancy at age of death (years) and $\mathrm{r}$ is the discount rate (e.g. $3 \%$ corresponds to a discount rate of 0.03 ).

Similarly, the formula for YLD is YLD $=\left(\mathrm{I} \times \mathrm{DW} \times \mathrm{L} \times\left(1-\mathrm{e}^{-\mathrm{rL}}\right)\right) / \mathrm{r}$.

where I is the number of incident/prevalence cases, DW is the disability weight, $\mathrm{L}$ is the duration of disability (years) and $\mathrm{r}$ is the discount rate.

Disability weight was borrowed from the Global Burden of Disease Study 2000.

Sullivan's health expectancy method reflects the current health of a real population adjusted for mortality and disability level and is independent of age structure. Health expectancy calculated by Sullivan's method is the number of remaining years at a particular age that an individual can expect to live in a healthy state.

Disability-free life expectancy is one of the prime Sullivan's health expectancies. DFLE is found by partitioning the person year lived in the interval into those who 
have lived with and without disability. If we assume two states called disability-free and with disability, then the disability-free life expectancy at age $\mathrm{x}\left(\mathrm{DFLE}_{\mathrm{x}}\right)$ and the life expectancy with disability $\left(\mathrm{DLE}_{\mathrm{x}}\right)$ at age $\mathrm{x}$ are defined by:

Years lived with disability between ages $\mathrm{x}$ and $\mathrm{x}+5={ }_{5} \mathrm{YD}_{\mathrm{x}}={ }_{5} \mathrm{~L}_{\mathrm{x}} \times{ }_{5} \operatorname{Prev}_{\mathrm{x}}$;

Years lived without disability between ages $\mathrm{x}$ and $\mathrm{x}+5={ }_{5} \mathrm{YWD}_{\mathrm{x}}={ }_{5} \mathrm{~L}_{\mathrm{x}} \times\left(1-{ }_{5} \operatorname{Prev}_{\mathrm{x}}\right)$.

$D_{L} E_{x}=$ sum of years lived with disability for ages $x$ and above, divided by $l_{x}$.

DFLE $_{\mathrm{x}}=$ sum of years lived without disability for ages $\mathrm{x}$ and above, divided by $\mathrm{l}_{\mathrm{x}}$.

where $\mathrm{l}_{\mathrm{x}}$ is the number of survivors at exact age $\mathrm{x},{ }_{5} \mathrm{~L}_{\mathrm{x}}$ is the number of years of life lived by the life table cohort between ages $x$ and $x+5$ and ${ }_{5} \operatorname{Prev}_{\mathrm{x}}$ is the prevalence of disability between ages $\mathrm{x}$ and $\mathrm{x}+5$ in the population.

\section{Results}

The prevalence of all self-reported communicable and non-communicable morbidities has increased from 2004 to 2014 in India. The prevalence of communicable diseases increased by 10 points and non-communicable diseases by more than 20 points. The prevalence of all diseases was higher for females than males (Figure 2). The prevalence of disability was the same for males and females (4\%). The maximum difference in the prevalence rate was observed for the category of non-communicable disease (33\% in males and 51\% in females) (Figure 2).

The study examines the prevalence rate of self-reported morbidities by age and sex in India for the year 2014. Females are at higher risk of suffering from disease. Risk of suffering from non-communicable diseases and other diseases increased with increasing age and reduced steadily for the communicable disease. The infant in the age group of 0-1 year suffered the largest burden of communicable diseases (overall 108 per 1000; male, 121 per 1000; female, 93 per 1000). Non-communicable disease prevalence was highest in the age group 70 and above (overall 274 per 1000 population; male 281 and female 267). Similarly, other disease prevalence remains higher for elderly age 70 years old and above. Male-female gap

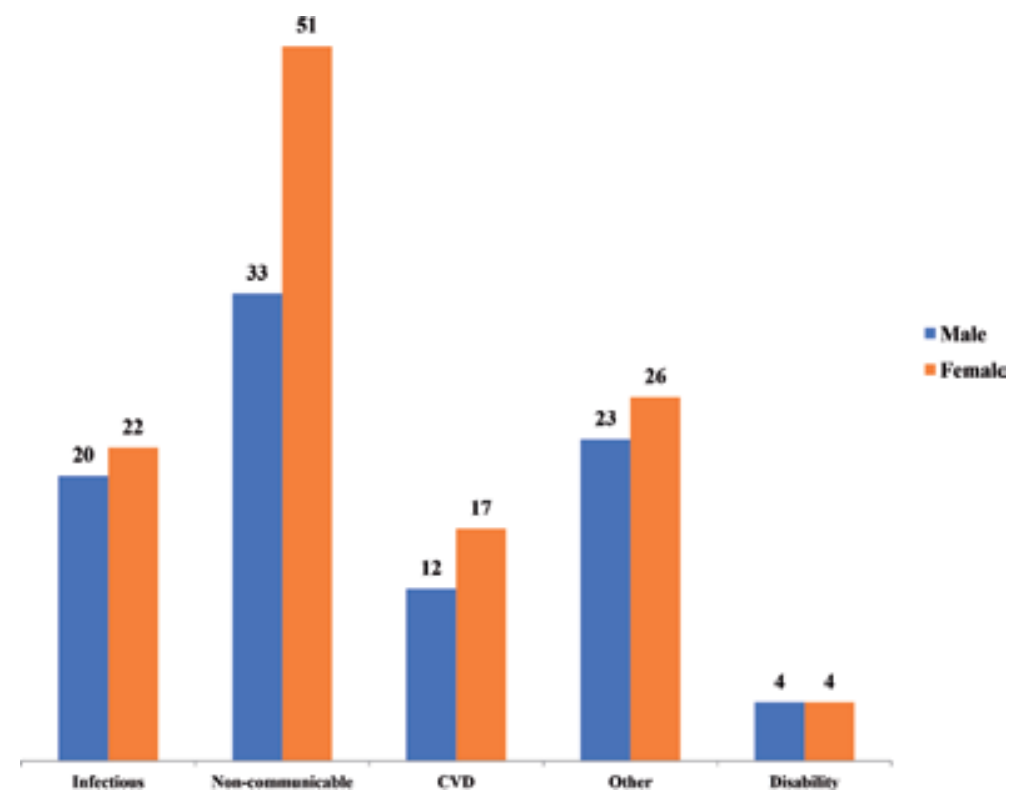

Figure 2.

Prevalence of different self-reported morbidities in India by Gender (2014). 
in the communicable disease prevalence was the highest for the infant age group. Females overpass the male prevalence of communicable disease from the age group 15-19 years and remain on the higher side except the oldest age group (65 and above). The prevalence of non-communicable diseases was higher for females than males in all the age group except the $70+$ and less than 10 years. Similar pattern by sex was observed for the other diseases and disability status (Figure 3).

Table 1 shows the results of logistic regression analysis by age after controlling the effect of other socio-economic factors. It is evident from the results that the odds of suffering from communicable diseases were maximum in the reference age group. The odds reduced significantly in the adult ages and increased steadily afterwards in the elderly age groups. This age pattern does not change significantly by sex. The lowest odds were observed in the age group of 25-30 (OR, 0.19) and 30-35 years old (OR, 0.20). A significant positive association can be seen between risk of suffering from non-communicable disease and age. The risk of suffering from noncommunicable diseases is more than 10 times higher in the age group 40 and above with the highest risk in the age group $70+$. The risk of suffering from NCD was 52 times higher for the elderly age 70 and above. Elderly males $\left(70_{+}\right)$have 48 times and

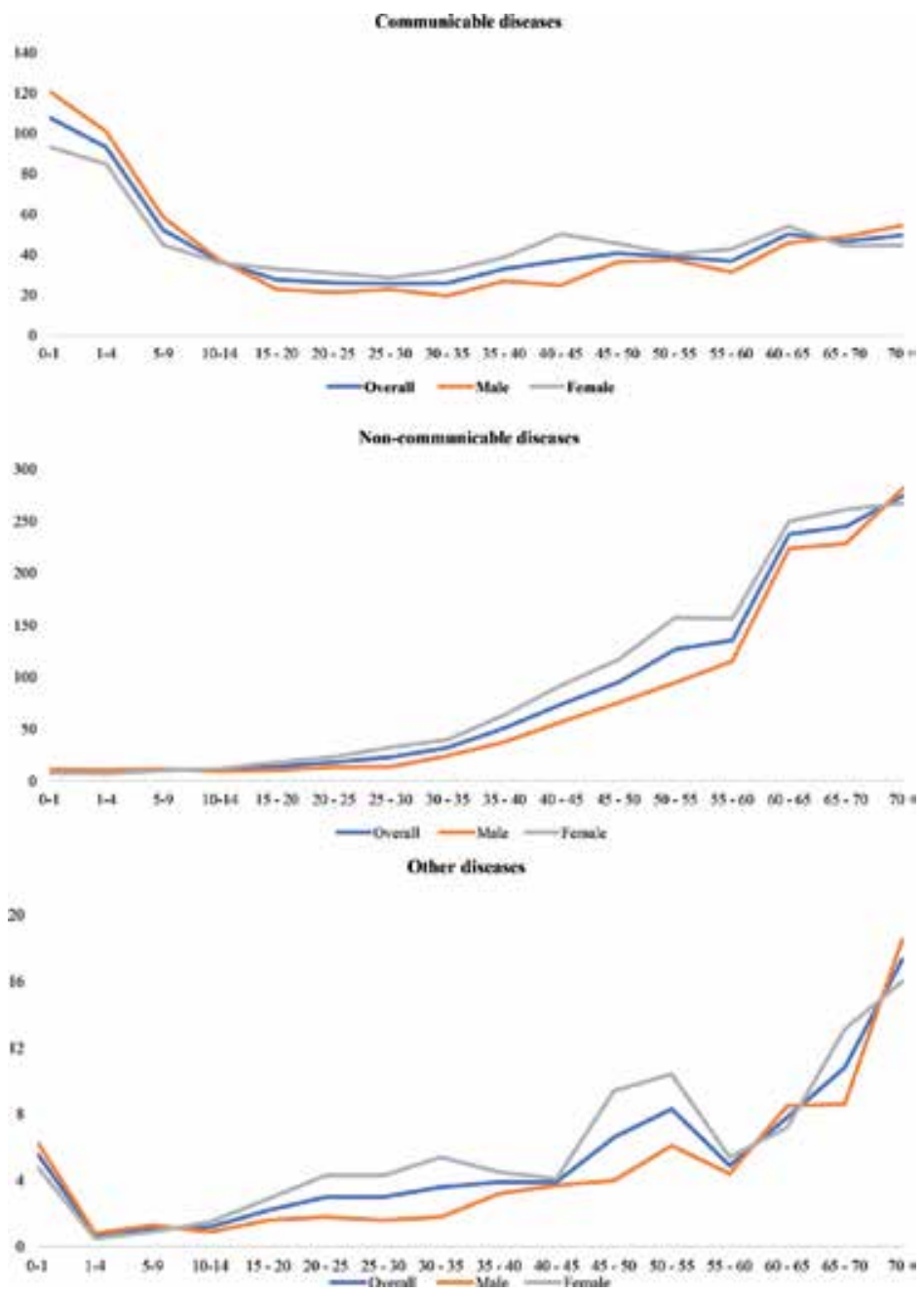

Figure 3.

Prevalence of self-reported morbidities by age and sex in India (2014). 
females $(70+) 58$ times higher odds of suffering from non-communicable diseases. With the increase of age, the likelihood of other diseases also increased significantly. For other diseases, the impact was greatest for the elderly population in the 70-year age group who have three times higher risk than the reference age group. In each age group, the odds of suffering from each type of disease were higher among females than males except a few age groups in the other disease category (Table 1).

The result for DALYs from Table 2 shows that the burden of communicable diseases was highest in the infancy ( $0-1$ years), followed by $1-5$ years. The two age groups contribute to $60 \%$ of the total DALYs in male children and $56 \%$ in females. The result clearly indicates that the burden of infectious diseases was higher during infancy and noticeably greater among males than females. The women in the age group $15-49$ contribute to $21 \%$ of the total DALYs. The age distributions of the DALY indicated that individuals aged below 5 and above 60 years were more susceptible to infections. The DALYs in each age group are higher for females than males except children aged below 5 years and the elderly aged $70+$. Females in the adult age group were more at risk of having infectious diseases than their male counterparts. The age distributions of the non-communicable disease DALYs

\begin{tabular}{|c|c|c|c|c|c|c|c|c|c|}
\hline \multirow[t]{2}{*}{ Age group } & \multicolumn{3}{|c|}{$\begin{array}{c}\text { Communicable } \\
\text { disease }\end{array}$} & \multicolumn{3}{|c|}{ Non-communicable disease } & \multicolumn{3}{|c|}{ Disability and others } \\
\hline & $\begin{array}{l}\text { Odds } \\
\text { ratio }\end{array}$ & \multicolumn{2}{|c|}{$95 \% \mathrm{CI}$} & $\begin{array}{l}\text { Odds } \\
\text { ratio }\end{array}$ & \multicolumn{2}{|c|}{$95 \% \mathrm{CI}$} & $\begin{array}{l}\text { Odds } \\
\text { ratio }\end{array}$ & \multicolumn{2}{|c|}{$95 \%$ CI } \\
\hline \multicolumn{10}{|l|}{ Overall } \\
\hline \multicolumn{10}{|c|}{ 0-1 Reference category } \\
\hline 1-4 & 0.77 & 0.72 & 0.82 & 1.17 & 0.95 & 1.43 & 0.30 & 0.20 & 0.44 \\
\hline $5-9$ & 0.43 & 0.40 & 0.46 & 1.28 & 1.05 & 1.55 & 0.29 & 0.20 & 0.43 \\
\hline 10-14 & 0.28 & 0.25 & 0.30 & 1.39 & 1.15 & 1.69 & 0.29 & 0.20 & 0.43 \\
\hline $15-20$ & 0.24 & 0.22 & 0.26 & 2.09 & 1.74 & 2.51 & 0.52 & 0.37 & 0.71 \\
\hline $20-25$ & 0.22 & 0.20 & 0.24 & 2.27 & 1.90 & 2.72 & 1.09 & 0.84 & 1.43 \\
\hline $25-30$ & 0.19 & 0.18 & 0.21 & 2.74 & 2.30 & 3.26 & 0.96 & 0.73 & 1.26 \\
\hline $30-35$ & 0.20 & 0.19 & 0.22 & 4.00 & 3.37 & 4.76 & 0.86 & 0.64 & 1.14 \\
\hline $35-40$ & 0.25 & 0.23 & 0.27 & 6.69 & 5.64 & 7.93 & 0.93 & 0.69 & 1.25 \\
\hline $40-45$ & 0.31 & 0.28 & 0.34 & 10.66 & 9.01 & 12.62 & 1.24 & 0.93 & 1.66 \\
\hline $45-50$ & 0.29 & 0.26 & 0.32 & 15.03 & 12.72 & 17.76 & 1.36 & 1.02 & 1.82 \\
\hline $50-55$ & 0.29 & 0.26 & 0.33 & 18.79 & 15.91 & 22.20 & 1.84 & 1.39 & 2.43 \\
\hline $55-60$ & 0.30 & 0.27 & 0.33 & 22.16 & 18.77 & 26.16 & 1.45 & 1.08 & 1.95 \\
\hline $60-65$ & 0.35 & 0.32 & 0.40 & 39.53 & 33.46 & 46.69 & 2.53 & 1.90 & 3.37 \\
\hline $65-70$ & 0.39 & 0.35 & 0.44 & 39.52 & 33.40 & 46.77 & 2.01 & 1.46 & 2.78 \\
\hline $70+$ & 0.38 & 0.34 & 0.43 & 52.09 & 44.14 & 61.47 & 3.15 & 2.40 & 4.14 \\
\hline \multicolumn{10}{|l|}{ Male } \\
\hline \multicolumn{10}{|c|}{ 0-1 Reference category } \\
\hline $1-4$ & 0.75 & 0.69 & 0.82 & 1.19 & 0.91 & 1.56 & 0.35 & 0.21 & 0.60 \\
\hline 5-9 & 0.42 & 0.38 & 0.46 & 1.21 & 0.94 & 1.57 & 0.31 & 0.18 & 0.52 \\
\hline 10-14 & 0.25 & 0.22 & 0.28 & 1.27 & 0.98 & 1.64 & 0.22 & 0.12 & 0.40 \\
\hline $15-20$ & 0.19 & 0.17 & 0.22 & 1.72 & 1.35 & 2.20 & 0.36 & 0.22 & 0.59 \\
\hline
\end{tabular}


Age-and Sex-Specific Burden of Morbidity and Disability in India: A Current Scenario DOI: http://dx.doi.org/10.5772/intechopen.89709

\begin{tabular}{|c|c|c|c|c|c|c|c|c|c|}
\hline \multirow{3}{*}{$\begin{array}{l}\text { Age group } \\
20-25\end{array}$} & \multicolumn{3}{|c|}{$\begin{array}{c}\text { Communicable } \\
\text { disease }\end{array}$} & \multicolumn{3}{|c|}{ Non-communicable disease } & \multicolumn{3}{|c|}{ Disability and others } \\
\hline & \multirow{2}{*}{$\begin{array}{c}\text { Odds } \\
\text { ratio }\end{array}$} & \multicolumn{2}{|c|}{$95 \% \mathrm{CI}$} & \multirow{2}{*}{$\begin{array}{c}\begin{array}{c}\text { Odds } \\
\text { ratio }\end{array} \\
1.85\end{array}$} & \multicolumn{2}{|c|}{$95 \% \mathrm{CI}$} & \multirow{2}{*}{$\begin{array}{c}\begin{array}{c}\text { Odds } \\
\text { ratio }\end{array} \\
0.38\end{array}$} & \multicolumn{2}{|c|}{$95 \% \mathrm{CI}$} \\
\hline & & 0.16 & 0.21 & & 1.45 & 2.36 & & 0.24 & 0.63 \\
\hline $25-30$ & 0.15 & 0.14 & 0.18 & 2.00 & 1.57 & 2.53 & 0.37 & 0.23 & 0.60 \\
\hline $30-35$ & 0.15 & 0.13 & 0.18 & 2.82 & 2.23 & 3.56 & 0.41 & 0.25 & 0.67 \\
\hline $35-40$ & 0.18 & 0.16 & 0.21 & 4.51 & 3.59 & 5.67 & 0.61 & 0.38 & 0.96 \\
\hline $40-45$ & 0.21 & 0.18 & 0.24 & 7.47 & 5.96 & 9.36 & 1.00 & 0.65 & 1.54 \\
\hline $45-50$ & 0.21 & 0.18 & 0.25 & 10.85 & 8.69 & 13.55 & 1.05 & 0.68 & 1.62 \\
\hline $50-55$ & 0.26 & 0.23 & 0.31 & 14.11 & 11.30 & 17.61 & 1.57 & 1.04 & 2.37 \\
\hline $55-60$ & 0.26 & 0.23 & 0.30 & 17.37 & 13.95 & 21.63 & 1.51 & 1.01 & 2.27 \\
\hline $60-65$ & 0.31 & 0.27 & 0.37 & 33.57 & 26.93 & 41.84 & 2.53 & 1.69 & 3.80 \\
\hline $65-70$ & 0.38 & 0.32 & 0.45 & 31.30 & 25.05 & 39.11 & 1.87 & 1.18 & 2.96 \\
\hline $70+$ & 0.35 & 0.31 & 0.41 & 48.27 & 38.81 & 60.02 & 3.05 & 2.08 & 4.48 \\
\hline \multicolumn{10}{|l|}{ Female } \\
\hline \multicolumn{10}{|c|}{ 0-1 Reference category } \\
\hline $1-4$ & 0.79 & 0.71 & 0.87 & 1.14 & 0.83 & 1.57 & 0.24 & 0.13 & 0.44 \\
\hline $5-9$ & 0.44 & 0.39 & 0.49 & 1.37 & 1.02 & 1.85 & 0.28 & 0.16 & 0.49 \\
\hline $10-14$ & 0.31 & 0.27 & 0.35 & 1.57 & 1.17 & 2.10 & 0.37 & 0.22 & 0.62 \\
\hline $15-20$ & 0.30 & 0.27 & 0.34 & 2.61 & 1.98 & 3.45 & 0.69 & 0.44 & 1.06 \\
\hline $20-25$ & 0.26 & 0.23 & 0.29 & 2.79 & 2.13 & 3.65 & 1.66 & 1.16 & 2.37 \\
\hline $25-30$ & 0.24 & 0.22 & 0.27 & 3.69 & 2.83 & 4.80 & 1.51 & 1.05 & 2.18 \\
\hline $30-35$ & 0.27 & 0.24 & 0.31 & 5.71 & 4.39 & 7.43 & 1.35 & 0.92 & 1.98 \\
\hline $35-40$ & 0.34 & 0.30 & 0.39 & 9.79 & 7.56 & 12.69 & 1.27 & 0.85 & 1.90 \\
\hline $40-45$ & 0.44 & 0.39 & 0.50 & 15.05 & 11.63 & 19.47 & 1.48 & 0.99 & 2.22 \\
\hline $45-50$ & 0.39 & 0.34 & 0.45 & 20.63 & 15.98 & 26.63 & 1.66 & 1.12 & 2.48 \\
\hline $50-55$ & 0.33 & 0.29 & 0.38 & 24.70 & 19.14 & 31.88 & 2.06 & 1.40 & 3.04 \\
\hline $55-60$ & 0.36 & 0.31 & 0.41 & 28.81 & 22.33 & 37.18 & 1.39 & 0.91 & 2.12 \\
\hline $60-65$ & 0.41 & 0.35 & 0.48 & 47.49 & 36.77 & 61.33 & 2.52 & 1.68 & 3.79 \\
\hline $65-70$ & 0.41 & 0.34 & 0.49 & 51.15 & 39.51 & 66.21 & 2.16 & 1.38 & 3.39 \\
\hline $70+$ & 0.42 & 0.36 & 0.49 & 57.55 & 44.59 & 74.28 & 3.25 & 2.20 & 4.79 \\
\hline
\end{tabular}

Table 1.

Logistic regression analysis with the disease status as a dependent variable.

(Table 2) indicated that individuals aged above 45 years are more susceptible to non-communicable diseases. The largest contribution of the total DALYs in noncommunicable diseases is from the age group 65-70 (males, 14\%, and females, $13 \%)$. The result also shows that the adult working age male and female population contributes more than half of the total DALYs in non-communicable diseases. The DALYs for non-communicable disease are higher in the male population than females in most of the age groups contrary to the fact that the prevalence of noncommunicable disease has been higher among females. 


\begin{tabular}{|c|c|c|c|c|}
\hline \multirow{3}{*}{ Age group } & \multicolumn{2}{|c|}{ Communicable } & \multirow{2}{*}{\multicolumn{2}{|c|}{$\begin{array}{l}\text { Non-communicable } \\
\text { DALY per } 100,000\end{array}$}} \\
\hline & \multicolumn{2}{|c|}{ DALY per 100,000} & & \\
\hline & Male & Female & Male & Female \\
\hline 0-1 & 2896 & 2489 & 470 & 320 \\
\hline $1-4$ & 641 & 541 & 104 & 70 \\
\hline $5-9$ & 233 & 236 & 154 & 130 \\
\hline 10-14 & 217 & 221 & 143 & 122 \\
\hline 15-19 & 102 & 163 & 204 & 173 \\
\hline $20-24$ & 109 & 167 & 219 & 176 \\
\hline $25-29$ & 118 & 174 & 236 & 184 \\
\hline $30-34$ & 128 & 156 & 493 & 374 \\
\hline $35-39$ & 126 & 154 & 484 & 372 \\
\hline $40-44$ & 135 & 177 & 517 & 425 \\
\hline $45-49$ & 128 & 125 & 748 & 634 \\
\hline $50-54$ & 145 & 149 & 845 & 759 \\
\hline $55-59$ & 166 & 172 & 1073 & 767 \\
\hline $60-64$ & 151 & 157 & 971 & 702 \\
\hline 65-69 & 185 & 188 & 1191 & 841 \\
\hline $70+$ & 102 & 96 & 472 & 307 \\
\hline
\end{tabular}

Table 2.

Burden of communicable and non-communicable disease by age and sex for total population in India, 2011.

\begin{tabular}{|c|c|c|c|c|c|c|c|c|}
\hline \multirow[b]{3}{*}{$\begin{array}{l}\text { Age } \\
\text { group }\end{array}$} & \multirow{2}{*}{\multicolumn{2}{|c|}{$\frac{\text { Total life }}{\text { Expectancy }\left(e_{\mathrm{x}}\right)}$}} & \multirow{2}{*}{\multicolumn{2}{|c|}{ Proportion with disability $\left(\pi_{x}\right)$}} & \multirow{2}{*}{\multicolumn{2}{|c|}{$\begin{array}{c}\text { Disability-free } \\
\text { Life expectancy }\end{array}$}} & \multirow{2}{*}{\multicolumn{2}{|c|}{$\begin{array}{c}\text { Suffering } \\
\text { Disability life years }\end{array}$}} \\
\hline & & & & & & & & \\
\hline & Male & Female & Male & Female & Male & Female & Male & Female \\
\hline 0-1 & 65.8 & 69.3 & 0.046066 & 0.050826 & 58.1 & 61.5 & 7.7 & 7.8 \\
\hline $1-4$ & 67.9 & 71.7 & 0.046066 & 0.050826 & 59.9 & 63.6 & 8.0 & 8.1 \\
\hline $5-9$ & 64.6 & 68.7 & 0.072173 & 0.07391 & 56.7 & 60.7 & 7.9 & 8.0 \\
\hline 10-14 & 59.9 & 64.0 & 0.174172 & 0.169639 & 52.3 & 56.4 & 7.6 & 7.7 \\
\hline 15-19 & 55.1 & 59.3 & 0.174172 & 0.169639 & 48.3 & 52.4 & 6.8 & 6.9 \\
\hline $20-24$ & 50.4 & 54.6 & 0.161413 & 0.149764 & 44.5 & 48.6 & 5.9 & 6.0 \\
\hline $25-29$ & 45.8 & 50.0 & 0.161413 & 0.149764 & 40.7 & 44.7 & 5.2 & 5.3 \\
\hline $30-34$ & 41.3 & 45.4 & 0.140982 & 0.128796 & 36.9 & 40.8 & 4.4 & 4.6 \\
\hline $35-39$ & 36.8 & 40.8 & 0.140982 & 0.128796 & 33.1 & 36.8 & 3.8 & 4.0 \\
\hline $40-44$ & 32.5 & 36.2 & 0.123556 & 0.106899 & 29.4 & 32.8 & 3.1 & 3.4 \\
\hline $45-49$ & 28.3 & 31.7 & 0.123556 & 0.106899 & 25.7 & 28.7 & 2.6 & 2.9 \\
\hline $50-54$ & 24.2 & 27.2 & 0.095472 & 0.089786 & 22.2 & 24.8 & 2.0 & 2.5 \\
\hline 55-59 & 20.4 & 23.0 & 0.095472 & 0.089786 & 18.7 & 20.9 & 1.7 & 2.1 \\
\hline $60-64$ & 16.9 & 19.0 & 0.093039 & 0.106845 & 15.6 & 17.2 & 1.3 & 1.7 \\
\hline $65-69$ & 13.6 & 15.4 & 0.093039 & 0.106845 & 12.7 & 14.1 & 1.0 & 1.3 \\
\hline $70+$ & 10.9 & 12.3 & 0.059046 & 0.074803 & 4.1 & 4.2 & 6.9 & 8.1 \\
\hline
\end{tabular}

Table 3.

Burden of disability by age and gender in India, 2011. 
The DFLE result (Table 3) shows that at birth, males in India are expected to live 58 years of life without disability out of the 66 years of the total life expectancy at birth. Similarly, females are expected to live 62 years of life without disability out of the total 69 years of life expectancy at birth. The age pattern of disability-free life expectancy does not change considerably till the age 70 in India. The elderly population aged 70 years and above are expected to live around two-thirds of their life in disability. Elderly males aged 70 years and above are expected to live $63 \%$ and females $66 \%$ of their total life with disability.

\section{Discussion}

The paper aims to examine the age and sex pattern of morbidity and its linkage with summary measures of health such as DALY and DFLE. India is also experiencing a similar epidemiological transition along with demographic transition. It is observed that during transition period, the age pattern of mortality and morbidity will be altered [16]. There has been a significant transition in age pattern of morbidity in India. A comparison of this study with other previous studies' findings suggests that the age-specific communicable and non-communicable diseases have increased over the last 20 years' time. The increase in the rate of non-communicable disease was much higher. With the increase in age, prevalence and odds of suffering from non-communicable diseases increase significantly. The risk of noncommunicable diseases increases from middle-aged adults to elderly population among males, and for females, the risk of having non-communicable diseases was significantly higher among the elderly age group. This finding supports the previous studies' findings that communicable diseases are more likely to occur in the younger ages while non-communicable diseases occur in the elderly population $[17,18]$.

The study further shows that the prevalence of self-reported non-communicable morbidities and disabilities was higher among females than their male counterparts in each age group and communicable. Gender gap in health and mortality exists all over the world. The unequal utilization of health care is the major factor that leads to uneven health disparity. Various reasons for differential morbidity are kinship system, gender ideologies, poverty, nutritional status, socio-economic condition, level of education and violence $[19,20]$. The age pattern of the disease also suggests that the prevalence of communicable and non-communicable diseases was higher among the females, but the gender gap was not apparent in disability.

In order to understand the burden of communicable and non-communicable disease for male and female population in India, we calculated the disabilityadjusted life year. The result shows that the burden of communicable disease was higher in infant males compared to infant females in India during 2014. In medical terms, it is seen that male children are more biologically weaker than female children and thus are more prone to various diseases and spend a larger amount of time fighting for the disease [21]. Contrary to the prevalence sex pattern, DALYs for non-communicable diseases in each age group were higher for males as compared to the females. The burden of non-communicable disease was more prominent in higher age group (60 years and above) of population across both sexes. The result also shows that the adult working age male and female population (15-59 years) contributes half of the total DALYs in non-communicable diseases, which is a serious cause of concern. The socio-economic impact of this morbidity and disability due to non-communicable diseases is enormous since these deaths often affect the main income earner in the household and those who rear those children [22].

The DFLE result shows that elderly 70 years and above are spending more than one-third of their life in disability. Further, females spend more life suffering from 
disability as compared to males. Due to higher life expectancy among females in the later ages, females spend more suffering years. The previous study for the earlier decade also suggests that the gender inequalities in DFLE are more evident in India and other low- and middle-income countries [23].

\section{Conclusions and limitations}

India's population is increasing at a tremendous rate. With increase in population, the prevalence of morbidity is also increasing. In spite of the vigorous efforts to reduce mortality and morbidity in India, India is still struggling with its unfinished agenda of restricting communicable disease. On the other side, the prevalence of non-communicable is rising rapidly. This leads to heavy double burden of disease in India. The prevalence of communicable diseases in the younger ages has become a threat for the newly born child, whereas the prevalence of non-communicable diseases in middle-aged adult and the older ages is concerning the adults and elderly population. Thus, both the working and dependent populations are in the clutch of morbidity and putting a question on the health system. Females are the real victims of disease sufferers and disability. The increasing significance of non-communicable disease burden also suggests the need for serious intervention strategies to prevent non-communicable disease burden not only for the elderly but also for the adult age group. The basic challenge would be to implement appropriate prevention strategies to halt the growing trend in non-communicable diseases against a background of infectious diseases, which remain out of control. The increasing burden of diseases among working adults and elderly in a country will impose high financial hardship on its government and households.

Though this study examines the burden of communicable and non-communicable disease in India, the result presented in the paper should be interpreted keeping the following limitation in mind: First, all the diseases estimated in this research paper are based on self-reporting rather than medical investigation. Self-reported morbidity is the only variable that gives us information about morbidity in the absence of information from medical fields. One of the major doubts that arise is about the validity of self-morbidity. In the absence of proper knowledge about the ailment, cultural and societal factors, lack of media exposure and socio-economic condition may lead to under- or overreporting and biasness towards self-reported morbidity. The states which are socio-economically well-off report higher morbidity in comparison to the other underprivileged states. A study states that Kerala which is the most developed state in country reports higher morbidity than Bihar which has lower life expectancy and lower educational level. The adequate measurement of morbidity is one of the important factors that do could give us a precise depiction of the prevalence of morbidity [24]. Second, information used (cause of death) in calculation of DALY is based on sample survey rather than complete enumeration. Third, age- and cause-specific proportion of death was not available at state level; therefore, we used the national-level estimate. Fourth, information on proportion of disability was given at 10 years of interval, which is bifurcated in 5 years of interval.

\section{Abbreviations}

DFLE

DALY

SDG

disability-free life expectancy

disability-adjusted life year

sustainable development goal 
Age- and Sex-Specific Burden of Morbidity and Disability in India: A Current Scenario DOI: http://dx.doi.org/10.5772/intechopen.89709

NSS

national sample surveys

YLLs

years of life lost

YLDs

NCD

$\mathrm{CD}$

years of life lived with disability

RGI

non-communicable disease

ORG

communicable disease

Registrar General of India

Office of Registrar General of India

\section{Author details}

Ajit Kumar Yadav ${ }^{1 *}$ and Akansha Singh ${ }^{2}$

1 International Institute for Population Sciences (IIPS), Mumbai, India

2 Department of Anthropology, Durham University, UK

*Address all correspondence to: ajitkumaryadav1989@gmail.com

\section{IntechOpen}

(C) 2020 The Author(s). Licensee IntechOpen. This chapter is distributed under the terms of the Creative Commons Attribution License (http://creativecommons.org/licenses/ by/3.0), which permits unrestricted use, distribution, and reproduction in any medium, provided the original work is properly cited. (cc) BY 


\section{References}

[1] GBD. Global, regional, and national disability-adjusted life-years (DALYs) for 315 diseases and injuries and healthy life expectancy (HALE), 1990-2015: A systematic analysis for the Global Burden of Disease Study 2015. The Lancet. 2016;388:1603-1658

[2] Registrar General of India. SRS Based Abridged Life Tables 2011-15. New Delhi: Office of Registrar the General; 2007

[3] Dandekar K. Mortality and longevity in India, 1901-1961. Economic and Political Weekly. 1972;7(18):889-892

[4] Registrar General of India. Sample Registration System Statistical Report 1971. New Delhi: Ministry of Home Affairs, Government of India, Office of RGI \& Census Commission of India; 1970

[5] Registrar General of India. Sample Registration System Statistical Report 2015. New Delhi: Ministry of Home Affairs, Government of India, Office of RGI \& Census Commission of India; 2015

[6] Saikia N, Ram F. Determinants of adult mortality in India. Asian Population Studies. 2010;6(2):153-171

[7] Rajaratnam JK, Marcus JR, Levin-Rector A, Chalupka AN, Wang H, Dwyer L, et al. Worldwide mortality in men and women aged 15-59 years from 1970 to 2010: A systematic analysis. The Lancet. 2010;375:1704-1720

[8] Chaurasia AR. Mortality transition in India 1970-2005. Asian Population Studies. 2010;6(1):47-68

[9] Dhillon P, Ladusingh L. Economic activity in post-retirement life in India. Asia-Pacific Population Journal. 2011;26(3):55-71

[10] Singh A, Ladusingh L. Increasing life expectancy and convergence of age at death in India. Genus. 2013;69(1):83-99

[11] Yadav S, Arokiasamy P. Understanding epidemiological transition in India. Global Health Action. 2014;2014(7):10

[12] Dandona L, Dandona R, Kumar GA, Shukla DK, Paul VK, Balakrishnan K, et al. Nations within a nation: variations in epidemiological transition across the states of India, 1990-2016 in the Global Burden of Disease Study. Lancet. 2017;390(10111):2437-2460

[13] Sinha R, Kapoor AK. Cultural practices and nutritional status among premenopausal women of urban setup in India. Open Anthropology Journal. 2010;3:168-171

[14] Prentice AM. The emerging epidemic of obesity in developing countries. International Journal of Epidemiology. 2006;35:93-99

[15] Registrar General of India. Sample Registration System Statistical Report 2006. New Delhi: Ministry of Home Affairs, Government of India, Office of RGI \& Census Commission of India; 2006

[16] Omran AR. The epidemiological transition: a theory of epidemiology of population change. Millbank Memorial Fund Quarterly XLIX. 1971;1:599-638

[17] Ghosh S, Arokiasamy P. Emerging pattern of reported morbidity and hospitalization in west Bengal, India. Global Public Health. 2010;1:1-114

[18] Yadav AK, Gouda J, Ram F. Selfreported morbidity and burden of disease in Uttar Pradesh, India: Evidence from a national sample survey and the million deaths study. Journal of Biosocial Science. 2016;48(4):472-485 
Age- and Sex-Specific Burden of Morbidity and Disability in India: A Current Scenario DOI: http://dx.doi.org/10.5772/intechopen.89709

[19] Meenakshi. Gender differentials of morbidity in India. International Research Journal of Commerce Arts and Science. 2014;5(11)

[20] Musaiger AO, Hassan AS, Obeid O. The paradox of nutritionrelated diseases in the Arab Countries: The need for action. International Journal of Environmental Research and Public Health. 2011;8(9):3637-3671

[21] Buvinic M, Médici A, Fernández E, Torres AC. Gender differentials in health. In: Jamison DT, Breman JG, Measham AR, Alleyne G, Claeson M, et al., editors. Disease Control Priorities in Developing Countries. 2nd ed.

Washington, DC: World Bank; 2006. pp. $195-210$

[22] Quigley MA. Commentary: Shifting burden of disease-Epidemiological transition in India. International Journal of Epidemiology. 2006;35:1530-1531

[23] Santosa A, Schröders J, Vaezghasemi M, et al. Inequality in disability-free life expectancies among older men and women in six countries with developing economies. Journal of Epidemiology and Community Health. 2016;70:855-861

[24] Prinja S, Jeet G, Kumar R. Validity of self-reported morbidity. Indian Journal of Medical Research.

2012;136(5):722 



\title{
Evaluating the Efficiency of a Collaborative Learning Network in Supporting Third Sector Organisations in the UK
}

\author{
Scott Steen and John Mellor-Clark
}

\begin{abstract}
Third-sector organisations are a collective term for voluntary and community services, charities, and social enterprises. Within the UK and internationally, a subset provides a crucial and ever-expanding role in mental health care provision, delivering valuable client and community-led services. However, in the UK these organisations are under increased pressure to demonstrate their value, and many are constrained by scarce resources and lack of expertise. The Service Improvement Learning Collaborative was conceived as an innovative model for shared learning to enhance the value of this sector in mental health care support, generating a valuable resource of practice-based learning and promoting the implementation of effective practices. The initiative combines a collaborative learning model with mentorship support and in-depth, data analytical profiling. This collaborative involved a network of six organisations focused on exploring the maximisation of data quality, the minimisation of client attrition, and the optimisation of clinical outcomes. Evaluating the collated data helped identify the many unique challenges facing the sector and evidenced the model as a pragmatic solution for service quality improvement. This chapter provides an overview of the project's methodology, including its underlying rationale, first year of operation, and value of experiential learning for the field.
\end{abstract}

Keywords: service quality development, collaborative learning networks, practice-based evidence, experiential learning, third-sector organisations, mental health

\section{Introduction}

In the UK, Third-Sector Organisations (TSOs) are a collective term for voluntary and community agencies, charities, and social enterprises, of which a sub-section provides health and social care via independent and value-driven services [1]. Recent audits of the whole sector reveal a notable presence, with over 160,000 organisations and nearly 1-million employees and volunteers operating in the UK [1]. Across many high-income countries, it is an area which is growing rapidly as governments seek to harness their innovation and local capabilities [1, 2]. Given their nature, TSOs tend to be highly regarded for their proximity to the community, welcoming facilities, and the ability to engage those with complex and chronic needs [1-4]. 
Despite the potential benefits of TSOs, little research has been undertaken to evidence their impact and effectiveness $[2,3]$. Research applicable to many mental health care TSOs in the UK, including systematic reviews [2], national audits [1] and interviews with mental health charities [3], highlight the clinical and economic barriers affecting the production and utilisation of practice-based evidence (PBE). Many are constrained by tight budgets and scarce resources and often exist as 'microentities' making bidding processes and research prohibitively expensive $[1,4]$. The evidence that has been produced has been characterised as low in quality, lacking methodological rigour, theoretical modelling, and reliance on non-representative stakeholder feedback $[2,3]$. Access to learning is equally challenging with constraints on resources to review the latest research literature $[3,4]$.

For TSOs to overcome these challenges, there must be greater alignment of needs and priorities between providers, commissioners, policymakers and academic institutions. One approach to optimising the production and sharing of knowledge has been to form collaborative learning networks (CLNs) of services using a similar treatment model or methodology for generating evidence [5]. By partnering with similar providers, these networks enable organisations to explore, share and integrate learning across a network, maximising the potential for practice-based learning. CLNs have demonstrable potential within the UK mental health care sector, having reported success in the Improving Access to Psychological Therapy (IAPT) programme [6] and Children and Young People's [5] services. The IAPT programme, which is a national government-funded initiative for English primary mental health services, has been an influential driver in generating public domain service performance data. Having mandated sessional measurement across all services over a decade ago, it has recently achieved pre-and-post outcomes completion rates of $98 \%$ for clients completing therapy [7]. These high levels of data completeness are essential for supporting CLNs [6].

The quality implementation framework (QIF) [8] has been previously used as a schematic structure to introduce practice changes, including routine outcome monitoring (ROM), within mental health care services [9]. This model synthesises 25 implementation methods from almost 2000 evaluation reports, comprising 4 action phases and 14 critical steps [8]. Combined with research on the value of CLNs, an initiative was undertaken to bring together multiple TSOs delivering mental health care to enhance service quality. This chapter describes the rationale, process, and outcome of this initiative across its initial start-up and first year of operation using a traditional storytelling structure, with reference to the QIF [8] and other implementation frameworks [10-13].

\subsection{Telling stories}

Implementation science is the scientific study of techniques to enhance the quality and effectiveness of health services by advancing the systematic uptake of evidence-based practice (EBP) in routine clinical settings [14]. The learning from the field demonstrates the gap between what is shown to be effective to what is implemented in practice [14]. According to the QIF, in preparation for implementing practice change, agents must assess the host setting and build capacity, meeting with the service, analysing its infrastructure, surveying and training practitioners, and securing buy-in $[8,9]$. Regardless of how well-founded and robust the evidence may be, it is no guarantee it will be accepted and readily adopted by stakeholders $[9,15]$. Persuasive communication is therefore critical for framing research findings for specific contexts to enhance their uptake and impact [16]. The power of storytelling is increasingly recognised as an effective technique for transforming attitudes, perceptions and behaviours as they summarise concepts simply, quickly 
and effectively, appealing directly to a stakeholder's values and interest [16]. For instance, within UK mental health care services, storytelling as a technique has been associated with rapid improvements in data quality [9]. It is for this reason, our chapter aims to share the experiential learning and evaluation of this CLN for mental health care TSOs using a traditional storytelling outline, describing its setting, characters, plot, and themes.

\section{The SILC story}

\subsection{Setting}

To overcome the challenges of effective service development, a CLN was devised to support TSOs in the collection and use of data to inform the future development of operational practice. Inspired by the Institute for Healthcare Improvement's (IHI) [12] 'Breakthrough Series' Collaborative Model and implementation science research [11-14], this initiative intended to break new ground by working in close partnership with TSOs to generate evidence and inform quality improvement. The framework integrated implementation techniques using plan, do, study, act (PDSA) cycles [10] focusing on specific areas of service delivery and, as modelled by the QIF, create a structure for implementation $[8,9]$. This would become known as the service improvement learning collaborative (SILC).

Working in partnership, TSOs were invited to upgrade their measurement system to a more sophisticated software platform providing additional reporting features relevant for service operation and development [17]. Services were required to verify their commitment and autonomy at a managerial, board and trustee level to commence on a year-long journey to profile and engage with subject-relevant resources and attend monthly mentorship sessions and quarterly overnight residentials. A memorandum of understanding was devised to emphasise that membership was contingent on full-service participation and this was incorporated into the development of an implementation plan $[8,9]$.

This project took place over the course of a year, focusing on a different challenge each quarter, including a focus on data collection, session attendance, endings, and clinical outcomes. The project commenced with a planning meeting involving introductions, training and attitudinal surveys. With reference to the QIF, these steps were undertaken to assess the fit between the organisation's aspirations and readiness for change, allowing for open discussion and early feedback $[8,9]$. Across the project, there were monthly supportive calls with an assigned mentor from the research team, and quarterly in-person residential meetings with fellow TSOs, each supported by in-depth data profiling throughout. The purpose of the mentorship and residential sessions were to support participants in monitoring aspects of service quality and provide supportive feedback mechanisms which, according to the QIF, are critical post-implementation support strategies [8]. To improve future applications, the end of the year culminated in a summative conference with fellow mental health services to share the findings from the project's first year in operation [8-10]. A diagram of the SILC CLN model, including the induction, mentorship, residentials and summative conference, is outlined in Figure 1.

\subsection{Characters}

The QIF emphasises the criticality in creating an implementation team to oversee its rollout and set targets and agree off-track remedial action [8, 9]. The SILC project team was assembled in 2016, consisting of academics and clinicians 


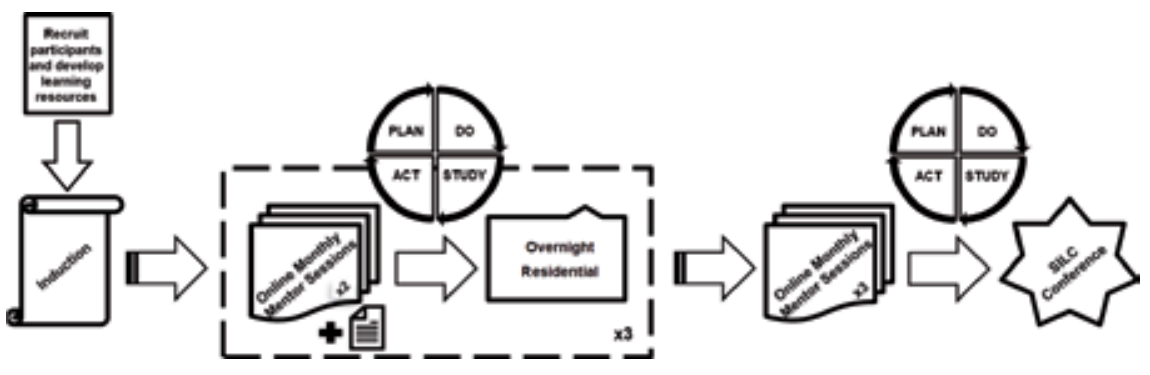

Figure 1.

The SILC CLN model, adapted from the IHI [10] 'breakthrough series' collaborative model.

with extensive experience in the field of talking therapies and service design [9]. This team was responsible for developing learning resources, providing mentorship support and tracking data through the relevant quarterly themes of service development. The team also worked directly with individual service leads to cascade learning and implement practice change, compiling routine reflective case notes and disseminating learning throughout the network.

A series of prospective pilot services were approached and recruited in early 2017, subject to expressions of interest and eligibility criteria. The SILC initiative was specifically aimed at mental health care TSOs using CORE IMS computerised quality evaluation systems [17] to obtain evidence on their delivery and strengthen their position for funding and benchmarking. Those eligible had been using CORE outcome measurement systems for over 5 years, primarily as an administrative tool to log clinical activity. Within all but one TSO expressing interest, there was little analysis of the data being undertaken, and no indication of it being used clinically or to enhance service quality. Prospective services were using traditional pre and post-therapy measurement approaches, acquiring outcomes data for around $40-50 \%$ of clients; a rate which is representative of the field and this methodology generally [18]. Many were also experiencing high rates of non-attendance and attrition, plus modest clinical outcomes for those with outcomes data.

The exploration phase of Aarons, Hurlburt and Horwitz [11] conceptual model for implementation identifies the importance of inner and outer contexts. In this project, it seems early withdrawal during the recruitment stages was due to a combination of socio-political factors and lack of absorptive capacity which impeded progress [11]. What had started as 12 prospective members soon halved to only six. Various reasons were given but discontinuation was mostly cited as being due to managerial turnover, lack of capacity for change, and workforce restructuring, or resistance. By contrast, the remaining TSOs demonstrated their levels of commitment via an initial attitudinal survey which, when disseminated to all practitioners $(\mathrm{n}=49)$, achieved a high response rate of around $80 \%$.

The six services joining the project ranged in size, geographical location and clinical specialism. Annual throughput ranged from around 80-300 clients per organisation. Clinical support specialisms included psychological support for female victims of domestic abuse; women on low incomes; parenting; unpaid carers; and general counselling support. Informed by QIF support strategies, each service was assigned a mentor from the SILC project team using a consultation and matching process $[8,9]$. Members received regular updates via a monthly blog post on the project's website (www.silcuk.org) and a quarterly newsletter via email. Resources were shared via the website and there were opportunities to contribute in online discussion forums. The combination of online meeting platforms and email correspondence enhanced the sharing of stories, communicating learning and progress, and helped to sustain the network. 
Evaluating the Efficiency of a Collaborative Learning Network in Supporting Third Sector... DOI: http://dx.doi.org/10.5772/intechopen.84294

\subsection{Plot}

Expanding on the story structure framework, this section will incorporate a generic narrative mountain structure, breaking down the plot by its background, rising action, climax, falling action, and resolution.

\subsubsection{Background}

During each quarter, the project team worked with each TSO to produce an implementation plan including a set of targets, infographics, quality checklists, report templates and mentorship support, with PDSA cycles to structure the process [8-10]. Many of these tools required regular, in-depth auditing of data recorded during assessment, treatment, and discharge. Analyses were complemented by attitudinal surveys to front-line practitioners focusing on their perceptions and experiences across each quarter. Services were encouraged to reflect and communicate their learning at the quarterly residential meetings, while critically appraising fellow member's contributions.

\subsubsection{Rising action: Events leading up to the main challenge(s)}

Throughout the project, it became clear that an organisation's success in addressing the challenges depended on their relationship with the process of using measurement questionnaires and how deeply practitioners and clients were engaged in responding to feedback. The team later conceptualised this as a development cycle with four distinct evolutionary stages that described the operational depth of practitioners' relationship with measurement: Pre and post-therapy measurement using paper forms; measurement at every session using paper forms; digital measurement at every session using tablets or computers; and digital measurement at every session tracking and sharing outcome progress directly with clients throughout

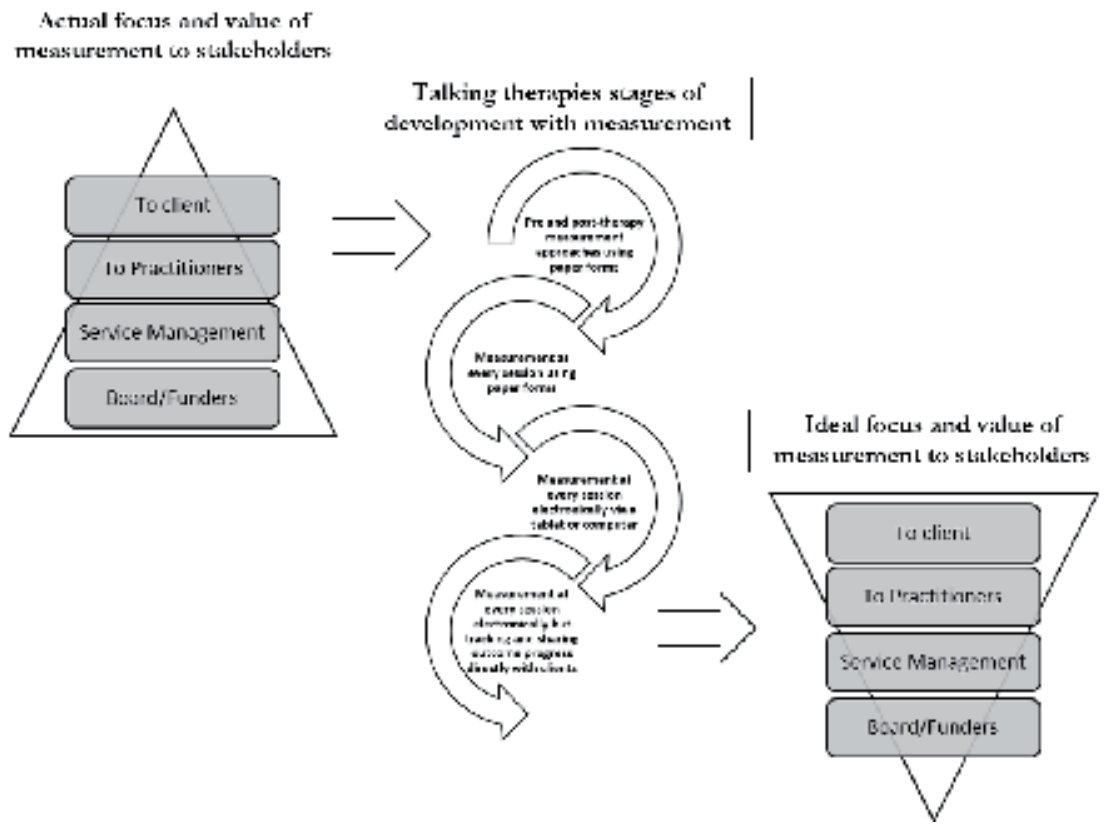

Figure 2.

The evolutionary stages of measurement within SILC TSOs illustrating the development cycle and value to stakeholders. 
the entire therapeutic encounter. It was recognised that services which were further along in this cycle had an inverse relationship with measurement in terms of its input and value towards stakeholders. Those in the later stages were able to maximise the value for clients that in turn benefitted other groups including practitioners, service management, and boards/funders. Conversely, those operating in the earlier stages were limited in their value to certain groups, typically to the boards/funders. Figure 2 shows a conceptual model of this, including the resulting value for stakeholders.

Conceptual implementation models highlight how the structures and processes that exist within organisations have an influence on the adoption of practice changes during the active implementation phases $[8,10,11]$. Within the SILC project, it was observed that completing paper forms, particularly at every session, generated huge administrative and inefficient burdens for members. This created barriers for practitioners looking to use data as feedback to enhance client outcomes and develop their clinical skills. During the year, most organisations evolved their administrative processes by replacing paper with digital methods, recording via electronic tablets. The services most successful in achieving the optimal rates for each quarterly challenge described understanding measurement as a construct and extension of the client. By focusing on creating the maximum value of measurement for clients, a myriad of other benefits at different stakeholder levels was also reported [19]. Naturally, some services were more equipped than others in accessing the appropriate technologies.

\subsubsection{Climax: The main challenge(s) reach a high point}

During the project, one of the participating TSOs withdrew due to a turnover in management and evolving financial pressures. Two other services experienced management turnover during the project which, although not impacting on their participation, did require additional input and training from the SILC project team. Practitioner turnover was understood to be common in TSOs [2-4], however, the rate of turnover concentrated at a managerial level had not been anticipated. For services with a complex management structure, this too complicated the sharing of learning and addressing each quarterly challenge. It was discovered that when managers with an on-hand leadership style were absent, this would impact on key aspects of their service operation, including the collection of high-quality data.

Another key challenge regarded the issue of session attendance and unplanned endings. A list of categorical reasons for why a session was not attended was compiled to record each time this occurred. Although the reasons recorded for cancellations were high, this was not the case for those who did not attend (DNA) (no advanced warning given) despite subsequent sessions being attended in approximately half of all instances. The most common reason for cancellations during the second quarter ( $\mathrm{n}=482$ ) was 'Health Problems' $(40 \%)$ while for DNAs $(\mathrm{n}=160)$ it was 'Unknown' or 'Not Recorded' (76\%). The absence of reasons recorded despite sessions being subsequently attended suggests practitioners either forgot or did not feel comfortable exploring why a session had been missed. This is concerning as DNAs were found to be indicative of an unplanned ending.

Definitions are important and have shown to vary the reported unplanned ending rate [20]. During the project, the unplanned ending rate reduced from 32\% at baseline to $27 \%$ at the end of the third quarter, however defining and interpreting these rates revealed notable issues. Among the participating members, there were multiple interpretations about what constituted a planned versus unplanned ending. Given its inherently subjective nature and potentially negative connotations, this limited the analysis somewhat. However, the links between session nonattendance and unplanned endings were consistent across all services and tended to occur early in treatment, as described in the next section. 


\subsubsection{Falling action: The characters work towards resolving the main challenge(s)}

One of the aims of the SILC project was to provide services with regular analyses to inform delivery and operation. This section reports on some of the headline findings along with extract quotes from two of the SILC TSOs. Systems-level modelling demonstrates the importance of considering the interrelationships between individual practice elements as opposed to solely focusing on each in isolation [11, 21]. Although the challenges during each quarter were distinct, the areas of overlap were noteworthy. Not only was session non-attendance linked with unplanned endings, but those TSOs with the longest standing commitment to high-quality data also reported the highest rates of clinical improvement.

\subsubsection{Data quality}

One major shift during the first quarter was to adopt sessional ROM, moving from traditional pre and post-therapy measurement approaches. This process was supported by a dedicated project member auditing and feeding back information to services. By the end of the first quarter, pre-and-post outcome completion rates increased from an average of $65 \%$ at baseline to $98 \%$, while by the end of the year, this was $97 \%$, with all TSOs achieving above $90 \%$ and half achieving $100 \%$ completion rates (Figure 3). These values were almost identical to the IAPT programme's recent achievement of $98 \%$, a decade after its first site implementation [7].

\subsubsection{Session non-attendance}

At the start of the second quarter, members began to record session nonattendance, including when an appointment was cancelled (by client) or the client DNA (no advanced warning given). One of the primary areas of interest was understood when sessions being missed were most likely to occur. Aggregating each service's datasets, the total number of appointments per sequential session number was tallied to assess what proportion was recorded as either cancelled or DNA. Including only session numbers with over 10 appointments each, it was possible to chart this data (Figure 4). It was identified that cancellations as a

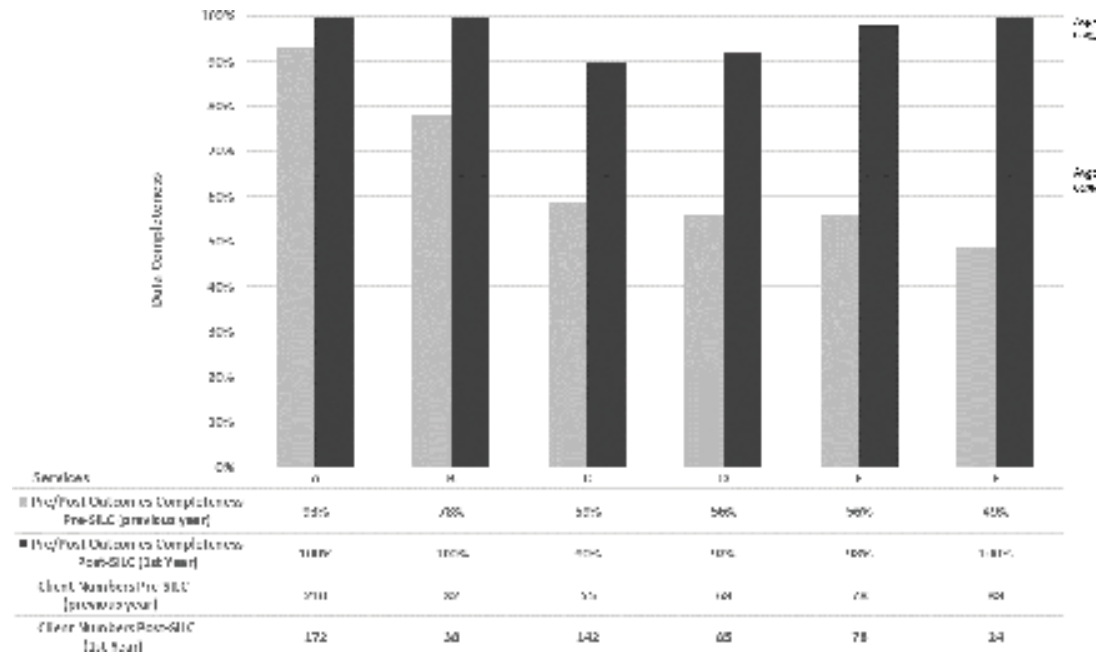

Figure 3.

Improvement of pre-and-post outcome measures completion rates for all SILC TSOs, 1 year before-and-after the project. 
proportion tended to increase the longer therapy progressed; although this might be due to a lower number of appointments at these stages. DNAs as a proportion did not exceed $10 \%$ for any session number although they did tend to occur earlier in therapy, with sessions $2-5$ reporting the highest rates of $7-8 \%$. The occurrence of DNAs declined somewhat as therapy progressed, possibly due to contracting which discharged clients after missed appointments without prior notice. Focusing on session non-attendance helped determine the scale of the challenge and how the pattern of cancellations and DNAs differed, prompting two participating services to a revise their policy in the interests of equitable access and service efficiency.

\subsubsection{Unplanned endings}

For the third quarter, the focus shifted to exploring the nature of unplanned endings. An analysis was undertaken to explore the potential associations between unplanned endings and the rate of non-attendance during therapy. This analysis found that, across all services, there was a link between session absence and ultimate attrition, especially regarding DNAs. For all TSOs, the DNA rate for clients with an unplanned (13\%) versus planned (2\%) ending was around $61 / 2$ times difference, ranging from 2 to 18 times across providers (Figure 5). By the end of the third quarter, those with planned endings attended almost 3 times more sessions (11) than those with unplanned endings (4) and were more likely to report reliable improvement for planned $(62 \%, \mathrm{n}=226)$ versus unplanned $(36 \%, \mathrm{n}=70)$ endings.

To assess how the pattern of non-attendance varied during therapy per ending type, session numbers and total appointments recorded were banded across all services (Figure 6). This analysis found that again, non-attendance was indicative of an unplanned ending, with higher rates of cancellations and DNAs. For those with an unplanned ending, it also revealed that while DNAs as a proportion were reduced in the lower session number bandings $(2-4 ; 5 \%)$, they remained consistent at around $17-21 \%$, excluding the $14-16$ banding which reported a rate of $30 \%$. Similar to the overall patterns of attendance, cancellations as a proportion of all appointments tended to increase the longer therapy progressed but again, this could be explained by a decrease in appointments recorded during these later subgroup stages.

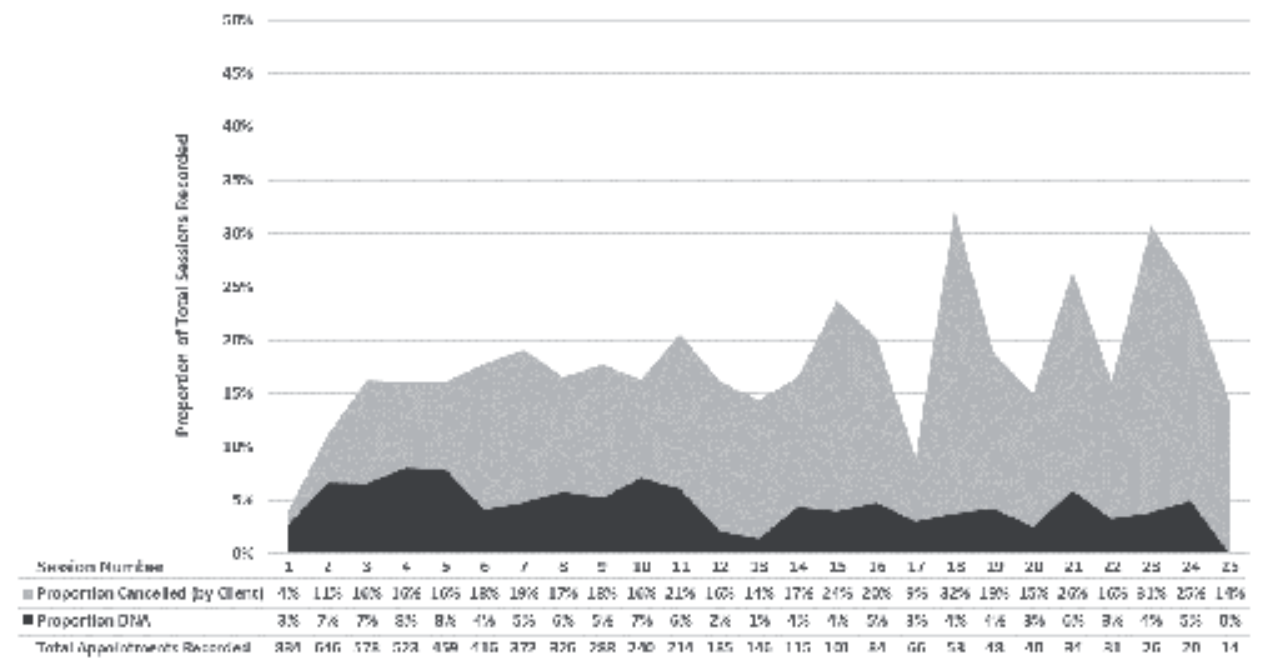

Figure 4.

The rate of appointment non-attendance per session number showing a higher proportion of DNAs earlier and cancellations later in therapy, across all SILC TSOs. 


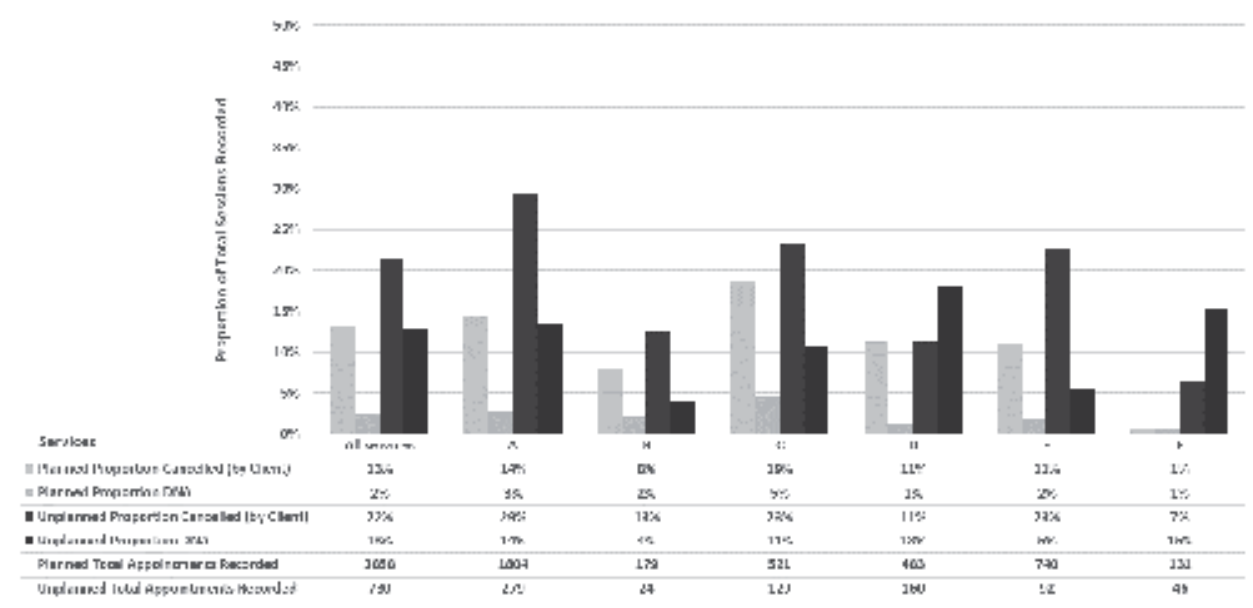

Figure 5.

A comparison of session non-attendance reporting a higher rate for unplanned versus planned endings across all SILC TSOs.

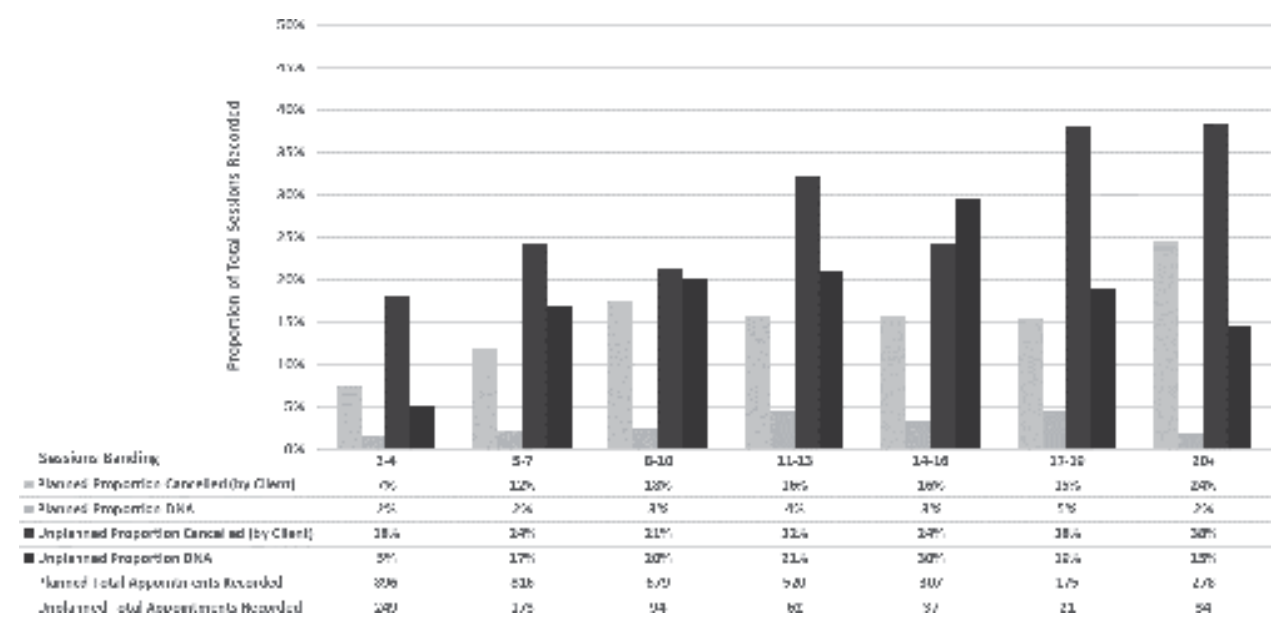

Figure 6.

A comparison of session non-attendance bandings showing a steady DNA rate and increasing cancellations for unplanned versus planned endings, across all SILC TSOs.

\subsubsection{Clinical outcomes}

In the final quarter, the project focused on clinical outcomes and understanding therapist variation and trajectories of change. To identify a possible dose-effect, an analysis was undertaken to assess the rates of change across individual domains of the CORE-OM (wellbeing, problems, functioning, and risk) within the one service using the full 34-item measure, as opposed to the shorter CORE-10 which does not record all domains [17]. A pattern of average scores were mapped relative to individual session numbers up to the 10th session (for clients having $10+$ appointments each) for those who reported reliable improvement ( $n=130 ; 891$ sessions) versus those who reported no reliable change ( $\mathrm{n}=39$ clients; 243 sessions) or reliable deterioration ( $\mathrm{n}=7$ clients; 53 sessions) (Figure 7). Based on this analysis, most of the score changes tended to occur early in treatment for those reporting reliable improvement, with an average decrease in scores of -6.1 across the first four sessions, remaining steady between sessions four to seven $(-0.5)$, and then 

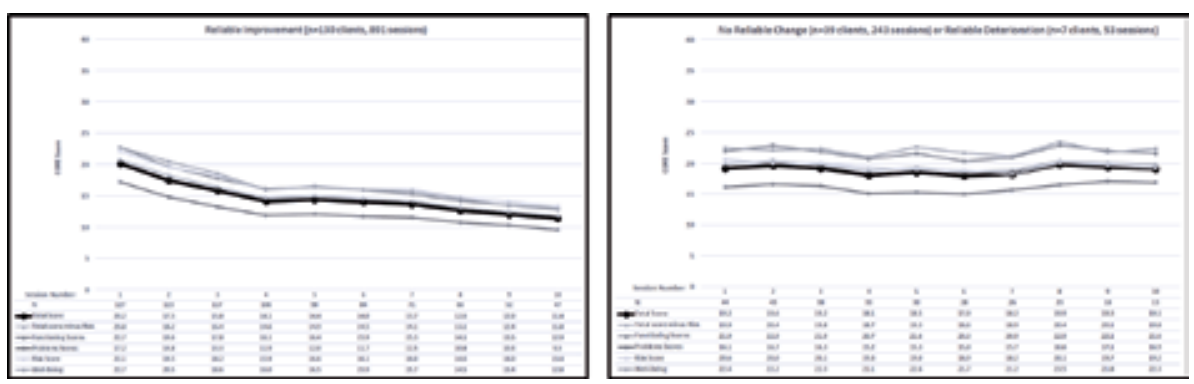

Figure 7.

A pattern-of-change comparison across the CORE-OM per session number illustrating early improvements for clients reporting reliable improvement compared with no reliable change or reliable deterioration.

decreasing steadily from sessions seven to $10(-2.3)$. For those reporting no reliable change or reliable deterioration, scores generally remained steady, with average changes ranging from 0.2 to 1.7. This suggests the first four sessions were important for identifying clients who were likely to improve or not. This triggered the integration of a flag feature to remind practitioners to review progress early in therapy to identify those at-risk of showing no change to provide additional support.

\subsubsection{The lived experiences of two TSOs engaging in the SILC project}

Informed by the QIF, improvement for future applications requires learning from experience [8]. To gauge the experiences of those participating in the project, a brief semi-structured interview was conducted at the end of the year to explore what service managers thought of the initiative, and how they might improve it for future services embarking on a similar journey of collaborative learning. The boxes below contain extracts from these interviews with two self-selected TSOs.

\footnotetext{
Service A: Interview Extracts

Our first question was how is it going to work for our clients? Building that value for them, and the practitioners, giving them a value to the work. This is not a measurement, it's not an outcome, it's an aide to the process, something that helps the work with clients. And then, once we all understood that, we could have an open conversation about why we might want something like this. You really need that opportunity to embed it early on though.

It completely allowed us to cement and consolidate how we work. I mean the data the project provided, really cemented what we were doing, how we were doing, we were using data in the right way, but it also gave us ways to look at data differently, what we could do, so it was an enhancing experience. That allowed us to feel quite proud of what we do, and have it validated, which for us a charity tucked away from others, that was a nice thing to have it validated on that level.

I did that like kind of cyclical journey, that it's not linear, we've got new practitioners all the time, we've just got 8 new practitioners in now, and they're going back through that loop. They're doing their first data clean this week where I'm just putting them through all the information, right we need to go through and see, right this is done, this is done, and you keep on embedding it, keeping the data quality up really. Constant, it must be really because when I've dipped out of the service, it went a little bit, my practitioners got a little bit complacent.

I think one of the biggest things for us, the 4-session thing, spotting that. We actively use that in supervision now, so it's really looking at, from that first session, you can see it quite clearly. So, there's more focus in those first 4 sessions, really looking at what the client needs, with a view to contracting through goals, further through that process. So that we're really meeting those needs, making that environment that's conducive then to achieving good outcomes. We're about sharing good practice, we're about empowerment, we're about creating choice and all those things. Being part of SILC fitted with part of the ethos so it was nice to go and be there in that capacity with other services. There's something about talking to someone who's been through it, we're just through it. It's that kind of picking their brains and have you thought this?

For me it's about credentialing the sector, it's about professionalism, it's about best practice, it's about evidence base, not being afraid to strive, to get to those levels, and get good outcomes and be accountable for that. I don't think therapy is any different from if you go to a shop to buy something you expect it to be good quality. I don't see why in therapy, clients shouldn't expect it to be any different.
} 


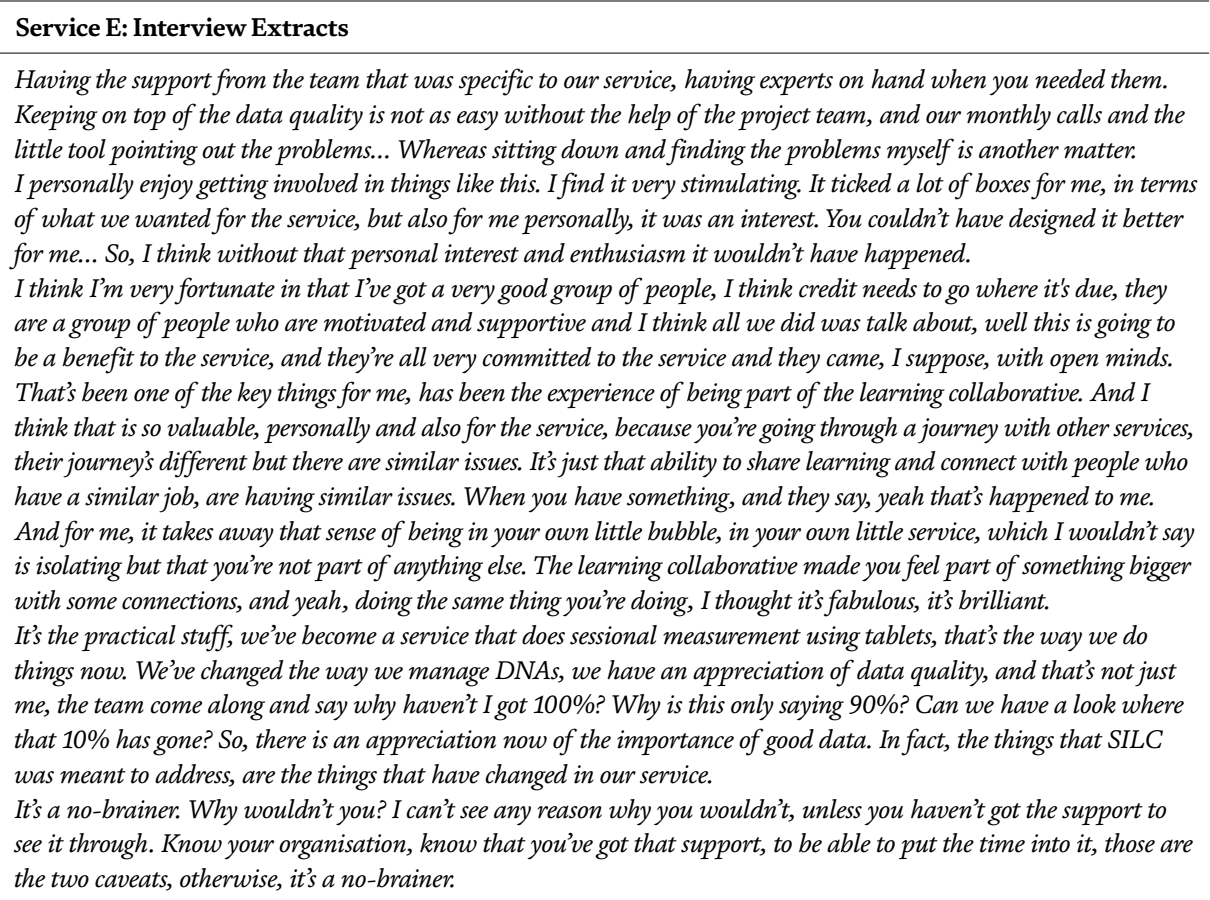

\subsubsection{Resolution: How things have ended up in this story}

In keeping with the IHI's [10] collaborative learning model framework, the first year of the SILC project culminated in a summative conference. Nearly 100 delegates were in attendance, each representing a range of different sectors within the field of talking therapies. Both the project team and self-selected SILC TSOs held a discussion regarding their experiential learning during the first year of the project. There was a consensus at the event about the operational challenges facing modern-day talking therapy services. While systems were becoming increasingly sophisticated, the training and support necessary to build in-house expertise were reportedly difficult to access due to time and resource constraints, a saturated and uncertain field, and isolated working practices. Providers, particularly in the thirdsector, desired the opportunity to work in partnership with others to share learning and enhance theirs and the sector's organisational and therapeutic models further.

With the first stage complete, the SILC project has amassed a wealth of learning which will be converted into a modular learning programme, providing a resource for future applications of the network $[8,9]$. This will replicate the CLN model and invite existing SILC members to act as guest speakers and offer unique support and valuable insights to newly recruited collaborative members. There are three existing SILC TSOs who have declared their interest and commitment to continuing with the project. Due to a turnover in management and decrease in contribution, two members have since withdrawn. The next phase of the initiative will focus on expanding the network, building on the existing knowledge and aggregate data to support ongoing analyses and resource development.

\subsection{Themes}

Themes are the essence of a story, the central constructs which reflect the actions, perceptions and experiences of the characters in their situational contexts. They represent the underlying 'big ideas' which transcend the distinctions between 
settings and circumstances and help conceptualise elements and links between them. This is important given the lack of guiding conceptual models for the sustainment phase of implementation [11]. Listed below is a discussion on some of the key themes both the participating services and project team uncovered during this stage of the project.

\subsubsection{The possibilities of CLNs in mental health TSOs}

The unintegrated nature of TSOs in the UK means there can be obstructions to developing and integrating EBP [2-4]. Within the field of talking therapies, determining what constitutes as EBP has been criticised for its reliance on controlled study methodologies which, due to their somewhat artificial nature, are considered detached from the clinical realities of routine practice settings [22, 23]. Certain advocates support a PBE approach to complement and address these limitations [24]. However, PBE relies on the collection of robust, aggregate datasets across multiple organisations sharing a common system or model.

Fragmentation, isolated working practices, and resource constraints can limit TSOs generating the PBE necessary to support their delivery [2-4]. Indeed, the primary interest from prospective members in this project was overcoming these barriers and demonstrating they were treating clients effectively. By pooling experience, resources and expertise around a central, unifying theme, TSOs were able to systematically explore, assess, understand and reflect upon key aspects of service quality development. Through iterative cycles, strategic improvement models and coordinated and collaborative dialogue [10], services were able to generate timely and actionable insights that were relevant to their unique circumstances. Testing practice changes on small scales, using focused inquiry and PDSA cycles, helped achieve small wins which, according to evaluation theories, can be an effective strategy for boosting perceived capabilities $[6,10]$.

Replicating previous research findings [2,3], access to a supportive academic project team was deemed invaluable for producing, mentoring and synthesising analyses and learning across the network. However, liaising with several TSOs proved to be a lengthier and more complicated process than first envisaged; an experience which is echoed elsewhere [6]. This identifies an important obstacle for sustaining CLNs, particularly those undertaking continuous analyses. It might be that by offsetting resources to a project team, this creates a more efficient process within individual services as it shares the expertise around a common need. If this were true, then it could prove more efficient and cost-effective for TSOs overall.

Given the central communicative nature of CLNs, it is important these channels are equitable. Within the third-sector, organisations tend to differ in size and can be equally varied in their operational modelling $[2,3]$. This inequity in size and visibility could feasibly leverage greater influence over smaller providers to work towards their agenda. To overcome the challenges of distinct delivery models within CLNs, a central governing platform using cooperative representation could therefore be valuable for identifying topics of interests and establishing a dictionary of terms. Similarly, these communication channels ought to use terminology that is consistent and agreed upon, particularly around subjective concepts such as ending types as doing so would ensure greater validity and reliability in data analytics [20].

\subsubsection{Management and leadership}

Many implementation frameworks emphasise the planning stages as critical to successfully embedding innovation $[8,11-13]$. Because implementation can be a complex process involving integrating existing practices with new, it typically 
requires a well-planned, structured and iterative process, addressing the various philosophical and practical barriers that can occur regularly $[9,15,21]$. It is within these contexts that supportive leadership can be a facilitating factor $[2,11,15,21,25]$. Without effective leadership to track, monitor and effectively champion the merging of practices, any expended effort can unravel $[9,15,25]$. Those in leadership positions need to be present and well-respected, retaining a detailed awareness and understanding of delivery and operation [15]. Service quality development through CLNs therefore appears to be reliant on management structures and local leadership.

In considering the scale of change and level of turnover in TSOs, particularly at a managerial level, the reliance on leadership highlights a notable barrier. Given the project team tended to work exclusively through managers brokering knowledge and training, their absence ultimately affected their organisation's participation and operational processes. It could be argued this was a sideeffect of the chosen methodology which may have benefitted from a broader involvement and contribution among the workforce. Advocates across the field recommend ensuring a local champion is permanently in place, advising that those departing a service provide sufficient training to those replacing them $[9,15,26]$. While this recommendation is practical, how it applies to TSOs is perhaps more complicated.

Continually nurturing the operational climate through sustained involvement and being present can help resolve the functional mechanisms of feedback systems $[15,25-28]$. A perceived lack of presence in the project among some practitioners served to undermine the initial enthusiasm and positive ethos established at the project's outset. Services which thrived tended to dedicate additional time and resources to sharing information in an open and accessible manner. This actively engaged the workforce in the minutiae of feedback informed treatment (FIT) [28] and encouraged more open dialogue. The literature on FIT teaches the value of routinely soliciting responses from clients about treatment progress, aiding practitioners at a therapeutic level [28-30]. However, there is an additional service-level which could also help inform practitioners and other stakeholders about enhancing client engagement and outcomes. By combining a FIT model with a feedback informed service, practitioners could have timely access to relevant learning. With reference to the QIF [8], supportive feedback mechanisms will be relevant to all stakeholder levels and through aggregate data, the client voice can be made accessible to all, helping sustain innovation.

\subsubsection{The resource challenge of TSOs}

Based on the learning from this initiative and relevant national and international research [2-4], there appears to be a significant resource challenge facing TSOs. Although many report having an interest in quality improvement [3], the constraints on providers including turnover, financial pressures and limited budgets, appear to greatly impact their ability to generate data and engage in practice development [2-4]. For a sector that relies heavily on volunteers, some of whom are in trainee positions [1], preserving a level of local expertise represents a continual challenge, particularly as systems become more expansive, specialised and costly. Although the CLN was a means to pool and share resources, supporting the implementation phase [11], external pressures had a notable influence on its integration, process and overall output. The level of attrition at the beginning and eventual withdrawal of others highlights the scale of this challenge. Consequently, this further demonstrates the criticality of the QIF phases in thoroughly assessing the fit between the host setting's aspirations and readiness for change $[8,9]$. 
Given the sheer scale of change and advancing pace of new technologies, feedback systems and innovations are becoming increasingly sophisticated while at the same time, access to training and support might not be keeping pace $[3,31]$. For many, including attendees at the summative conference and across the wider literature [3], allocating resources to this endeavour might be considered non-feasible as few can afford or justify it economically. This issue is further compounded by the fluctuating and isolated nature of services as well as barriers in accessing the literature due to subscription paywalls $[2,3]$. Accordingly, this highlights the need to consider the additional training and support required when adopting new innovations.

Despite its limitations, a CLN could address some of the resource challenges identified, increasing the opportunities for learning. Disseminating feedback throughout a network might help overcome some of the barriers to accessing research and forming partnerships $[5,6,10]$. Shared learning across all levels of the network, could foster a broader culture of openness and training, supporting collaboration across multiple platforms, while also generating an asset for feeding back insights across the sector. Undoubtedly, this would rely on the aggregation of robust datasets and communication platform to support this process [5].

\subsubsection{Designing the infrastructure}

The experiences from this project revealed the influence of organisational factors and infrastructure on the uptake of practice changes. Although research on the integration of feedback systems and ROM have identified numerous practical barriers, much of the emphasis has focused on practitioners [9, 15, 31-37]. Indeed, positive attitudes towards feedback have been shown to facilitate the effect on clinical outcomes improvement, while resistance can have the opposite effect [33, 38-40]. Resistance reportedly stems underlying performance anxiety or negativity about the relevance and utility of the practice $[9,15]$. However, the learning from this project highlights how positivity and motivation might not be sufficient in isolation.

Despite the generally positive attitudes from the survey and among the management mentees, itself likely a result of the selection process, many TSOs still encountered challenges, many of which appeared to be due to limitations in the infrastructure and frustrations with the technology. This, in turn, affected their capacity to use the system, something which is shown to be a facilitator in implementing EBP [25, 27, 31]. Restrictive and frustrated working practices can lead to negative perceptions forming $[25,27,36,41]$, suggesting attitudes might be mediated by how user-friendly and engaging a system is. For TSOs facing time and resource constraints, the simplicity of a feedback system is perhaps more pivotal. In these circumstances, systems may benefit from a uniform, standardised approach so that training and support can be refined and accessible via fully integrated and self-led instructional packages [32]. In terms of the QIF [8], the critical steps for assessing the needs and resources, capacity, and pre-implementation training would benefit from accessible resources which are intuitive and easy to understand.

\subsubsection{Refocusing measurement to respond and maximise the value to clients}

Traditionally, measurement in TSOs have been undertaken to satisfy the needs of boards and funders and to a lesser extent, service managers [3, 4]. The pressures on services have meant that pre and post-measurement approaches have dominated, with its purpose serving mainly administrative rather than clinical needs [3,9]. ROM established a method for improving data quality and representativeness, 
although the emphasis regarding its clinical utility or use in service development has only recently been advanced [7]. This illustrates how the focus and value of measurement have been positioned to satisfy a broader sector-level drive. However, by framing measurement in a way to maximise the value for clients, as observed in this project, there appear to be many cumulative gains for all stakeholders, including practitioners, service managers and boards/funders.

Across each of the common challenges, there seemed to be a critical period, usually within the first four to six sessions, which correlated with eventual outcome. For instance, a large proportion of DNAs tended to occur early in treatment which were a useful indicator of an unplanned ending, and by extension, a reduced chance of reliable improvement [20]. For clients reporting reliable improvement in one TSO, most change seemed to occur during the first four sessions, while those reporting no reliable change or reliable deterioration showed little change across a 10 -session period. This emulates the wider literature which identifies the initial stages as being a useful indicator for a client's subsequent engagement and outcome [42-45]. Accordingly, this trend highlights the criticality of early engagement and warrants a further discussion about the implications of keeping clients involved in therapy who report no change or attend infrequently. Evidence has shown that decisions to prolong or conclude therapy despite a lack of positive therapeutic change can be influenced by subjective beliefs, norms and attitudes, sometimes superseding what feedback monitoring and practice guidelines recommend [45].

According to the literature, the clinical benefit of measurement can be mediated by a practitioner's engagement and attitude towards outcomes monitoring [33, 38, 39]. Moreover, timely access to feedback has been shown to be a critical factor in the use of data among practitioners [27, 34, 36, 46]. TSOs which encourage open dialogue and pay greater attention to this information could produce cumulative benefits in each of the quarterly themes identified [10, 30,47]. An organisational culture of openness and commitment to learning was important and replicates findings reported elsewhere $[15,46]$. Additionally, giving practitioners access to service-level data might assist them in overcoming residual ambivalence because its application to service quality development is readily observable.

\subsubsection{Recommendations}

For those interested in implementing a CLN to support TSOs, there are several recommendations based on this project's findings. Firstly, recording high-quality data is crucial to this model. Securing high-quality data helps support the network and aggregate learning by effectively threading the client voice throughout all stakeholder levels. Promoting client engagement in the process of measurement is an effective strategy for enhancing data quality and building the opportunities for clinical application $[9,31,47]$. Because of this, it is important that implementation teams do not underestimate the infrastructure necessary to support practitioners working to deliver these innovations $[15,32,35,46]$. While pooling resources can help overcome challenges relating to cost and access to expertise, without a shared framework and understanding of the key concepts, a CLN and its associated analyses are likely to be impacted. In keeping with the wider literature, access to expertise and committed project team can be beneficial for supporting the network $[2,3,5,6,9]$. Focusing on distinct areas of service delivery through iterative improvement cycles and acknowledging their interdependency can help achieve cumulative benefits through the combination of smaller gains [6, 21, 25]. For TSOs, the role of leadership and effects of turnover cannot be understated. While it might not be feasible in TSOs to ensure a local champion is always in place, it is valuable to build a system that enables receptiveness towards continual practice 
innovation. A broader involvement and contribution among the workforce through wider supportive feedback mechanisms represents one effective strategy to overcome this.

\section{Conclusion}

TSOs represent a valuable and growing player in the provision of mental health care, yet many are constrained by limited budgets, isolated working practices, and a constantly shifting workforce. Together, these make producing and accessing evidence difficult, further limiting the sector from credentialing their impact and engaging in service development. To overcome these challenges, a CLN was implemented involving six TSOs and a dedicated project team to share learning and resources with the aim of improving delivery and operation in the areas of data quality, session attendance, unplanned endings and clinical outcomes. The CLN was inspired by the IHI collaborative model [10] framework for integrating and testing improvements using PDSA cycles and the implementation process was guided by the QIF [8]. It was found that introducing ROM substantially improved data quality which acted as the bedrock for all subsequent analyses and discussion. There appeared to be strong links between each of the common challenges, including increased non-attendance being associated with the occurrence of an unplanned ending, itself linked with a lower chance of reliable improvement. Overall, this approach to generating timely and relevant practice-based insight through partnership working and mentorship support proved to be effective for stimulating service quality enhancement. Although TSOs face many unique challenges, including high staff turnover and strained budgets, those with on-hand and inspirational leadership and commitment towards maximising the value of measurement for clients reported most success.

\section{Acknowledgements}

This work was supported by the Artemis Trust (No grant number). The funder had no further role in the design, collection, analysis, interpretation and compilation of this paper and no financial interests or benefits have arisen from the direct applications of this research.

\section{Conflict of interest}

Scott Steen and John Mellor-Clark declare they have no conflicts of interest. 
Evaluating the Efficiency of a Collaborative Learning Network in Supporting Third Sector... DOI: http://dx.doi.org/10.5772/intechopen.84294

\section{Author details}

Scott Steen ${ }^{1 *}$ and John Mellor-Clark ${ }^{2}$

1 SILC UK, Birmingham City University, Birmingham, UK

2 SILC UK, CORE IMS, Rugby, UK

*Address all correspondence to: scott.steen@coreims.co.uk

\section{IntechOpen}

(C) 2019 The Author(s). Licensee IntechOpen. This chapter is distributed under the terms of the Creative Commons Attribution License (http://creativecommons.org/licenses/ by/3.0), which permits unrestricted use, distribution, and reproduction in any medium, provided the original work is properly cited. (cc) BY 


\section{References}

[1] The National Council for Voluntary Organisations (NCVO). UK Civil Society Almanac; 2017. DOI: 10.1007/ springerreference_75878. Available from: https://data.ncvo.org.uk/almanac17 [Accessed: 12 December 2018]

[2] Bach-Mortensen AM, Montgomery P. What are the barriers and facilitators for third sector organisations (nonprofits) to evaluate their services? A systematic review. Systematic Reviews. 2018;7:13. DOI: 10.1186/ s13643-018-0681-1

[3] Buckland L, Fiennes C. An Exploration of the Evidence System of UK Mental Health Charities. Giving Evidence; 2016. pp. 1-58. Available from: https://www.nationalelfservice. net/cms/wp-content/uploads/2016/07/ Evidence-system-of-UK-MH-charitiesJuly-2016.pdf

[4] Dickinson H, Allen K, Alcock P, Macmillan R, Glasby J. The Role of the Third Sector in Delivering Social Care. London: National Institute for Health Research; 2012

[5] Fleming I, Jones M, Bradley J, Wolpert M. Learning from a learning collaboration: The CORC approach to combining research, evaluation and practice in child mental health. Administration and Policy in Mental Health and Mental Health Services Research. 2016;43:297-301. DOI: 10.1007/s10488-014-0592-y

[6] Lucock M, Barkham M, Donohoe G, Kellett S, McMillan D, Mullaney $\mathrm{S}$, et al. The role of practice research networks (PRN) in the development and implementation of evidence: The northern improving access to psychological therapies PRN case study. Administration and Policy in Mental Health and Mental Health Services Research. 2017;44:1-13. DOI: $10.1007 /$ s10488-017-0810-5
[7] Clark DM, Canvin L, Green J, Layard R, Pilling S, Janecka M. Transparency about the outcomes of mental health services (IAPT approach): An analysis of public data. The Lancet. 2017;391:679-686. DOI: 10.1016/ s0140-6736(17)32133-5

[8] Meyers DC, Durlak JA, Wandersman A. The quality implementation framework: A synthesis of critical steps in the implementation process. American Journal of Community Psychology. 2012;50:462-480. DOI: 10.1007/s10464-012-9522-x

[9] Mellor-Clark J, Cross S, Macdonald J, Skjulsvik T. Leading horses to water: Lessons from a decade of helping psychological therapy services use routine outcome measurement to improve practice. Administration and Policy in Mental Health and Mental Health Services Research. 2016;43:279285. DOI: 10.1007/s10488-014-0587-8

[10] Institute for Healthcare Improvement. The Breakthrough Series: IHI's Collaborative Model for Achieving Breakthrough Improvement. IHI Innovation Series White Paper. Boston: Institute for Healthcare Improvement; 2003

[11] Aarons GA, Hurlburt M, Horwitz SM. Advancing a conceptual model of evidence-based practice implementation in public service sectors. Administration and Policy in Mental Health and Mental Health Services Research. 2011;38:4-23. DOI: 10.1007/s10488-010-0327-7

[12] Damschroder LJ, Aron DC, Keith RE, Kirsh SR, Alexander JA, Lowery JC. Fostering implementation of health services research findings into practice: A consolidated framework for advancing implementation science. Implementation Science. 2009;4:50. DOI: $10.1186 / 1748-5908-4-50$ 
[13] Nilsen P. Making sense of implementation theories, models and frameworks. Implementation Science. 2015;10:53. DOI: 10.1186/ s13012-015-0242-0

[14] Bauer MS, Damschroder L, Hagedorn H, Smith J, Kilbourne AM. An introduction to implementation science for the non-specialist. BMC Psychology. 2015;3:32. DOI: 10.1186/ s40359-015-0089-9

[15] Boswell JF, Kraus DR, Miller SD, Lambert MJ. Implementing routine outcome monitoring in clinical practice: Benefits, challenges, and solutions. Psychotherapy Research. 2013;25:6-19. DOI: 10.1080/10503307.2013.817696

[16] Davidson B. Storytelling and evidence-based policy: Lessons from the grey literature. Palgrave Communications. 2017;3:17093. DOI: 10.1057/palcomms.2017.93

[17] Barkham M, Mellor-Clark J, Stiles WB. A CORE approach to progress monitoring and feedback: Enhancing evidence and improving practice. Psychotherapy. 2015;52:402-411. DOI: 10.1037/pst0000030

[18] Stiles WB, Barkham M, Mellor-Clark J, Connell J. Effectiveness of cognitivebehavioural, person-centred, and psychodynamic therapies in UK primarycare routine practice: Replication in a larger sample. Psychological Medicine. 2008;38:677-688. DOI: 10.1017/ s0033291707001511

[19] Cross S, Mellor-Clark J, Macdonald J. Tracking responses to items in measures as a means of increasing therapeutic engagement in clients: A complementary clinical approach to tracking outcomes. Clinical Psychology \& Psychotherapy. 2015;22:698-707. DOI: 10.1002/cpp.1929

[20] Swift JK, Greenberg RP. Premature discontinuation in adult psychotherapy: A meta-analysis. Journal of Consulting and Clinical Psychology. 2012;80:

547-559. DOI: $10.1037 / \mathrm{a} 0028226$

[21] Bickman L, Douglas SR, De Andrade ARV, Tomlinson M, Gleacher A, Olin S, et al. Implementing a measurement feedback system: A tale of two sites. Administration and Policy in Mental Health and Mental Health Services Research. 2016;43:410-425. DOI: 10.1007/s10488-015-0647-8

[22] Kendrick T, Peveler R. Guidelines for the management of depression: NICE work? British Journal of Psychiatry. 2010;197:345-347. DOI: 10.1192/bjp.bp.109.074575

[23] Lees J. The Future of Psychological Therapy: From Managed Care to Transformational Practice. Oxon: Routledge; 2016. DOI: 10.4324/9781315708294

[24] Barkham M, Hardy GE, MellorClark J. Developing and Delivering Practice-Based Evidence: A Guide for the Psychological Therapies. Chichester: Wiley-Blackwell; 2010. DOI: 10.1080/14733145.2010.548158

[25] Douglas S, Button S, Casey SE. Implementing for sustainability: Promoting use of a measurement feedback system for innovation and quality improvement. Administration and Policy in Mental Health and Mental Health Services Research. 2014;43:286-291. DOI: $10.1007 /$ s10488-014-0607-8

[26] De Jong K. Challenges in the implementation of measurement feedback systems. Administration and Policy in Mental Health and Mental Health Services Research. 2015;43:467470. DOI: $10.1007 / \mathrm{s} 10488-015-0697-y$

[27] Gleacher AA, Olin SS, Nadeem E, Pollock M, Ringle V, Bickman L, et al. Implementing a measurement feedback system in community mental health clinics: A case study of multilevel barriers and facilitators. Administration and Policy 
in Mental Health and Mental Health Services Research. 2015;43:426-440. DOI: 10.1007/s10488-015-0642-0

[28] Miller SD. Feedback-Informed Treatment: Improving the Quality and Outcome of Psychotherapy One Person at a Time. PsycEXTRA [Internet]. American Psychological Association (APA); 2012. DOI: 10.1037/ e633962012-001

[29] Goldberg SB, Rousmaniere T, Miller SD, Whipple J, Nielsen SL, Hoyt WT, et al. Do psychotherapists improve with time and experience?: A longitudinal analysis of outcomes in a clinical setting. Journal of Counseling Psychology. 2016;63:1-11. DOI: 10.1037/ cou0000131

[30] Rousmaniere T. Deliberate Practice for Psychotherapists: A Guide to Improving Clinical Effectiveness. Oxon: Routledge; 2016

[31] de Jong K, van Sluis P, Nugter MA, Heiser WJ, Spinhoven P. Understanding the differential impact of outcome monitoring: Therapist variables that moderate feedback effects in a randomized clinical trial. Psychotherapy Research. 2012;22:464-474. DOI: 10.1080/10503307.2012.673023

[32] Lyon AR, Lewis CC, Boyd MR, Hendrix E, Liu F. Capabilities and characteristics of digital measurement feedback systems: Results from a comprehensive review. Administration and Policy in Mental Health and Mental Health Services Research. 2016;43:441-466. DOI: 10.1007/ s10488-016-0719-4

[33] de Jong K, de Goede M. Why do some therapists not deal with outcome monitoring feedback? A feasibility study on the effect of regulatory focus and person-organization fit on attitude and outcome. Psychotherapy Research. 2015;25:661-668. DOI: 10.1080/10503307.2015.1076198
[34] Sharples E, Qin C, Goveas V, Gondek D, Deighton J, Wolpert $\mathrm{M}$, et al. A qualitative exploration of attitudes towards the use of outcome measures in child and adolescent mental health services. Clinical Child Psychology and Psychiatry. 2016;22:219-228. DOI: $10.1177 / 1359104516652929$

[35] Moltu C, Veseth M, Stefansen J, Nøtnes JC, Skjølberg Å, Binder P-E, et al. This is what I need a clinical feedback system to do for me: A qualitative inquiry into therapists' and patients' perspectives. Psychotherapy Research. 2016;28:250-263. DOI: 10.1080/10503307.2016.1189619

[36] Lutz W, De Jong K, Rubel J. Patientfocused and feedback research in psychotherapy: Where are we and where do we want to go? Psychotherapy Research. 2015;25:625-632. DOI: 10.1080/10503307.2015.1079661

[37] Jensen-Doss A, Haimes EMB, Smith AM, Lyon AR, Lewis CC, Stanick CF, et al. Monitoring treatment progress and providing feedback is viewed favorably but rarely used in practice. Administration and Policy in Mental Health and Mental Health Services Research. 2016;45:48-61. DOI: 10.1007/ s10488-016-0763-0

[38] Lucock M, Halstead J, Leach C, Barkham M, Tucker S, Randal C, et al. A mixed-method investigation of patient monitoring and enhanced feedback in routine practice: Barriers and facilitators. Psychotherapy Research. 2015;25:633-646. DOI: 10.1080/10503307.2015.1051163

[39] Lutz W, Rubel J, Schiefele AK, Zimmermann D, Böhnke JR, Wittmann WW. Feedback and therapist effects in the context of treatment outcome and treatment length. Psychotherapy Research. 2015;25:647-660. DOI: 10.1080/10503307.2015.1053553 
[40] Sapyta J, Riemer M, Bickman L. Feedback to clinicians: Theory, research, and practice. Journal of Clinical Psychology. 2005;61:145-153. DOI: $10.1002 /$ jclp.20107

[41] Delgadillo J, McMillan D, Lucock M, Leach C, Ali S, Gilbody S. Early changes, attrition, and dose-response in low intensity psychological interventions. The British Journal of Clinical Psychology. 2014;53:114-130. DOI: 10.1111/bjc. 12031

[42] Delgadillo J, Moreea O, Lutz W. Different people respond differently to therapy: A demonstration using patient profiling and risk stratification. Behaviour Research and Therapy. 2016;79:15-22. DOI: 10.1016/j. brat.2016.02.003

[43] Stiles WB, Leach C, Barkham M, Lucock M, Iveson S, Shapiro DA, et al. Early sudden gains in psychotherapy under routine clinic conditions: Practice-based evidence. Journal of Consulting and Clinical Psychology. 2003;71:14-21. DOI: 10.1037/0022-006x.71.1.14

[44] Lutz W, Stulz N, Köck K. Patterns of early change and their relationship to outcome and follow-up among patients with major depressive disorders. Journal of Affective Disorders. 2009;118:60-68. DOI: 10.1016/j. jad.2009.01.019

[45] Delgadillo J, Gellatly J, StephensonBellwood S. Decision making in stepped care: How do therapists decide whether to prolong treatment or not? Behavioural and Cognitive Psychotherapy. 2013;43:328-341. DOI: $10.1017 / \mathrm{s} 135246581300091 \mathrm{x}$

[46] Goldberg SB, Babins-Wagner R, Rousmaniere T, Berzins S, Hoyt WT, Whipple JL, et al. Creating a climate for therapist improvement: A case study of an agency focused on outcomes and deliberate practice. Psychotherapy.
2016;53:367-375. DOI: 10.1037/ pst0000060

[47] Lambert MJ. Maximizing psychotherapy outcome beyond evidence-based medicine.

Psychotherapy and Psychosomatics. 2017;86:80-89. DOI: 10.1159/000455170 



\title{
Outbreak of Cholera Due to Cyclone Idai in Central Mozambique (2019)
}

\author{
Edson Mongo, Edgar Cambaza, Robina Nhambire, \\ Jacinto Singo and Edsone Machava
}

\begin{abstract}
Idai was a strong tropical cyclone in Central Mozambique, causing over 1000 deaths, destroying schools, hospitals, roads, and more than 239,731 houses, displacing thousands of people to 136 accommodation sites, and leaving people in need for assistance. The resulting precarious hygienic conditions caused outbreaks of diseases such as malaria and cholera. This communication summarizes the onset of cholera outbreak in Sofala province and its response. It was declared on $27 \mathrm{March}$, and the number of cases raised up to 6766 and 8 confirmed deaths, with the highest incidence in the city of Beira. The government and partners made integrated efforts to control the disease, establishing treatment centers and units and improving sanitation and hygiene and surveillance. Furthermore, 800,000 people were immunized, and the results seemed satisfactory considering the response. Although cyclones are rare, Mozambique has a very limited capacity to handle their impact, and this urges the country to keep a contingency fund for future disasters.
\end{abstract}

Keywords: cholera, Cyclone Idai, Sofala, Center of Mozambique, outbreak

\section{Introduction}

In mid-March 2019, Tropical Cyclone Idai from category 4 hit Mozambique, devastating the port city of Beira and surrounding areas, following torrential rains and strong winds, causing massive flooding and leaving entire communities submerged [1-3]. It has damaged supplies, cut off clean water and sanitary facilities, and destroyed different infrastructures including schools, hospitals, houses $(239,731)$, roads, rails, disrupting regional trade, and supplies of fuel, wheat, medicines, and other goods, even from neighbor countries such as Zimbabwe and Malawi [3-5].

Thousands of displaced people were sheltering in 136 accommodation sites, including schools, across Sofala, Manica, Zambezia, and Tete, as reported by the National Institute of Disaster Management (INGC) $[4,6,7]$.

Idai caused a range of public health consequences, including mortality (598 confirmed deaths until 02 April 2019), injury, and infections [8, 9] due to waterborne and vector-borne diseases including cholera, malaria, and measles, and more than half of affected people are children $[2,10,11]$. Two weeks after Cyclone Idai's landfall, the index of cholera was confirmed in Mozambique with the death of five 
people. After the Ministry of Health declared a cholera outbreak on 27 March, 4979 cases and six deaths were confirmed $[1,3,5,8,12]$.

Cholera is an acute, secretory diarrhea caused by strains of the Gram-negative bacterium Vibrio cholerae that occurs in both endemic and epidemic patterns, presenting symptoms like watery diarrhea, rice-water stools, fishy odor to stools, vomiting, rapid heart rate, loss of skin elasticity, dry mucous membranes, and low blood pressure. This bacterium is usually found in food or water contaminated by stools from a person with the infection, and, if untreated, the fatality rate can be as high as $30-50 \%$, but with rehydration and electrolyte replacement, the death rate decrease to $1 \%[8,13]$.

Environmental factors play an important role in the epidemiology of cholera. The flooding and displacement of people has increased the risk of cholera because many of them spent days without accessing safe water supplies, resorting to drink the floodwaters. There are some videos of children playing with the same water that unfortunately were strewn bodies of humans and animals. Beyond that, menstruated women are also susceptible to waterborne diseases due to the use of unsafe water to wash their clothes, during the bath or while collecting water to prepare food $[1,8,14-16]$.

Idai survivors received supplies to purify their drinking water, food supplies, and items such as soap, nappies, towels, and blankets, to stop spreading cholera. The Mozambican Ministry of Health (MISAU), World Health Organization (WHO), Cooperative for Assistance and Relief Everywhere (CARE), and other NGOs worked in setting up treatment centers and clinics, as well as helping to run a massive campaign, where 800,000 doses of oral cholera vaccines were distributed and dispensed $[2,4,10]$. This paper aims to summarize the status of the outbreak of cholera in Mozambique due to the deadliest storm Cyclone Idai.

\section{Sources and documentary analysis}

This short communication was based on simple reviews of the most relevant literature related to the cholera outbreak as a result of Cyclone Idai. The documentary analysis was performed through ATLAS.ti (ATLAS.ti GmbH, Berlin, Germany) and partly in Microsoft Excel ${ }^{\mathrm{TM}}$ (Microsoft, Redmond, Washington, USA) and mainly based on flash updates by the United Nations Office for the Coordination of Humanitarian Affairs (OCHA), WHO, UNICEF, OXFAM, Health Cluster of Mozambique, and other agencies.

\section{Overview of Cyclone Idai}

Due to the damages caused by Cyclone Idai, it is important to know that different humanitarian helps were given, coming from national and international entities, both to the outbreak of cholera and to other diseases, in order to reduce the impact caused to the cyclone victims.

The central region of Mozambique was affected by heavy rains since 6 March 2019. It was a system formed in the Mozambican channel, which evolved from tropical depression to moderate tropical storm called Idai that took more than 800 lives and displaced thousands of individuals [17].

The house's destruction, roads, hospitals, clean water, and sanitary facilities also puts the traveler's health at risk, so they should always take the basic prevention, such as drinking and using safe water, washing hands often with soap, avoiding bug bites and direct contact with contaminated floodwater, or avoiding travels to dangerous areas $[18,19]$. 
Idai was one of the worst tropical cyclones on record to affect Africa and the southern hemisphere and caused catastrophic flooding, landslides, and large numbers of causalities in Mozambique, Zimbabwe, and Malawi, affecting more than 3 million people, but the most affected area was Beira, Mozambique's second largest port city, where the cyclone's landfall was on 14 March [17]. The heavy rains, strong winds, and severe flooding caused problems with water and food supplies, sanitation, electricity, transportation, shelter, communication, security, medical care, and mosquito control, creating opportunities for outbreak diseases, such as cholera. Due to the disasters caused by Idai, 6766 cholera and 43,556 malaria cases were registered [1, 19-21].

Idai affected $1,85 \mathrm{M}$ people (more than half were children), displacing 90,000 to 136 accommodation sites, mostly schools and churches. The sheltered people were sleeping in open spaces, increasing the risks of gender-based violence [11].

Tropical Cyclone Idai was outside the range expectations for a typical tropical cyclone that has happened in Mozambique and its neighboring countries. More than 14 countries provided supplies to help the affected areas. The United Nation's Central Emergency Response Fund (CERF) launched an emergency appeal for US $\$ 282$ million to respond to cyclone, which affected Mozambique, Malawi, and Zimbabwe. Furthermore, goods and military or rescue planes, helicopters, ships, and boats were provided to aid the huge search and rescue effort needed. Only $17 \%$ of the total amount required had been funded [3, 10, 22].

\subsection{Area of impact}

The most impacted area includes the city of Beira, in the center of Mozambique, province of Sofala (Figure 1). Sofala is a vast province composed of 12 districts located in central-eastern Mozambique with a total area of 68,018 square kilometers and population of $28,861,863$ individuals (2017 census). It is bordered to the

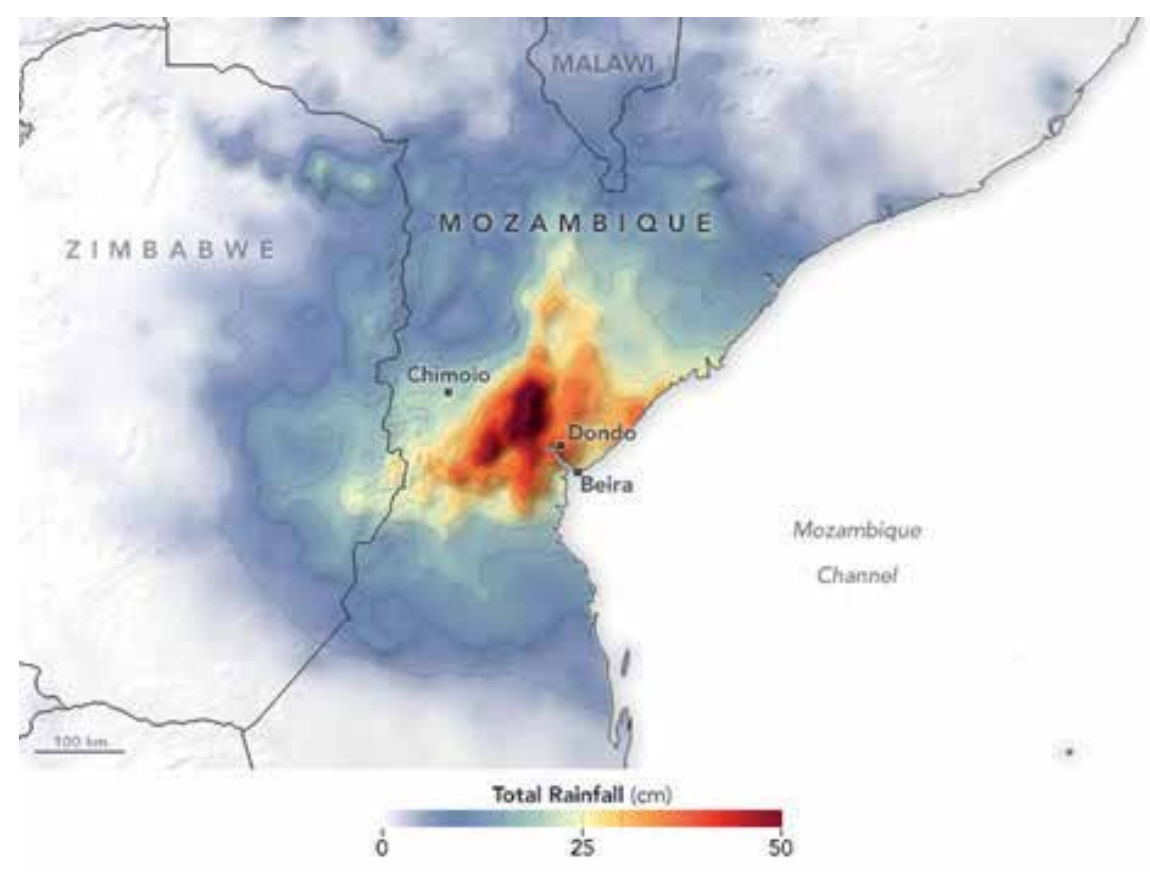

Figure 1.

Draft of Mozambican map showing the affected areas by Cyclone Idai in Sofala province. Source: Dauphin and Stevens [23], under public domain. 
north by Tete province, to the northeast by Zambezia province, to the south by Inhambane province, and to the west by Manica province.

\section{The outbreak of cholera}

A high number of cases of cholera were reported in April 2019, after the catastrophic disasters caused by Cyclone Idai in the center of Mozambique. About 4979 cases of cholera and six deaths were confirmed in emergency clinics created by the government of Mozambique aided by NGOs and other institutions [12], but until May the number of cumulative cases increased to 6766 and 8 deaths, according to the Health Cluster of Mozambique. Flooding and house destruction forced 68,974 displaced people living in accommodation places, making some places overcrowded, and increasing the risk of spreading cholera among the people there $[1,21]$.

The symptoms of cholera vary depending on the period of the infection. Between $18 \mathrm{~h}$ and 5 days, it is characterized by incubation period, followed by profuse watery diarrhea, rice-water stools, fishy odor to stools, vomiting, rapid heart rate, loss of skin elasticity, dry mucous membranes, and low blood pressure [24]. Most people are asymptomatic, but they remain carriers of the disease, excreting the bacteria in their faces, usually for 2 weeks but occasionally for several years. Approximately 2.8 million cases and 91,000 related deaths are reported annually, and the spreading of this disease included insufficient access to clean water, reduction of immunity, and taking of antacids [25].

Without the access of clean water and sanitary facilities, thousands of families were at risk of cholera mainly children because they used to play in dirty water which were strewn bodies of humans and animals, and women, during the menstruation period, sometimes needed to clean their bodies and only untreated water were available $[8,16]$. In the beginning, the destruction of road and infrastructure corridor that connected Sofala to other parts, it was very difficult to help those people with water, food medical, and relief supplies, forcing the use of helicopters, rescue planes, boats, and ships [1,3].

According to the Oxford Committee for Famine Relief (OXFAM), the Mozambican government worked quickly to set up cholera treatment centers in the city of Beira [22]. Supported by the WHO and funded by the GAVI (the Vaccine Alliance), more than 800,000 doses of oral cholera vaccines had been distributed in just 6 days, from 3 to 9 April 2019, since a vaccination campaign has launched. Fixed points were created to administrate vaccines to children and adults on schools and health center and on districts of Beira, Dondo, Nhamatanda, and Buzi [26]. It resulted in a decrease of the daily reporting number of cholera cases $[1,3,14]$, with a cost of US $\$ 1.85$ per dose [27]. They also provided supplies to purify their drinking water and stop to spread the cholera [4], but the sanitization of drinking water can be achieved through boiling, and all food must be well cooked and consumed immediately [8]. After the humanitarian response plan had been created to respond the outbreaks across the globe, millions of doses of oral cholera vaccine have already been shipped in many countries [26].

\section{Epidemiological accounts}

According to the Health Cluster of Mozambique, there were a total of 6735 cumulative cholera cases, as of 6 May 2019. Until 31 May 2019, the number 


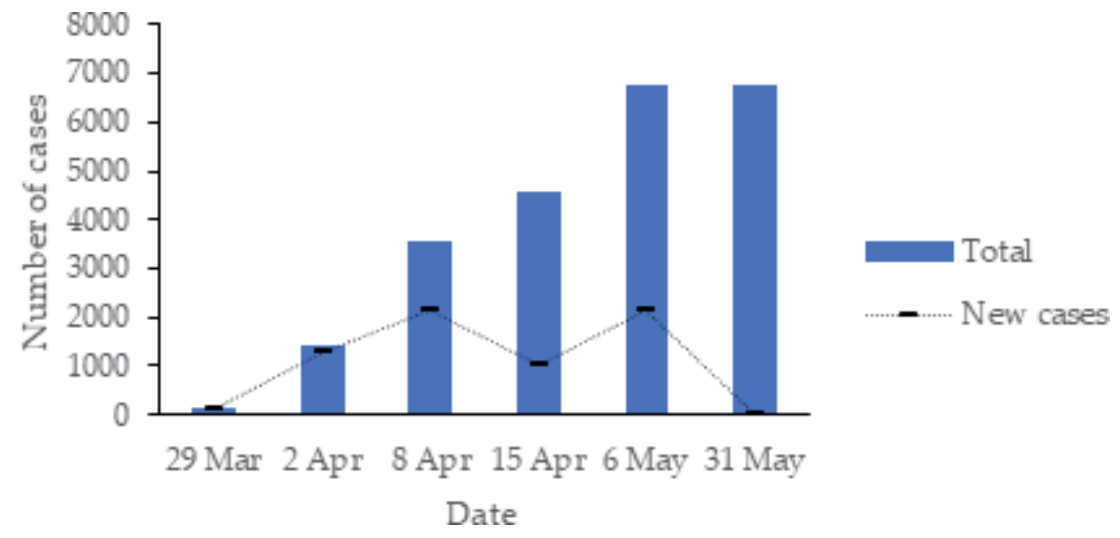

Figure 2.

Epidemiological curve of cholera outbreak attributed to Cyclone Idai, March-May 2019.

increased to 6766 cases, identified in emergency clinics, according to the National Situation Report [21].

The Figure 2 shows that the number of cases of the present outbreak is lower than 7073 cholera cases observed in 2015, even though Cyclone Idai caused a much higher destruction of infrastructure [3, 28]. The Ministry of Health of Mozambique declared a cholera outbreak on 27 March after the epidemiological conclusions made in areas affected by Idai, and more than 4000 cases were recorded in the city of Beira [1,29]. Figure 2 shows how the number of confirmed cases of cholera increased from the day it was announced as an outbreak, up to 31 May.

As the capital of Sofala and because it is the most populous city in the province, Beira registered 4745 cases, followed by Dondo with 1094 cases, Nhamatanda with 793 cases, and Buzi with 134 cases of cholera [20, 21, 29-31].

The Mozambican government, with the help of international entities, reacted to this happening with the supply of vaccines and water purification supplies, and, according to some reports, the daily reporting number of cholera cases reduced [1], but they do not show the numbers or percentages.

Cholera is just a part of the disasters; there were other concerns such as malaria, measles, respiratory infections, mental disorders, and the material damages. Restoration of the damages is still ongoing, and there are more people waiting for help; in some areas, people are already living in chronic poverty and now face huge challenges to survive.

\section{Conclusions}

Cyclone Idai hit the center of Mozambique in mid-March 2019 causing thousands of deaths. The destruction of infrastructures contributed to the epidemiology of cholera, and the Ministry of Health declared a cholera outbreak on 27 March, after identifying more than 4000 cases, number that increased to 6766 until 31 May; eight deaths in emergency clinics created to reduce the impact of diseases in that area. Flooding and overcrowding in accommodation places increased the risk of spreading cholera; however, considering the magnitude of the disasters caused by Idai, the outbreak of cholera was well managed with the efforts of the Mozambican government and partners, such as the WHO and CARE. Mozambique has already faced other outbreaks, which helped the country to create ways to confront the recent outbreak, due to Cyclone Idai. 
Many infrastructures were destroyed, including roads, hospitals, schools, and houses, and only $17 \%$ of the money required had been provided. However, food, water, and medicine supplies arrived to the affected areas through planes, helicopters, and boats. The outbreak was controlled certainly due to the setting up of treatment centers and clinics, where more than 800,000 people were immunized with doses of oral cholera vaccines. They also provided supplies to purify the drinking water and campaigns to spread the information about treatment of water and food, resulting in a decrease of the daily reporting number of cholera cases. It is important to know that even with all of this help, there are people who still need help.

\section{Funding}

This research received no external funding.

\section{Author details}

Edson Mongo*, Edgar Cambaza, Robina Nhambire, Jacinto Singo and Edsone Machava

Department of Biological Sciences, Faculty of Sciences, Eduardo Mondlane University, Maputo, Mozambique

*Address all correspondence to: eddsonmongo@gmail.com

\section{IntechOpen}

(C) 2020 The Author(s). Licensee IntechOpen. This chapter is distributed under the terms of the Creative Commons Attribution License (http://creativecommons.org/licenses/ by/3.0), which permits unrestricted use, distribution, and reproduction in any medium, provided the original work is properly cited. (cc) BY 


\section{References}

[1] Médecins Sans Frontières. Chapter 4: Strategies for epidemic response. Management of a cholera epidemic: Practical guide for doctors, nurses, laboratory technicians, medical auxiliaries, water and sanitation specialists and logisticians. Médecins Sans Frontières; 2018

[2] Rajeswari S, Ramaswamy NM. Pollen tube growth and embryology of ovule abortion in Sesamum alatum and $S$. indicum crosses. Journal of Genetics and Breeding. 2004;58(2):113-118

[3] Devi S. Cyclone Idai: 1 month later, devastation persists. Lancet. 2019;393(10181):1585

[4] Águeda Marujo H, Neto LM. Positive nations and communities: Collective, qualitative and cultural-sensitive processes in positive psychology. In: Cross-Cultural Advancements in Positive Psychology. Dordrecht: Springer; 2014 xxiv, 262 pages

[5] United Nations Office for the Coordination of Humanitarian Affairs. 2018-2019 Mozambique Humanitarian Response Plan: Revised following Cyclone Idai, March 2019. New York, New York, USA: United Nations Office for the Coordination of Humanitarian Affairs; 2019

[6] Jutla A et al. Environmental factors influencing epidemic cholera. American Journal of Tropical Medicine and Hygiene. 2013;89(3):597-607

[7] Wheeler J, Agha S. Use of Certeza point-of-use water treatment product in Mozambique. Journal of Water, Sanitation and Hygiene for Development. 2013;3(3):341-348

[8] Cambaza EM, Cândido F, Constantino NCC. Seroprevalência e factores de risco associados ao vírus da Hepatite B (HBV) em presidiários infectados pelo vírus da Imunodeficiência Humana (HIV) em alguns centros penitenciários de Moçambique. Maputo, Mozambique: Department of Biological Sciences, Faculty of Science, Eduardo Mondlane University; 2019

[9] UNFPA Procurement Services Branch. UNFPA Basic Dignity Kit. 2019 [cited 12 June 2019]. Available from: https://www.unfpa.org/resources/ unfpa-basic-dignity-kit

[10] Dupont B. File:Winged-seed Sesame (Sesamum alatum) (15890637053). jpg. Wikimedia Commons 2015 [cited 11 June 2019]; S25 Road East of Malelane, Kruger NP, South Africa. This file is licensed under the Creative Commons Attribution-Share Alike 2.0 Generic license. Available from: https://commons.wikimedia.org/wiki/ File:Winged-seed_Sesame_(Sesamum_ alatum)_(15890637053).jpg

[11] Mozambique Humanitarian Response Plan. 2019. p. 62

[12] Cambaza E, Koseki S, Kawamura S. Fusarium graminearum growth and its fitness to the commonly used models. International Journal of Agriculture, Environment and Food Sciences. 2019;3(1):10-14

[13] Chilaule I, Parruque M, Cossa H. Alta frequência de infecções por parasitas intestinais em adultos assintomáticos no hospital militar de maputo. In: Livro de Resumos da X Conferência Científica da UEM. 2018. p. 94

[14] World Health Organization. Oral Cholera Vaccines in Mass Immunization Campaigns: Guidance for Planning and Use. Geneva, Switzerland: WHO Press; 2010

[15] World Health Organization and United Nations Children's Fund. 
Drinking water | JMP. Joint Monitoring Program (JMP) for Water Supply and Sanitation 2019 [cited 31 May 2019]. Available from: https://washdata.org/ monitoring/drinking-water

[16] Cambaza EM, Samo Gudo E, Muianga AF. Prevalência e factores de risco para infecção pelo vírus chikungunya em pacientes com febre aguda no. Maputo, Mozambique: Centro de Saúde do Mavalene, em Maputo, Department of Biological Sciences, Faculty of Science, Eduardo Mondlane University; 2015

[17] Jenner L. Idai (Southern Indian Ocean): Mar. 28, 2019-Darkness in the Wake of Idai; 2019 [cited 17 June 2019]. Available from: https://blogs.nasa.gov/ hurricanes/tag/idai-2019/

[18] An update on Tropical Cyclone Idai; 2019

[19] Cyclone Idai in Mozambique, Malawi, and Zimbabwe; 2019

[20] United Nations Office for the Coordination of Humanitarian Affairs. Tropical Cyclones Idai and Kenneth, Mozambique National Situation Report 4, 31 May. Reliefweb 2019 [cited 12 June 2019]. Available from: https:// reliefweb.int/report/mozambique/ tropical-cyclones-idai-and-kennethmozambique-national-situation-report4-31-may

[21] Tropical Cyclones Idai and Kenneth, Mozambique 4; 2019

[22] Idenyi J et al. Antioxidant activity of diet formulated from selected leafy vegetables commonly available and consumed in Abakaliki, Nigeria. The Internet Journal of Alternative Medicine. 2009;8(2)

[23] Dauphin L, Stevens J. File:Idai mrg 2019079.png-Wikipedia. 2019 [cited 31 May 2019]. Available from: https:// en.m.wikipedia.org/wiki/File:Idai_ mrg_2019079.png
[24] Mandal S, Mandal MD, Pal NK. Cholera: A great global concern. Asian Pacific Journal of Tropical Medicine. 2011;4(7):573-580

[25] Tatebe $\mathrm{M}$ et al. A case of Vibrio cholerae infection in Japan not associated with overseas travel. Internal Medicine. 2019

[26] Cumberland S, McCarthy C.

Cholera Vaccination Campaign Begins in Mozambique. World Health Organization; 2019. Available from: https://www.who.int/news-room/ detail/03-04-2019-cholera-vaccinationcampaign-begins-in-mozambique [cited 16 August 2019]

[27] Khan IA et al. Coverage and cost of a large oral cholera vaccination program in a high-risk cholera endemic urban population in Dhaka, Bangladesh. Vaccine. 2013;31(51):6058-6064

[28] Vanormelingen K, Le Pechoux M, Bonde T. Cholera outbreaks in Tete, Sofala, Zambezia, Nampula and Niassa provinces. Mozambique 2015 Flood \& CholeraUpdate SitRep 2015 [cited 02 June 2019]. Available from: www. unicef.org/appeals/files/UNICEF_ Mozambique_SitRep_26_March_2015. pdf

[29] Camacho A et al. Cholera epidemic in Yemen, 2016-2018: An analysis of surveillance data. The Lancet Global Health. 2018;6(6):e680-e690

[30] Tropical Cyclones Idai and Kenneth, Mozambique 1. 2019

[31] Tropical Cyclones Idai and Kenneth, Mozambique 3. 2019 
Section 3

\section{Economic Evaluation}





\title{
Weighing Price and Performance for Decisions for Multisource Pharmaceutical Bidding in Public Hospitals in Thailand
}

\author{
Anunchai Assawamakin, Anke-Peggy Holtorf \\ and Nikolaos Maniadakis
}

\begin{abstract}
Following a national law introduced in 2017 in Thailand, the selection of winning bidders for multisourced pharmaceuticals and medical supplies in public hospitals must reflect "price-performance" aligned with the principles of worthiness, transparency, efficiency, effectiveness and accountability. We describe how a practical tool using Multiple Criteria Decision Analysis (MCDA) for evidence-based decision making in hospital bidding (tender) was developed through a multistakeholder workshop format. The local leader of the initiative together with 2 international advisors guided the 37 workshop participants through five interactive steps for local adaptation of the previously developed and validated global MCDAtool: (1) Criteria selection, (2) Scoring definition, (3) Weighting of price criterion, (4) Definition of cut-off point for price criterion, (5) Ranking and weighting of remaining criteria. All consensus judgments were imported to the decision tool which can later be used in the real-world situation in the hospitals to support the selection and document the underlying rationale. The final list of criteria differs from the previously suggested international template and now reflects the Thai decision priorities and current decision processes. In the book chapter, the resulting model will be presented and a pathway for implementation will be discussed.
\end{abstract}

Keywords: multiple-criteria decision analysis, MCDA, Thailand, multisource pharmaceuticals, hospital tender, hospital bidding, performance

\section{Introduction}

Pharmaceutical procurement in Thailand has a long history of deconcentration of procurement management and decisions to the Provincial Health Office (PHO) and all public hospitals. This includes the delegation of power to generate, retain, and use financial revenues according to regulations and subject to regular audits by the auditor general [1]. Thus, purchasing for hospital pharmaceuticals is strongly decentralized. Before the deployment of the Public Procurement Act BE 2560 (AD 2017) in 2017, the single selection criterion in the tender or bidding, as called in Thailand, was the lowest price. Since the establishment of Public Procurement Act, the bidder selection for multisourced supplies, including pharmaceutical and medical products, 
has been expanded beyond "price" to "price-performance" in order to align with the principles of the Act concerning worthiness, transparency, efficiency, effectiveness, and accountability. While public hospitals are encouraged to use performance criteria to determine the suppliers for pharmaceutical products, there is still a lack of a standard definition of what these criteria encompass and how important each of them is in making the decision. This may lead to a high level of variation between the hospitals on the formulary composition and in the methods used to shape the specific bidding process. To increase the overall quality and transparency based on the Public Procurement Act BE 2560 (AD 2017), the government is now requiring a solid rational and transparent documentation of hospital purchasing decisions.

Multiple-criteria decision analysis (MCDA) is a method which has been suggested as a tool for the evidence-based assessment of multisource pharmaceuticals in developing countries [2]. MCDA can help to consider multiple and sometimes conflicting criteria in the evaluation of the available alternatives [3].

By considering multiple criteria, individuals or groups can follow an explicit structure for arriving at a decision that best fulfills the criteria [4]. In 2016, a task force of the International Society for Pharmacoeconomics and Outcomes Research (www.ispor.org) set out to give guidance for the best practices of MCDA in healthcare decision-making [5, 6]. In this, the development and use of MCDA are described as an iterative process containing several elements, which may be adapted to the specific use by the key stakeholders involved in the decision. At the start, it is important to define the decision problem with the objective, the stakeholders, the expected alternatives, and the expected output. Based on this, criteria for evaluation can be determined which reflect the important attributes or drivers for the success in the decision. For each of the criteria, a scoring scale or graduation needs to be determined. If the criteria (or attributes) have a different importance in reaching the overall objective, the criteria will have to be weighted according to their importance $[5,6]$.

In the actual evaluation of the alternatives, the performance in each criterion is scored separately for the available alternatives and contributes with the predetermined weight, according to its relative importance, to the composite score reflecting the overall performance of the alternative. ${ }^{1}$ When comparing alternatives, the MCDA will result in a "score profile" for each alternative and a composite score, which is generated by the MCDA model. The result is not the decision but structured information to better inform the decision to be made. MCDA is being used widely to inform decision-making in healthcare, including benefit-risk assessment of medicine, formulary listing, or reimbursement decisions $[5,7]$. Examples for using MCDA in decision-making for multisource medicines in developing countries are emerging in several countries such as China, Thailand, or Egypt $[8,9]$. MCDA could be a solution for hospitals in Thailand to select those products which best meet the needs of the patients, providers, and the national policy makers for healthcare.

Thailand has a strong history of using multiple-criteria decision analysis (MCDA), considering the value of pharmaceuticals as an important component in pharmaceutical policy planning, price negotiation, development of clinical practice guidelines, and communication with health professionals [10,11]. It has been recognized that MCDA enhances the legitimacy of policy decisions by increasing the transparency, systematic nature, and inclusiveness of the process [10]. Examples for using the MCDA method on a national level for rational, transparent, and fair priority setting in the context of single-source drugs have been described [12].

The objective of this initiative was to develop a simple tool for improving decision-making in the hospital bidding setting, based on the MCDA methodology,

\footnotetext{
${ }^{1} \mathrm{~A}$ short explanation of MCDA in lay language (English) can be seen under https://www.youtube.com/ watch?v=7OoKJHvsUbo.
} 
through a multi-stakeholder workshop format to attain consensus. This tool should integrate a set of standard decision criteria, which (1) can be used by hospital purchasers to base bidding decisions on both performance and price, (2) would be applicable across diverse hospitals and institutions, but (3) would also allow for adaptation to local priorities.

\section{Methods}

On June 29, 2018, key stakeholders and experts in pharmaceutical bidding policies in Thailand came together on invitation by the Pharmaceutical Association of Thailand under Royal Patronage (PAT). The 37 active workshop participants represented multiple perspectives in Thailand (24 pharmaceutical purchasing (12 of these from leading hospitals), 7 academic pharmacy education leaders, 4 from the Ministry of Health, 1 from PAT, and 1 from an industry association) in addition to 2 observers from the regulatory perspective. During the 1-day workshop, all active participants were involved in developing an MCDA tool which can be used in making decisions in the hospital bidding setting.

Two international health policy advisors moderated the workshop following a validated MCDA calculation model and process for local adaptation [13]. Together with the local leader of the initiative, the international experts used a structured process as described in Figure 1 to prepare the workshop, align the participants' expectations and knowledge at the workshop, and to guide the workshop participants through five steps for the local adaptation of the MCDA format. The international advisors conducted the workshop in English language. However, to ensure that all participants could follow the discussions and freely express their experiences and opinions at all times, independent of their knowledge of either Thai or English, the workshop was supported by a two-way simultaneous translation.

The workshop started by defining all non-price criteria which may be relevant in the Thai decision process. These were defined starting from the
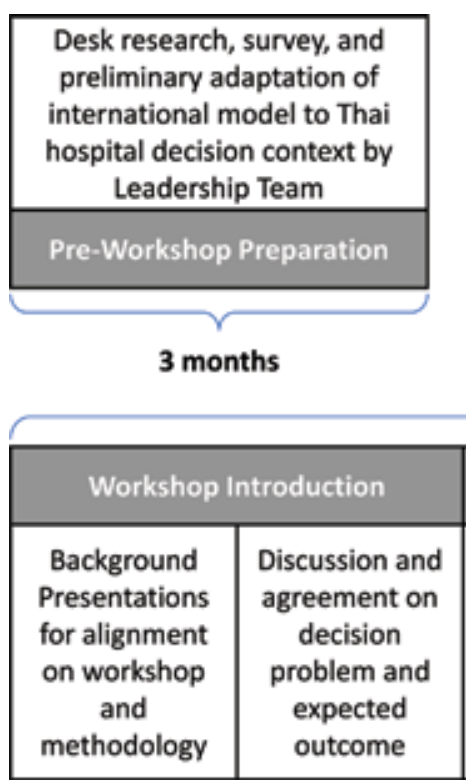

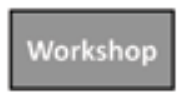

1 day

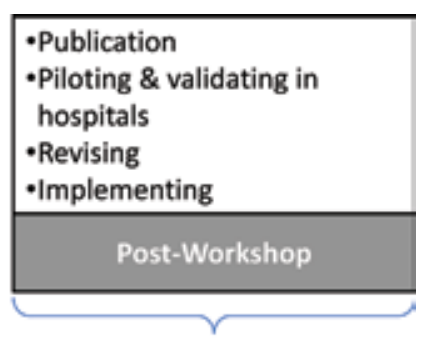

12-18 months

\section{Interactive MCDA Development}

Five Steps:

1.) Selection of Criteria

2.) Define Scoring for each criterion

3.) Weight of Price criterion

4.) Cut-off point for price scores

5.) Ranking and weighting of non-price criteria

Figure 1.

Description of the entire process for developing a value-based decision tool for multisource pharmaceutical bidding in Thai hospitals. 
basic decision criteria proposed by international health policy thought leaders [2] and an adapted set of these criteria which had gone through a preliminary adaptation to current Thai decision priorities before the workshop, by the local leadership team of the initiative (Step 1). This involved a detailed moderated discussion of each of the criteria and of the measures used for scoring each of the criteria (Step 2).

Subsequently, the participants determined the weight of the price criterion (Step 3) in the overall decision and the acceptable price range and cutoff point qualifying a product for positive ratings on the price criterion (Step 4). After this, the relative importance of each of the criteria in the overall decision was determined following the modified simple multi-attribute rating technique (SMART) method [9] for ranking and swing weighting of the criteria (Step 5). Steps 3-5 included anonymous voting by the participants using an audience response system (Ombea ${ }^{\circledR}$ with OMBEA ResponsePad $\left.{ }^{\mathrm{TM}}\right)$. The results of each voting were shown directly to the audience. In case of large variations or disagreements between the voters, the arguments of the participants in support of their votes were deliberated in open discussion followed by a second voting. For the voting on price and the cutoff point, the result was computed by assessing the median value. For the ranking of the criteria, the majority vote was used in repeated voting rounds to select the most important of the remaining criteria.

An important step after the workshop will be the testing and validation of the tool in a realistic setting (piloting) with monitoring of the results, the revision based on the learnings during the pilot, and, finally, the full implementation as summarized in the right part of Figure 1.

\section{Results of the workshop}

The discussion among the participants confirmed that currently there is no uniform evaluation method applied to bidding decision-making in hospitals and that there is a need for more consistency and better decision documentation on one side but also a need to adapt the weighting or criteria to local situations in cases where there are special environmental conditions. In addition, there was a general agreement that the decision should not solely be based on price, because major differences relating to quality and reliability or other factors with the healthcare impact are observed in real life between the products offered by different suppliers in Thailand. The advantages of using a consistent approach involving the MCDA methodology would be, on the one hand, the improved decision consistency and equity and, on the other hand, the high transparency and documentation of decisions versus all stakeholders with interest in the decision (e.g., manufacturers, government agencies, quality control, hospital administration, and providers).

\subsection{Pre-workshop preparation}

Based on experience with the local legal-structural setting, desk research, and a pre-workshop survey among the workshop participants, the leadership team (Thai academic pharmacy experts with international advisors) described 11 relevant criteria, including:

- Six product quality criteria, equivalence with the reference (original) product, stability and drug formulation, product quality determined by the Certificates of Analysis (CoA) of both the finished product and the active pharmaceutical ingredient (API), and the product specifications of both the finished product and the API 
Weighing Price and Performance for Decisions for Multisource Pharmaceutical Bidding in Public... DOI: http://dx.doi.org/10.5772/intechopen.83823

- Three criteria relating to the manufacturer quality, the manufacturing standard of both the finished product and the API, as well as the reliability of drug supply, pharmacovigilance, and added value service related to the product.

\subsection{Workshop}

\subsubsection{Step 1: selection of non-price criteria}

At the beginning of the interactive part of the workshop, the participants discussed and selected the most important non-price criteria which should be considered for determining the value of multisource pharmaceuticals starting from the set of criteria resulting from the pre-workshop preparation. During this discussion, several alterations were adopted so that it finally resulted in 10 non-price selection criteria, of which:

\begin{tabular}{|c|c|c|}
\hline Criterion name & Scoring (possible outcomes) & Score \\
\hline \multirow{6}{*}{$\begin{array}{l}\text { Equivalence with the } \\
\text { reference (original) } \\
\text { product }\end{array}$} & No data on pharmaceutical equivalence & $0 \%$ \\
\hline & Pharmaceutical equivalence & $10 \%$ \\
\hline & Bioequivalence proven in compliance with the Thai FDA & $30 \%$ \\
\hline & $\begin{array}{l}\text { Bioequivalence approved by the Thai FDA and with the European } \\
\text { EMA or US FDA standard }\end{array}$ & $70 \%$ \\
\hline & $\begin{array}{l}\text { Bioequivalence approved by the Thai FDA and with the European } \\
\text { EMA or US FDA approval }\end{array}$ & $80 \%$ \\
\hline & Therapeutic efficacy or equivalence proven in a clinical trial & $100 \%$ \\
\hline \multirow{5}{*}{$\begin{array}{l}\text { Stability and drug } \\
\text { formulation }\end{array}$} & No data on product expiry or stability & EXCL \\
\hline & $\begin{array}{l}\text { Have data (1) long-term study (full shelf life), but do not follow the } \\
\text { ASEAN guidelines }\end{array}$ & $10 \%$ \\
\hline & $\begin{array}{l}\text { Have data (1) long-term study (full shelf life) and follow the ASEAN } \\
\text { guidelines }\end{array}$ & $50 \%$ \\
\hline & $\begin{array}{l}\text { Have data (1) and (3) latest yearlong-term stability study or (4) } \\
\text { in-use stability data for the drug which needed to be mixed before } \\
\text { use (drug to be mixed before use must have "in-use stability data") } \\
\text { but do not follow the ASEAN guidelines or have only data (1) which } \\
\text { follow the ASEAN guidelines }\end{array}$ & $75 \%$ \\
\hline & $\begin{array}{l}\text { Have data (1) and (3) or (4) completely follow the ASEAN } \\
\text { guidelines }\end{array}$ & $100 \%$ \\
\hline \multirow{4}{*}{$\begin{array}{l}\text { Quality: manufacturing } \\
\text { standard finished } \\
\text { product }\end{array}$} & Limited information on quality assurance & EXCL \\
\hline & Country of origin GMP quality assurance & $33 \%$ \\
\hline & WHO GMP certification & $67 \%$ \\
\hline & EU or PIC/S GMP & $100 \%$ \\
\hline \multirow{3}{*}{$\begin{array}{l}\text { Quality: certificate of } \\
\text { analysis (CoA) finished } \\
\text { product }\end{array}$} & Not comply with registered finished product specification & EXCL \\
\hline & Partially comply with registered finished product specification & EXCL \\
\hline & Comply with registered finished product specification & $100 \%$ \\
\hline \multirow{3}{*}{$\begin{array}{l}\text { Quality: product } \\
\text { specification (finished } \\
\text { product) }\end{array}$} & Do not comply with registered specification & EXCL \\
\hline & $\begin{array}{l}\text { Follow the previous pharmacopeia version or in-house specification } \\
\text { with topics not aligned with the general chapters }\end{array}$ & $50 \%$ \\
\hline & $\begin{array}{l}\text { Follow updated pharmacopeia or in-house specification with topics } \\
\text { recommended by pharmacopeia }\end{array}$ & $100 \%$ \\
\hline
\end{tabular}

Table 1.

List of criteria with consensus scoring (qualitative descriptive) (Part 1). 
- Five relate specifically to the product (equivalence with the reference (original) product, stability, and drug formulation, the product quality determined by the CoA of the finished product, and the product specifications of both the finished product and the API).

- Three relate to the manufacturer (the manufacturing standard of both the finished product and the API as well as the reliability of drug supply).

- Two relate to additional value beyond the actual product (added value services at the hospital level and macroeconomic benefit in terms of local investments by the manufacturer).

Two other criteria have been considered but were not adopted to the final essential list of decision criteria: The Certificate of Analysis for the API was considered a prerequisite to enter the bidding and, therefore, would not be relevant for further differentiation between the products; pharmacovigilance was also not considered relevant for the multisource pharmaceuticals used in the hospital setting. In addition, it was warned that this criterion might introduce an unfair bias toward the originator products who are usually the only ones pursuing a pharmacovigilance database on the national or international level.

\begin{tabular}{|c|c|c|}
\hline Criterion name & Scoring (possible outcomes) & Score \\
\hline \multirow{4}{*}{$\begin{array}{l}\text { Quality: manufacturing } \\
\text { standard API }\end{array}$} & Limited information on quality assurance & EXCL \\
\hline & Country of origin GMP quality assurance & $33 \%$ \\
\hline & WHO GMP certification & $67 \%$ \\
\hline & EU or PIC/S GMP & $100 \%$ \\
\hline \multirow{3}{*}{$\begin{array}{l}\text { Quality: product specification } \\
\text { API }\end{array}$} & Not comply with registered specification & EXCL \\
\hline & $\begin{array}{l}\text { Follow the previous pharmacopeia version or in-house } \\
\text { specification with topics not aligned with the general chapters }\end{array}$ & $50 \%$ \\
\hline & $\begin{array}{l}\text { Follow updated pharmacopeia or in-house specification with } \\
\text { topics recommended by pharmacopeia }\end{array}$ & $100 \%$ \\
\hline \multirow{4}{*}{$\begin{array}{l}\text { Added value service on the } \\
\text { hospital level }\end{array}$} & No program or service & $0 \%$ \\
\hline & Low value (meets one criterion) & $33 \%$ \\
\hline & Moderate value (meets two criteria) & $66 \%$ \\
\hline & High value (meets three criteria) & $100 \%$ \\
\hline \multirow[t]{4}{*}{ Macroeconomic benefit } & The manufacturer has no local investment in the country & $0 \%$ \\
\hline & The manufacturer has minor local investment in the country & $33 \%$ \\
\hline & $\begin{array}{l}\text { The manufacturer has moderate local investment in the } \\
\text { country }\end{array}$ & $67 \%$ \\
\hline & $\begin{array}{l}\text { The manufacturer has significant local investment in the } \\
\text { country }\end{array}$ & $100 \%$ \\
\hline \multirow[t]{5}{*}{ Reliability of drug supply } & Major and multiple problems in the last 2 years & $0 \%$ \\
\hline & Minor and occasional problems in the last 2 years & $20 \%$ \\
\hline & Single precedence of supply problems in the last 2 years & $50 \%$ \\
\hline & No precedent of supply problems in the last 2 years & $80 \%$ \\
\hline & $\begin{array}{l}\text { Manufacturer is financially capable and willing to guarantee } \\
\text { supply }\end{array}$ & $100 \%$ \\
\hline
\end{tabular}

Table 2.

List of criteria with consensus scoring (qualitative descriptive) (Part 2). 
Weighing Price and Performance for Decisions for Multisource Pharmaceutical Bidding in Public... DOI: http://dx.doi.org/10.5772/intechopen. 83823

\subsubsection{Step 2: criteria scoring}

For all selected criteria, the measurement scales were discussed in some cases; the previously suggested rating were adapted by the participants as considered more appropriate in the Thai hospital setting. The detailed descriptions of the criteria scoring are listed in Tables $\mathbf{1}$ and 2.

\subsubsection{Step 3: weight of price criterion}

Subsequently, the relative importance of the price criterion was determined by voting and was determined to be $40 \%$ of the overall decision, which is already established as a general ratio for chemical pharmaceutical products.

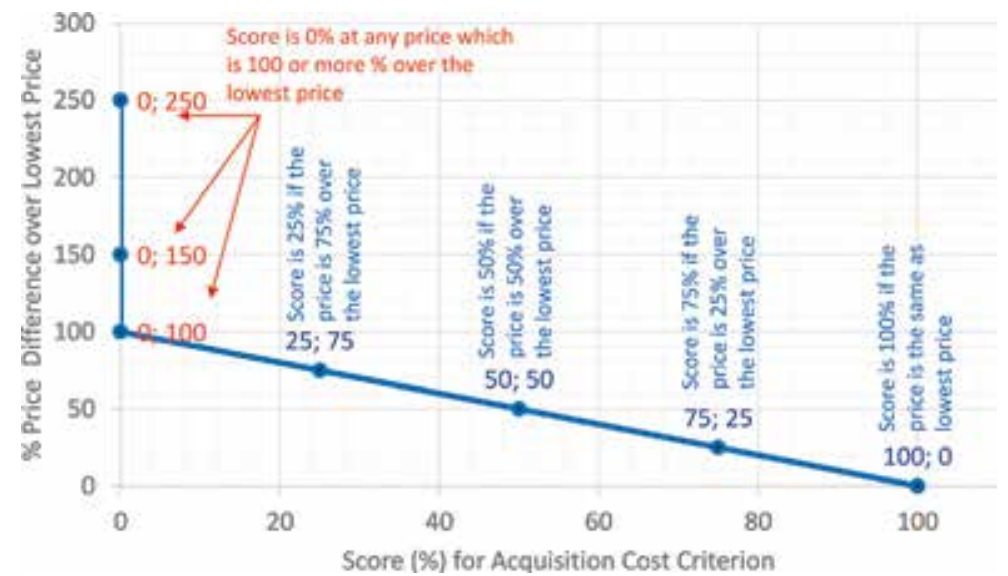

Figure 2.

Graphic representation of the scoring for the procurement price difference in comparison to the lowest price product. The cutoff point determined in the workshop was an excess price of $100 \%$. All prices higher than this cutoff point receive a score of $0 \%$.

\begin{tabular}{llcc}
\hline Criterion & Measures & $\begin{array}{c}\text { Rank } \\
\text { (importance) }\end{array}$ & $\begin{array}{c}\text { Final } \\
\text { weights* }\end{array}$ (\%) \\
\hline Price & Quantitative & 1 & 40 \\
\hline $\begin{array}{l}\text { Equivalence with the reference } \\
\text { (original) product }\end{array}$ & Qualitative & 2 & 12.2 \\
\hline $\begin{array}{l}\text { Product quality: certificate of analysis } \\
\text { (CoA) finished product }\end{array}$ & Yes/no (no = exclusion) & 3 & 8.7 \\
\hline $\begin{array}{l}\text { Manufacturer quality: manufacturing } \\
\text { standard finished product }\end{array}$ & Qualitative & 4 & 8.7 \\
\hline Stability and drug formulation & Qualitative & 5 & 7.3 \\
\hline $\begin{array}{l}\text { Product quality: product specification } \\
\text { (finished product) }\end{array}$ & Qualitative & 6.8 \\
\hline $\begin{array}{l}\text { Quality: product specification API } \\
\text { Quality: manufacturing standard API }\end{array}$ & Qualitative & 7 & 4.9 \\
\hline Added value service on the hospital level & Qualitative & 8 & 4.0 \\
\hline Reliability of drug supply & Qualitative & 9 & 3.1 \\
\hline Macroeconomic benefit & Qualitative & 10 & 2.8 \\
\hline
\end{tabular}

Table 3.

Results of the consensus workshop for the relative importance of the evaluation criteria and their weight in the final score for each option. 


\subsubsection{Step 4: scoring of price criterion}

To enable a quantitative scoring function for the price criterion, the participants had to determine the cutoff point for the price. This median cutoff point was voted to be an excess price of $100 \%$ based on the acceptance threshold defined by the current guideline of Comptroller General's Department. As shown in Figure 2, this means that all products with prices which are $100 \%$ or higher than the lowest price

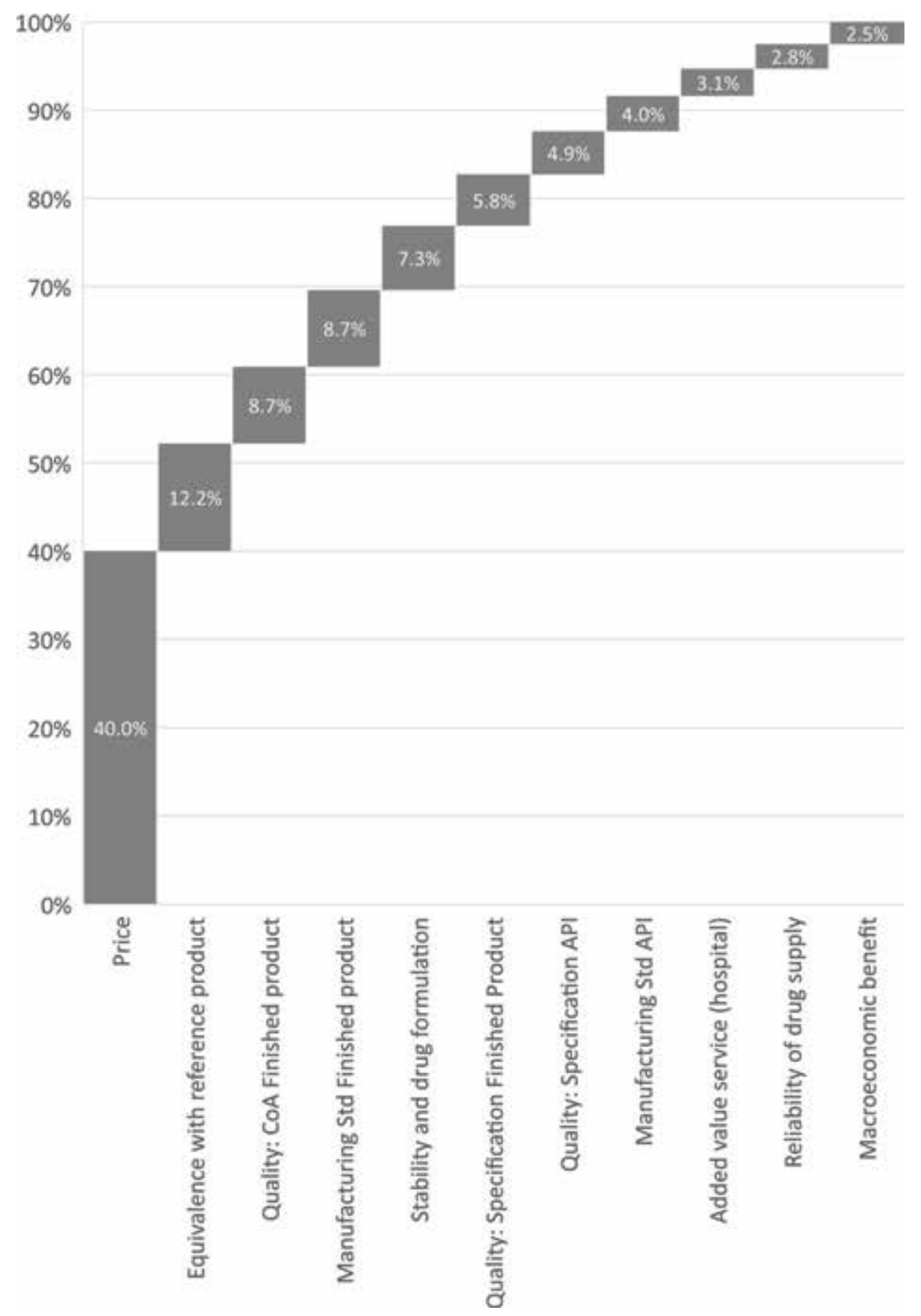

Figure 3.

Impact of each decision criterion in the evaluation on the final decision (top axis: impact percentage). Abbreviations: $C o A=$ certificate of analysis, Std. = standard, API = active pharmaceutical ingredient. 
Weighing Price and Performance for Decisions for Multisource Pharmaceutical Bidding in Public... DOI: http://dx.doi.org/10.5772/intechopen.83823

offered in the bidding would receive a score of zero for the pricing criterion in the evaluation.

\subsubsection{Step 5: ranking and weighting of non-price criteria by "SMART and swing" method}

Finally, the selected criteria were ranked and rated for their weight in the final decision round [7]. The results are summarized in Table 3 in the column "Final weights." The impact of each criterion on the final decision is shown in Figure 3.

\subsection{Workshop follow-up}

Finally, all participants agreed that the resulting model seemed appropriate to be used for selecting bidding winners in Thai hospitals and that it should be tested in real-life pilot applications. Hence, after the MCDA model has in this workshop been adapted to the Thai hospital decision context by Thai stakeholders from a broad range of healthcare-related institutions, two additional steps are important to ensure applicability in the hospital setting: (1) piloting and validating in real-life decision processes and (2) refinement based on the experiences in the piloting in selected hospitals. Realizing such a pilot application will require involvement of all functions concerned in the specific hospital decision process and their agreement. This will be facilitated through support from the local leader of the initiative.

\section{Discussion}

In this report we have described a structured process to adapt the template of a validated international multiple-criteria scoring decision format to the specific setting of making performance-based decisions for public purchasing in Thai hospitals. The involvement of a broad stakeholder group in the design process is critical for the acceptance and subsequent implementation of the methodology. In this workshop, there were 37 participants who represented the user perspectives as well as the administrative or regulatory perspectives, the academic expertise and the perspectives of the pharmacist profession through PAT and of the industry by representation of the Pharmaceutical Research and Manufacturers Association (PReMA, http://www.prema.or.th).

Although using a standardized process for the workshop and a previously designed Excel-based model template [13], the participants were involved in each step of designing the specific Thai decision tool during a 1-day workshop. Continuing the participatory process by involving the important purchasing stakeholders in the pilots and the evaluation will further foster full transparency and improvement through user feedback, and, finally, it should support endorsement of the process in the specific Thai hospital bidding decision context. The participants agreed to the approach and considered the resulting MCDA tool to be suitable to improve the transparency and consistency of decision-making for multisource pharmaceuticals in Thai hospitals.

The MCDA model is a living instrument which can be revised when the priorities and needs in the healthcare system and policies change. Therefore, criteria can be included, excluded, or adapted at a later stage once a new consensus on the importance and the transparent measures for qualification is reached among the users of the instrument due to new developments and experiences. For example, it has been proposed by some participants that some flexibility might be advisable 
for the weighting of the price criterion when evaluating a specific type of product such as lifesaving medicines or a stricter scoring of the quality criteria when it comes to narrow therapeutic window drugs. An adaptation of the price weight depending on such considerations is possible on the hospital level if required. Another point for reconsideration after testing the tool in the real-life situation resulted from the discussion of the criterion of the "Certificate of Analysis for the finished product": in the final model, the scoring was determined as either complying with the specifications $(=100 \%)$ or not complying (exclusion). Thus, this criterion may be considered as another prerequisite to enter the bidding instead of a MCDA decision criterion.

The final list of criteria selected in this initial workshop for the resulting MCDA model shows some deviations from the criteria which were previously suggested by an international expert group [2] and which were selected in other countries which adapted the tool to their settings [13]. This reflects the active engagement and contribution of the participants who critically questioned and deliberated each of the proposed criteria in comparison to their current decision processes.

After successful piloting, evaluation, and refinement of the model based on the real-life experience, a roadmap for further dissemination and implementation should be developed.

The process presented here for the adaption of a multiple-criteria scoring format to the specific decision problem in Thailand follows the general process as suggested by the ISPOR task force $[5,6]$. The core elements in this process were addressed with a group of Thai stakeholders in the hospital purchasing processes, who represented a range of hospitals.

While the selection of criteria, the ranking, and the weighting require adaptation to the specific decision problem and policy framework, the process itself can be generalized and transferred to other countries or organizations. The foundation for the course of work steps in preparation of the workshop, conduct of the workshop, and follow-up has been formed through the experience from three countries, Indonesia, Kazakhstan, and Vietnam [13,14]. In each of these countries, different types of purchasing or tender decision problems (national purchasing, public tender) had been addressed. In this book, another example is presented, where the process was followed to develop a decision analysis tool to help provincial policy makers with the comparison of alternative insurance policies in China [15]. For that, a new set of decision criteria had to be compiled, which reflected the needs to be addressed by a policy change from the stakeholder perspective. However, despite that the objective to select the optimal future insurance policy is very different from the objective which guided the Thai initiative, the same process was followed in China: preparation with desk research and discussions with local stakeholders, workshop with consensus on the purpose of the tool, selection of the criteria, prioritization and ranking of the criteria, and follow-up with testing and piloting. The most important element is the engagement with and of those stakeholders who are concerned by the decision. How each of the procedural elements is shaped in the specific local application will strongly depend on the local preferences and needs. If the participating stakeholders are already familiar with the principles of MCDA, such as in Thailand, a 1-day workshop format may suffice. In Indonesia and Kazakhstan, a 2-day format was preferred which allowed for more presentation of the technical and methodological information before entering the interactive workshop parts. In all cases, we saw that the discussion at each step throughout the workshop is essential for building consensus.

Another important consideration should be that the current values and daily routines are considered when selecting the criteria. For example, the original list of internationally validated criteria was modulated in Thailand to satisfy the 
traditionally high use of specific quality measures. If the MCDA process shall be used for tender decisions, it will be important to train the users who may previously only have used the price or a very limited amount of information to select the winning bid. A standard template for dossier submission may facilitate the targeted supply of data and information for the manufacturers, a standard template for data as has been proposed by Brixner et al. in consequence of the experiences in the previous workshops [16]. Increasing experience with the implementation for further applications in CEHCs and ongoing evaluation and communication will help in the efficient implementation of new initiatives.

A limitation of the approach presented here for developing a MCDA tool to be used for hospital purchasing may be that the initial design is limited to the number of participants and the breadth of stakeholder groups involved in the design workshop. However, further involvement will be achieved throughout the piloting through communication of the experiences after each step of the process and through updating of the tool based on the practical experience.

\section{Conclusions}

The present paper describes how MCDA can be easily adapted to different countries and decision-making settings to improve the efficiency and transparency of the decision-making process, in the case of the undertaking of pharmaceutical bidding. The approach described here can be easily adapted to other countries and decision-making settings.

A short explanation of the principles of multiple-criteria decision analysis and the use in decisions on pharmaceuticals can be viewed at https://www.youtube.com/ watch?v=7OoKJHvsUbo.

\section{Conflict of interest}

The research underlying this methodology was partially financed by Abbott Products Operations AG, Switzerland. The workshop was hosted by the Pharmaceutical Association of Thailand under Royal Patronage (PAT) who received funding by an unrestrictive educational grant. The international facilitation and the open-access publication fee were also financed by Abbott Products Operations AG, Switzerland.

\section{Notes/thanks/other declarations}

All workshop participants have actively contributed to the results of the workshop. We would specially thank the following participants, who have supported us during the preparation and the workshop and in the writing of this manuscript:

Ms. Jutatip Meepadung, Buddhachinaraj Hospital, Buddhachinaraj Hospital 90 Srithammaratipitak Road Amphoe Mueang Phitsanulok, Chang Wat Phitsanulok 65000.

Ms. Warawan Chungsivapornpong, Veterans General Hospital, Veterans General Hospital 123 Vibhavadi Rangsit Road, Samsennai Phayathai Bangkok 10400.

Mrs. Patcharin Suvanakoot, Ramathibodi Hospital, Bangkok.

Mrs. Montakarn Rahong; Bhumibol Adulyadej Hospital, Khlong Toei.

Mrs. Kannika Pongthranggoon, Thammasat University Hospital, Khlong Luang. 
Dr. Suriyan Thengyai, School of Pharmacy, Walailak University, Nakhonsithammarat.

Mr. Thurdsak Piriyakakul, Ratchaburi Hospital, Ratchaburi.

Assoc. Prof. Payom Wongpoowarak, Faculty of Pharmacy, PSU (Prince of Songkla University), Songkhla.

Mr. Hatairat Panparipat, Rayong Hospital, Rayong.

Mr. Thanapoom Kiewchaum, Faculty of Pharmacy Chiang Mai University, Chiang Mai.

Mrs. Patcharawan Meesilp, Faculty of Pharmacy Chiang Mai University, Chiang Mai.

Mrs. Surirat Tangsangasaksri, Hatyai Hospital; Songkhla.

\section{Author details}

Anunchai Assawamakin ${ }^{1}$, Anke-Peggy Holtorf ${ }^{2 *}$ and Nikolaos Maniadakis ${ }^{3}$

1 Department of Pharmacology, Faculty of Pharmacy, Mahidol University, Bangkok, Thailand

2 Health Outcomes Strategies GmbH, Basel, Switzerland

3 National School of Public Health, Greece

*Address all correspondence to: anke.holtorf@health-os.com

\section{IntechOpen}

(C) 2019 The Author(s). Licensee IntechOpen. This chapter is distributed under the terms of the Creative Commons Attribution License (http://creativecommons.org/licenses/ by/3.0), which permits unrestricted use, distribution, and reproduction in any medium, provided the original work is properly cited. (cc) BY 
Weighing Price and Performance for Decisions for Multisource Pharmaceutical Bidding in Public... DOI: http://dx.doi.org/10.5772/intechopen.83823

\section{References}

[1] Jongudomsuk P, Srithamrongsawat S, Patcharanarumol W, Limwattananon S, Pannarunothai S, Vapatanavong P. The Kingdom of Thailand health system review. Manila, Philippines: World Health Organization, Regional Office for the Western Pacific; 2015. Available from: http://www.searo.who.int/entity/ asia_pacific_observatory/publications/ hits/hit_thailand/en/ [Accessed: 23 July 2018]

[2] Brixner D, Maniadakis N, Kaló Z, $\mathrm{Hu}$ S, Shen J, Wijaya K. Considering multicriteria decision analysis (MCDA) simple scoring as an evidence-based HTA methodology for evaluating off-patent pharmaceuticals (OPPs) in emerging markets. Value in Health Regional Issues. 2017;13c:1-6. DOI: 10.1016/j.vhri.2017.02.001

[3] Keeney RL, Raiffa H. Decisions with Multiple Objectives: Preferences and Value Trade-Offs. United Kingdom: Cambridge University Press; 1993. ISBN10: 0521438837, ISBN-13: 978-0521438834

[4] Belton V, Stewart T. Multiple Criteria Decision Analysis: An Integrated Approach. Springer US: Springer Science \& Business Media, Kluwer Academic; 2002. ISBN-10: 079237505X, ISBN-13: 978-0792375050

[5] Thokala P, Devlin N, Marsh K, Baltussen R, Boysen M, Kalo Z, et al. Multiple criteria decision analysis for health care decision making-An introduction: Report 1 of the ISPOR MCDA emerging good practices task force. Value in Health. 2016;19:1-13. DOI: 10.1016/j.jval.2015.12.003

[6] Marsh K, Ijzerman M, Thokala P, Baltussen R, Boysen M, Kalo Z, et al. Multiple criteria decision analysis for health care decision makingEmerging good practices: Report 2 of the ISPOR MCDA emerging good practices task force. Value in Health. 2016;19:1-13. DOI: 10.1016/j. jval.2015.12.003

[7] Communities and Local Government. Multi-criteria analysis: A manual. Wetherby, Great Britain: Department for Communities and Local Government; 2009. Available from: http://www.communities.gov.uk/ documents/corporate/pdf/1132618.pdf [Accessed: 24 March 2018]

[8] Hu S, Zhang Y, He J, Du L, Xu M, Xie C, et al. A case study of pharmaceutical pricing in China: Setting the price for off-patent originators. Applied Health Economics and Health Policy. 2015;13:13-20. DOI: 10.1007/s40258-014-0150-5

[9] Tuan PL, Tuan Kiet PH, Brixner DI, Ngo VH. Development of Multiple Criteria Decision Analysis Framework for Off-patent Pharmaceuticals Decision Making in Vietnam | European Chamber of Commerce in Vietnam. Hanoi, Vietnam: European Chamber of Commerce Vietnam; 2017. Available from: https://www.eurochamvn.org/ node/16937 [Accessed: 23 March 2018]

[10] Youngkong S. Application of HTA research on policy decision-making. Journal of the Medical Association of Thailand. 2014;97(Suppl. 5):S119-S126

[11] Youngkong S, Teerawattananon Y, Tantivess S, Baltussen R. Multi-criteria decision analysis for setting priorities on HIV/AIDS interventions in Thailand. Health Research Policy and Systems. 2012;10:6. DOI: 10.1186/1478-4505-10-6

[12] Youngkong S, Baltussen R, Tantivess S, Mohara A, Teerawattananon Y. Multicriteria decision analysis for including health interventions in the universal health coverage benefit package in Thailand. Value in Health. 2012;15:961-970 
[13] Inotai A, Brixner D, Maniadakis N, Dwiprahasto I, Kristin E, Prabowo A, et al. Development of multi-criteria analysis (MCDA) framework for offpatent pharmaceuticals - an application on improving tender decision making in Indonesia. BMS Health Services Research. 2018;18. (online) https://doi. org/10.1186\%2Fs12913-018-3805-3

[14] Inotai A, Nguyen HT, Hidayat B, Nurgozhin T, Kiet PHT, Campbell JD, et al. Guidance towards the implementation of multi-criteria decision analysis framework in developing countries. Expert Review of Pharmacoeconomics and Outcomes Research. 2018;18:585-592. https://doi. org/10.1080\%2F14737167.2018.1508345

[15] Hu S, Holtorf AP, Wijaya K, He J, Brixner D. Value based evaluation for health insurance policy schemes in China's provinces. In: Evaluation of Health Programs. London, UK; 2019

[16] Brixner D, Maniadakis N, Kaló Z, Kim K, Wijaya K. An evidence framework for off-patent pharmaceutical review (EFOR) for health technology assessment in emerging markets. Value in Health Regional Issues. 2018;16c:9-13. Available from: http://www. valuehealthregionalissues.com 


\title{
The Burden of Informal Caregivers of Alzheimer's Patients: An Estimation to Portugal
}

\author{
Aida Isabel Tavares and Carolina Freitas
}

\begin{abstract}
The demographic phenomenon of ageing is speeding up in Europe. People live longer and so the prevalence of dementia increases, including Alzheimer's disease. This is a progressive disease in which people slowly lose their cognitive and physical capacities until death takes over. Alzheimer's disease not only imposes a very high burden in the affected person but also inflicts a high and overwhelming burden of the caregivers. The carers' burden includes health deterioration, labour damaging and loses and financial and social costs, while the care provided is not well valued. The aim of this chapter is to review the main trends and concepts related to ageing, caregivers and Alzheimer's disease. It also presents the economic burden associated with the disease and the monetary value of the care provided by caregivers in Portugal.
\end{abstract}

Keywords: informal care, Alzheimer's disease, burden of disease, Portugal

\section{Introduction}

Alzheimer's disease is the most common form of dementia, and it accounts for about $60-70 \%$ of the 50 million people suffering from dementia worldwide [1]. This means that between 30 and 35 million of people suffer from Alzheimer's disease across the world. However, the numbers of those with this disease may be underestimated as only about $40-50 \%$ of the cases of dementia are identified in developed countries [2].

Dementia and, in particular, Alzheimer's disease are a major reason for the disability and dependency across older people. The individual impact burden due to this disease is broad. It includes physical, psychological, social and economic aftermaths. But also the burden is shared with carers, families and society in general [1]. About $50 \%$ of carers say that their own health was affected by the responsibility of caring their Alzheimer's patients despite their positive sentiments about their role [3]. The economic repercussions of Alzheimer's disease are diverse, and they include the direct medical costs, the social care costs and the costs of informal care. The magnitude of these economic repercussions cannot be ignored neither by society nor by politicians.

The aim of this chapter is of twofold. Firstly, we review the phenomenon of ageing and describe the increasing prevalence of Alzheimer's disease; additionally, we highlight the relevance of informal care and the burden supported by informal caregivers. Secondly, this chapter aims to describe the social and financial burden of informal caregivers of Alzheimer's patients in Portugal and to estimate a monetary value for the care they provide and have to bear. 
The chapter proceeds with a section describing the ageing phenomenon and Alzheimer's disease, as well as the increasing prevalence of this disease. Next, it reviews the type of care available to deal with Alzheimer's patients, and a particular emphasis is placed on informal care. In the following section, the socio-economic burden of informal caregivers is outlined. The chapter continues with a section presenting the estimation of the financial burden of carers of Alzheimer's patients in Portugal followed by a conclusion section.

\section{Ageing and the Alzheimer's disease}

The current major demographic phenomenon in Europe is ageing. The share of older people in the population is increasing, and the age distribution picture is changing to an oval shape, and it is tending to look like a block. The ageing trend may be explained by (i) the increased longevity of people, (ii) the declined fertility and (iii) the ageing of "baby boom" generations.

In Europe, as the cohort of baby boomers gets older, the wider stripes of the pyramid move up in direction of the top of the pyramid. Younger generations and their low fertility are reflected by their narrow stripes at the base of the age pyramid. As the time goes by, the top highest age group of the pyramid enlarges as an increasing large share of very old people who are living longer lives

(Figure 1) [4].

So life expectancy has been increasing and people are living longer. These longer lives may be lived in a healthy status, but most likely the additional years of life are lived in unhealthy conditions, in particular, the last years of life. Among the health conditions, the most prevalent in older ages is dementia, which includes Alzheimer's disease. This health condition is not a consequence of the ageing natural process, but it has a high prevalence among the older group of people [5]. It generates high economic and social costs, and for this reason it may be considered as one of the great challenges of society nowadays [5].

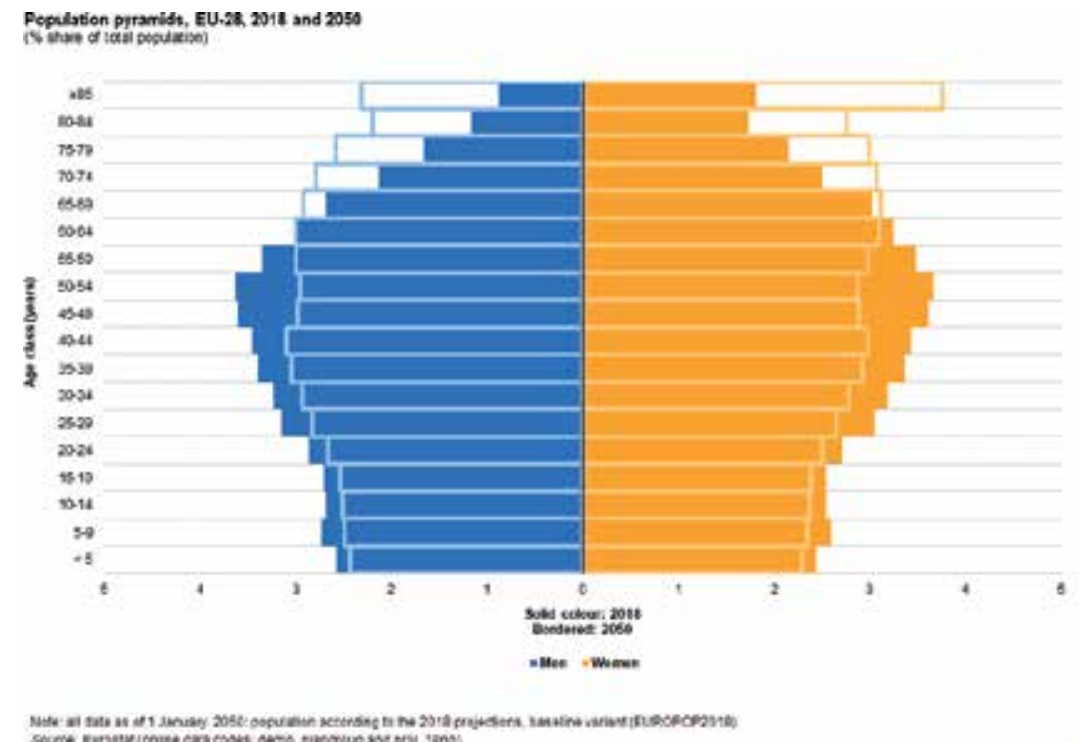


The Burden of Informal Caregivers of Alzheimer's Patients: An Estimation to Portugal DOI: http://dx.doi.org/10.5772/intechopen.90673

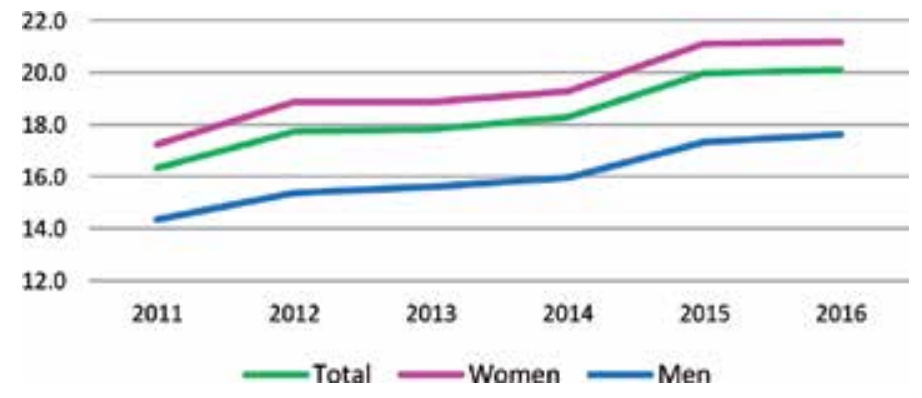

Figure 2.

Standardised death rate due to Alzheimer's disease. Source: Based on Eurostat [hlth_cd_asdr2] [8].

Dementia (and Alzheimer's disease) is a syndrome, chronic or progressive, characterised by an abnormal and fast decline in the ability of people to reason and think (the decline of the cognitive function). Although consciousness is not affected, the remaining capacities are strongly diminished such as memory, thinking, orientation, comprehension, calculation, learning, language and judgement. Additionally, there is a decline in the emotional control and social behaviour [1].

Life expectancy for an Alzheimer's patient, after his diagnosis, is about 10 years. There are three stages of progressive gravity of the disease: early (2-4 years), mild (2-10 years) and late (1-3 years or more) stages. In the early stage, illness goes unnoticed, and its signs include forgetfulness, losing oneself in familiar surroundings and losing track of time. As the illness progresses, at the mild stage, the signs become clear, and patients begin to forget recent events and people's names, forget where they are, have difficulty communicating with others, need help with personal care and start to show behavioural changes as wandering and repeat questioning. When the last stage is reached, Alzheimer's patients are inactive and dependent. Their memories are seriously damaged and physical signs are obvious.

The clinical dementia rating (CDR) is the clinical instrument that measures the severity of dementia, including Alzheimer's disease. This instrument evaluates six domains of cognitive and functional performance of patients, including memory, orientation, judgement and community affairs. This instrument scores the patients impairment in five levels so that medical intervention is more adequate and effective.

$\mathrm{CDR}$ is not a clinical diagnosis; it rather is a measurement scale that helps the diagnosis of Alzheimer's disease. In fact, there is no single test that provides a consistent diagnosis of Alzheimer's disease. The diagnosis is a process of careful evaluation done by a multidisciplinary team which may include neurologists, geriatricians, nurses, psychologists and psychiatrists [6].

In Western Europe, in 2016, it has been estimated that 4,499,078 disabilityadjusted life years (DALY) were attributed to Alzheimer's dementia disease [7]. Mortality associated to Alzheimer's disease has been increasing in Europe (Figure 2). Women die more than men, but the rate of increase has been identical for both genders. This trend is expected under the current conditions of longer lives and advance medical knowledge.

Currently, there are no medicines that prevent Alzheimer's disease or cure it, and so the numbers of patients and deaths will continue to grow, as well as the burden on the people suffering the disease, on the caregivers and on the health system as a whole.

\section{Informal caregiver and the socio-economic burden}

Caring of Alzheimer's patients may take place in two frameworks, which may be supplemental or complementary: the formal care and the informal care. 


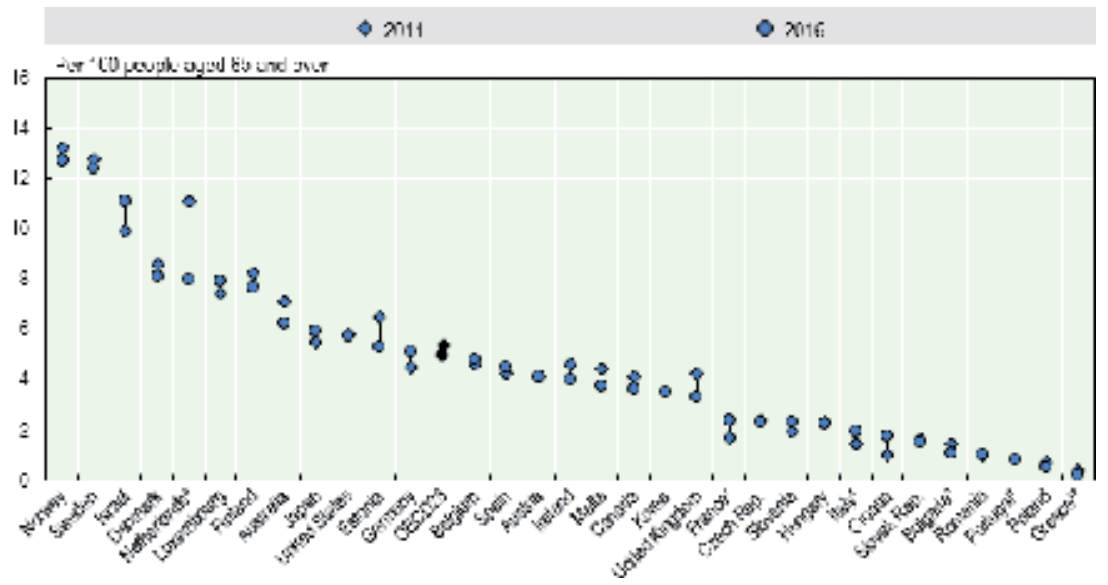

Figure 3.

The number of LTC workers per 100 individuals aged +65, 2011 and 2016 (or nearest year). Note: LTC, long-term care. Source: OECD [9].

The formal care is supplied by the public or private sector and by its health-care professionals, who provide a service and are paid for that service. Across Europe, the number of formal carers is low. In some countries, such as Portugal, the number of formal carers is extremely low, less than an average of 2 long-term care (LTC) professionals per 100 older persons aged above 65 (Figure 3). While in some countries the number of LTC workers per old person has increased between 2011 and 2016 (as in France and Croatia), in other countries there has been a decrease (as in the Netherlands, Estonia and the UK) (Figure 3).

Informal care is offered by someone who is close to the older patient, either family, friends or neighbours. Informal carers provide help in a voluntary and non-paid manner. Usually caregivers provide assistance to patients in their own home, and this assistance is mainly directed for patients' daily tasks [9].

Despite international data on informal carers is hard to compare and it is based in several sources of information, the OECD has gathered the information for several countries concerning the share of informal carers among the population aged more than 50 (Figure 4) [10].

In spite of being difficult to find numbers for informal carers along the time and across countries, it is expected that this number will not be sufficient to attend to the increased number of dependent older people [11].

The total cost of dementia in EU27 in 2008 was estimated in round number of $\$ 160$ billion, and $56 \%$ of these are costs of informal care. While in Northern Europe the larger proportion goes for formal care, in Southern Europe the larger share is on the informal care [12].

The importance of informal care has become a more prominent issue recently, as the share of elderly in the population began to increase and as the LTC system funding began to be a social concern. Not only informal care is a cost-effective alternative, but also it is a well-being alternative for patients who may remain at their homes. So in several countries across Europe, different public supports have been offered to informal care as a form of incentive and as a support to families and friends of patients. That being so the distinction between formal and informal and paid and unpaid care is becoming unclear in European countries [13].

Informal care is provided at home, and it basically aims to help Alzheimer's patients in activities of daily living (ADLs) and instrumental activities of daily living (IADLs) but also to give emotional support. ADLs are activities that include 
The Burden of Informal Caregivers of Alzheimer's Patients: An Estimation to Portugal DOI: http://dx.doi.org/10.5772/intechopen.90673

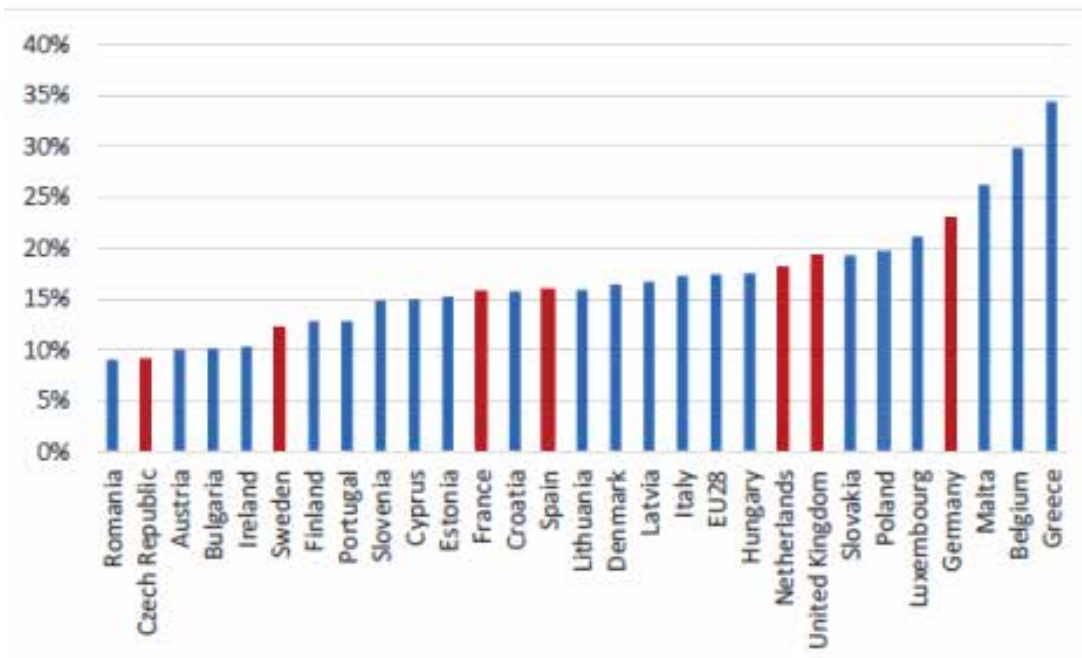

Figure 4 .

Informal carers as a \% of total population, EQLS 2016. Source: EQLS 2016, figure adapted from EQLS overview report [10].

basic self-care tasks such as walking, toileting, bathing, feeding and dressing. IADLs are self-care activities, which require some complex thinking, skills and organisation. These include managing finance, transportation, shopping, meal preparation, communication and managing medications.

Helping with these activities systematically along time is uncomfortable, unpleasant and overwhelming. Informal caregiving is emotionally rewarding, bringing up self-esteem and sense of worthiness and life mission. But it is a very demanding role, and informal carers very often suffer burnout and health problems [14]. On top of this, several carers have difficulties combining the care with their labour responsibilities, and some quit their jobs to be able to respond the patient needs. In fact, this decision may be harmful in their future as it compromises future employability and leads to permanent drop-out from the labour market [15].

Several studies have been devoted to estimate the cost of taking care of Alzheimer's patients. In general, these costs depend on the number of hours of care, the severity degree of the disease, the use of formal care and the weather the carer is cohabiting with the patient [16].

The most used methods to estimate the monetary value of informal care to Alzheimer's patients are those based on "stated preferences" and those based on revealed preferences, which include the "proxy-good method" (also called market cost method) and the "opportunity cost method" [17].

"Stated preferences" is a method to provide a monetary value to something that has no market value. It is based on questions collected by a survey. The answers are given in the form of monetary amounts, choices, ratings or other scales which allow the monetary value.

The "proxy-good method" values time spent on informal care at the market prices of a close market substitute. So an almost perfect substitute in the market needs to be found and used as a reference. The "opportunity cost method" values the informal caregiver's benefit forgone due to spending time on providing informal care. Usually this is done using the individual's wage rate. Both these methods do not cover all costs and effects of informal care, and so they are usually used as complements [17]. However, in our work due to the data availability, only "proxy-good method" is used. 
Concerning the care provided, data is collected using the instrument called Resource Utilization in Dementia (RUD), which provides information relative to the formal and informal care given to the patient according to his level of dementia [18].

\section{Estimation of the burden of carers in Portugal}

It has been estimated that the number of people with dementia in Portugal, in 2012, was 182,526 in a population of less than 10 million people. This number represents about $1.7 \%$ of Portuguese population, and it is higher than the EU averages of 1.55\% [19] (Alzheimer Europe 2019). Considering that $60-70 \%$ of those patients with dementia suffer from Alzheimer's disease, it means that currently there are more than 110,000-128,000 Alzheimer's patients in Portugal. It is estimated that in the next 20 years, the number of Alzheimer's patients in this country will be around 322,000 [9].

The current health expenditure (CHE) in Portugal directed for long-term care (LTC) has two functions, both social and health. Despite the inexistence of the EU average reference and comparing with Sweden which has some well-functioning long-term care system, Portugal presents a low share of expenditure (CHE) in long-term care expenditure for health but a reasonable level for long-term care expenditure for social support (Figure 5).

Public aid to informal caregivers in Portugal is in its infant stages, and the formal care is insufficient for the current demand. This national institutional framework pushes nearly all the care of Alzheimer's patients to their families, who have stood for the overwhelming task of taking care of them, even if they do it with affection and love or even if they have no conditions to do so.

\subsection{Method for collecting data}

To collect data for Portugal, a questionnaire based on RUD, which includes questions about the informal caregiver concerning their socio-demographic characteristics, health status, received external support, professional status, activities performed and time management, was used [20].

This questionnaire was applied over 5 months, in 2018, in the Neurology Services of the Hospital Centre of the University of Coimbra, Portugal, to informal caregivers of Alzheimer's patients. This study has been approved by the ethical commission of the hospital centre, and participants have signed an informed consent form. Confidentiality and anonymity are guaranteed to participants in this study.

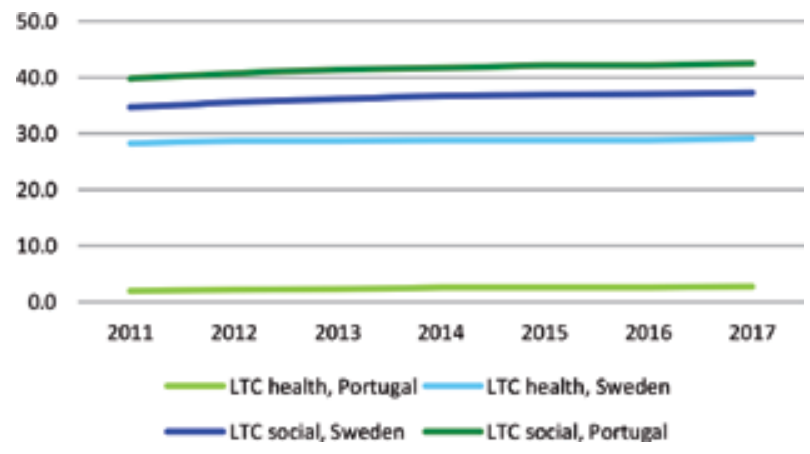

Figure 5.

Share of LTC expenditure in total current health expenditure. Note: LTC, long-term care expenditure.

Source: Based on Eurostat [hlth_sha11_hc] [8]. 
The study includes 86 Alzheimer's patients and 97 informal caregivers. The difference in these numbers is due to the fact that some patients have more than one carer.

\subsection{Descriptive results}

Alzheimer's patients were on average 75 years old, and about $60 \%$ were women; around $28 \%$ were in the very early stage of the disease, $28 \%$ were in the mild stage, $20 \%$ were in the moderate stage and, finally, about $24 \%$ were in the severe stage.

Informal caregivers were on average 60 years old, and the majority of them (about $67 \%$ ) were women, $53.6 \%$ of carers live in the same home as the patient, $50.5 \%$ are spouses, ad more than $60 \%$ of carers reported suffering some health problem; and nearly $50 \%$ reported being professionally inactive, the remaining share of carers reported being absent from work for about 4 days a year to comply with the patient needs, and $70 \%$ of them report penalties in terms of salary and day off reduction and hour replacement from these work absences.

Lastly, it must be highlighted that $90 \%$ of the carers have no public financial support, and so all expenses are supported privately, by the patient, by the carer or by the family budget.

\subsection{Estimated monetary costs}

The results concerning the costs and monetary values relatively to the informal caregivers are expressive and informative for policymakers. From the point of view of the cost with health care supported by caregivers, data shows that the total amount spent annually is almost $590 €$ or almost $50 €$ a month. These costs are reported by caregivers (Table $\mathbf{1}$ ).

From the different activities performed by caregivers for their patients, data obtained from the questionnaire unveil that the activities that absorb the highest share of daily hours are the activities of daily living (ADL), such as toilet visits, eating, dressing, grooming, walking and bathing, and the instrumental activities of daily living (IADL), such as shopping, food preparation, housekeeping, laundry, transportation, taking medication and managing financial matters and supervision (Figure 6).

Finally, according to hours of care provided for the Alzheimer's patient, the total average annual monetary value of those hours may be estimated. Taking into account the average number of daily hours of care and the monetary value of each hour (the value is estimated using the proxy-good method), the total average annual value of care sums up to $14,152.32$ euros (Table 2 ). The values may vary according to the level of severity of the disease. At the most severe level of severity, these values decrease because there is an increasing share of burden with formal care.

\begin{tabular}{lc}
\hline Type of annual average costs & Monetary value $€$ \\
\hline Emergency care & 9.00 \\
\hline Consultations & 51.58 \\
\hline Diagnostic tests & 65.78 \\
\hline Medication & 469.08 \\
\hline Total annual average costs & 586.44 \\
\hline Total monthly average costs & 48.87 \\
\hline Source: Freitas [20]. & \\
\hline
\end{tabular}

Table 1.

Annual average costs supported by informal carers. 


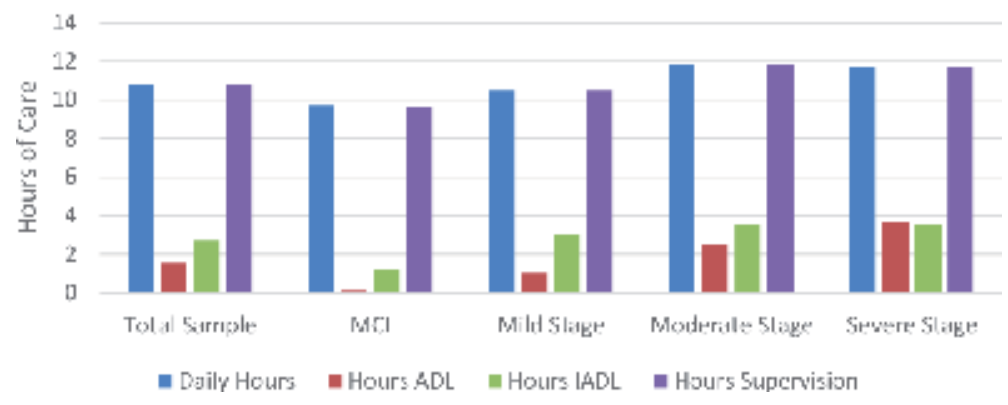

Figure 6.

Distribution of daily hours across activities. Source: Freitas [20].

\begin{tabular}{lccccc}
\hline Average Numbers & Total & $\begin{array}{c}\text { Early } \\
\text { stage }\end{array}$ & Mild stage & $\begin{array}{c}\text { Moderate } \\
\text { stage }\end{array}$ & $\begin{array}{c}\text { Severe } \\
\text { stage }\end{array}$ \\
\hline No. of daily hours & 10.8 & 9.7 & 10.5 & 11.8 & 11.7 \\
\hline Daily cost $€$ & 45.36 & 40.74 & 44.10 & 49.56 & 49.14 \\
\hline Days of week & 6 & 5.7 & 6 & 6.3 & 6.3 \\
\hline Week cost (7 days) $€$ & 272.16 & 232.22 & 264.60 & 312.23 & 309.58 \\
\hline Annual cost (52 weeks) $€$ & $14,152.32$ & $12,075.34$ & $13,759.20$ & $16,235,86$ & $16,098.26$ \\
\hline Source: Freitas [20]. & & & & &
\end{tabular}

Table 2.

Monetary value for care given by the informal carer.

Summing up, the burden taken by an Alzheimer's patient caregiver includes the costs related to labour absence, to the lack of social activities and to health deterioration which may be reflected in health-care costs or untreated health conditions. These health-care costs were valued by $586.44 €$ average a year, even though caregivers seldom find time to look after themselves.

On the other hand, the caregivers provide care which was estimated to value over an average of $14,100 €$ per year, mainly resulting from daily activities and supervision activities. However, these values may be underestimated. On the one hand, caregivers tend to under-report the time spent providing care; on the other hand, the proxy-good method does not account for all cost, and it undervalues some activities, because they are associated with low labour market qualifications.

\section{Conclusion}

Undoubtedly one of the great challenges of society nowadays is to deal and to manage the increasing trend of Alzheimer's patients in families as well as its associated increasing burden in the suffering individuals, in their caregivers and in society in general.

The care provided to Alzheimer's patients may be formal or informal. In the latter case, it is provided by family, neighbours and friends in the patient home. The burden imposed on carers is heavy. It includes health deterioration, labour negative impacts, inexistent social life and a cost of the time spent helping the patient with their daily activities and supervising their actions.

In this chapter, the burden and value of caregivers of Alzheimer's patients in Portugal were estimated and presented. The values may be underestimated, but they serve as a floor cost reference for policymakers. Several measures may be 
undertaken in order to alleviate the burden supported by these carers. For instance, substitute carers, supplied by the health or social system, could coordinate tasks and daily help so that the caregiver himself could have more time to do other things such as go medical consultations, sleep and perform other social activities. Another measure that would be welcome is to provide a complementary subsidy for the patient expenditures in medical treatment and formal care. In this way, the caregiver budget would be protected, and it could be used on the carer's own needs. Informal care is an increasing substitute and complement of formal care, and it should be valued from a societal perspective. Caregivers must be looked after and protected for their valuable contribution to society.

\section{Author details}

Aida Isabel Tavares ${ }^{1,2 *}$ and Carolina Freitas ${ }^{3}$

1 ISEG, Lisbon School of Economics and Management - University of Lisbon, Portugal

2 CEISUC, Centre for Health Studies and Research - University of Coimbra, Portugal

3 FEUC, Faculty of Economics - University of Coimbra, Portugal

*Address all correspondence to: aitavar@gmail.com

\section{IntechOpen}

(C) 2019 The Author(s). Licensee IntechOpen. This chapter is distributed under the terms of the Creative Commons Attribution License (http://creativecommons.org/licenses/ by/3.0), which permits unrestricted use, distribution, and reproduction in any medium, provided the original work is properly cited. (cc) BY 


\section{References}

[1] WHO. 2019. Available from: https:// www.who.int/news-room/fact-sheets/ detail/dementia

[2] Prince $\mathrm{M}$ et al. World Alzheimer Report 2015. Improving Healthcare for People Living with Dementia. London: Alzheimer's Disease International; 2015

[3] Alzheimer's Disease International. World Alzheimer Report 2019: Attitudes to Dementia. London: Alzheimer's Disease International; 2019

[4] Eurostat. Population Projections. 2019a. Available from: https://ec.europa. eu/eurostat/statistics-explained/index. php?title=File:Population_pyramids,_ EU-28,_2018_and_2050_(\%25_ share_of_total_population)_AE2019. png\&oldid=449039

[5] WHO. Dementia: A Public Health Priority. WHO Library Cataloguing-inPublication Data; 2012

[6] Alzheimer's Association. Alzheimer's disease facts and figures: Includes a special report on the financial and personal benefits of early diagnosis. Alzheimer's \& Dementia. 2018;14(3):367-429

[7] Collaborators D. Global, regional, and national burden of Alzheimer's disease and other dementias, 1990-2016: A systematic analysis for the global burden of disease study 2016. Lancet Neurology. 2019;18:88-106

[8] Eurostat. Eurostat Database. 2019b. Available from: https://ec.europa.eu/ eurostat/data/database

[9] OECD. OECD Indicators. Informal carers. Health at a Glance 2017. Paris: OECD Publishing; 2017

[10] Eurofound. European Quality of Life Survey (EQLS) 2016. 2018. Availabkle from: https://www. eurofound.europa.eu/surveys/ european-quality-of-life-surveys/ european-quality-of-life-survey-2016

[11] Tronto JC. Caring Democracy. Markets, Equality, and Justice. New York and London: New York University Press; 2013

[12] Wimo A et al. The economic impact of dementia in Europe in 2008-Cost estimates from the Eurocode project. International Journal of Geriatric Psychiatry. 2011;26:825-832

[13] European Commission. Informal Care in Europe - Exploring Formalisation, Availability and Quality. Valentina Zigante London School of Economics and Political Science April - 2018. Directorate-General for Employment, Social Affairs and Inclusion. London: LSE Consulting; 2018

[14] Gérain P, Zech E. Informal caregiver burnout? Development of a theoretical framework to understand the impact of caregiving. Frontiers of Psychology. 2019;10:1748

[15] OECD. OECD Health Policy Studies. Help Wanted? Providing and Paying for Long-Term Care. Paris: OECD; 2011

[16] Gerves C et al. Evaluation of full costs of care for patients with Alzheimer's disease in France: The predominant role of informal care. Health Policy. 2014;116(1):114-122

[17] van den Berg B et al. Economic valuation of informal care: The contingent valuation method applied to informal caregiving. Health Economics. 2005;14(2):169-183

[18] Wimo A et al. The GERAS study: A prospective observational study of costs and resource use in community dwellers with Alzheimer's disease in three European countries - study design and 
The Burden of Informal Caregivers of Alzheimer's Patients: An Estimation to Portugal DOI: http://dx.doi.org/10.5772/intechopen.90673

baseline findings. Journal of Alzheimer's

Disease. 2013;36(2):385-399

[19] Alzheimer Europe. Country

Comparisons. 2019. Available from:

https://www.alzheimer-europe.org/

[20] Freitas C. Impacto socioeconómico nos cuidadores informais de doentes de Alzheimer (The socioeconomic impact on informal carer of Alzheimer patients) [master thesis]. Master in Management and Economics of Health of the Faculty of Economics of the University of Coimbra, Portugal; 2019 



\title{
Methodology of Estimating Socioeconomic Burden of Disease Using National Health Insurance (NHI) Data
}

\author{
Hyeon-Jin Choi and Eun-Whan Lee
}

\begin{abstract}
The cost-of-illness (COI) studies convert the burdens associated with certain illnesses into economic and monetary values so as to measure the socioeconomic costs that are inevitably incurred by a given society in association with certain illnesses. The estimated costs provided by COI studies provide an important basis for estimating the amounts of public health resources spent and productivity losses incurred and thereby make it possible to quantify the socioeconomic burdens that illnesses impose on society in general. In this chapter, we review the diverse methodologies and techniques for estimating the socioeconomic burden of disease, which is widely used in the established literature all over the world, and compare the pros and cons of each. This chapter introduces the existing COI studies in terms of their research designs, data selection and value assessment processes, applied perspectives, and chosen components of costs. Furthermore, this chapter introduces a real-world example of estimating the national economic burden of disease by using the National Health Insurance (NHI) data. We hope that this chapter will help readers better understand and use the COI study.
\end{abstract}

Keywords: socioeconomic burden of disease, economic burden of disease, cost of illness, cost of disease, financial burden of disease, disease cost

\section{Introduction}

The cost-of-illness (COI) studies convert the burdens associated with certain illnesses into economic and monetary values so as to measure the socioeconomic costs that are inevitably incurred by a given society in association with certain illnesses. The estimated costs provided by COI studies provide an important basis for estimating the amounts of public health resources spent and productivity losses incurred and thereby make it possible to quantify the socioeconomic burdens that illnesses impose on society in general. In other words, COI studies provide important information for determining the socioeconomic costs of illnesses, which, in turn, makes it possible to better prioritize public health policy tasks and issues. In particular, the findings of such studies tend to be straightforward and intuitive and aid policymakers in making related decisions. 
In this chapter, we review the diverse methodologies and techniques for estimating the socioeconomic burden of disease, which is widely used in the established literature all over the world, and compare the pros and cons of each. Furthermore, this chapter introduces a real-world example of estimating the national economic burden of disease by using the National Health Insurance (NHI) data.

\section{Review of methods for estimating the costs of illness}

This section introduces the existing COI studies in terms of their research designs, data selection and value assessment processes, applied perspectives, and chosen components of costs.

\subsection{Study designs}

COI studies can be roughly divided into two groups, depending on the approaches they adopted to estimate the socioeconomic costs of illnesses. These two approaches are the incidence-based approach and prevalence-based approach [1-3].

\subsubsection{Incidence-based approach}

The incidence-based approach involves estimating the socioeconomic cost of a given illness throughout the entire lifespan of the illness, from its initial stage to the patient's complete recovery or death. This involves estimating not only the economic burden currently imposed by the illness but also the cost of future healthrelated losses, including those caused by sequela. This approach allows the researcher to identify economic losses over time, from the present into the future, but makes it impossible to take into account patients who have already suffered from the same disease. In other words, the incidence-based approach may not be well suited to estimating the economic burdens of certain types of illnesses (i.e., those that currently have low incidence rates but high prevalence rates) at certain moments in time.

\subsubsection{Prevalence-based approach}

Contrary to the incidence-based approach, the prevalence-based approach considers economic burdens accruing from not only existing patients suffering from a given illness for a fixed period of time but also from future and potential patients. This approach is well suited to estimating the economic costs of an illness at certain points in time but may not allow the researcher to estimate the cost accrued throughout the lifespan of the illness, from its initial stage to the patient's complete recovery (or death). Furthermore, this approach may not be so amenable to estimating the costs of frequent yet short-lived illnesses that do not last long enough for the researcher to find and identify suitable patients within a given period of time.

The prevalence-based approach is by far the more popular method used in previous studies. This is because it is important to take into account both new and existing patients suffering from the given illnesses in order to estimate the socioeconomic costs of those illnesses during certain periods.

The characteristics and pros and cons of these two approaches are summarized below (Table 1). 
Methodology of Estimating Socioeconomic Burden of Disease Using National Health Insurance... DOI: http://dx.doi.org/10.5772/intechopen. 89895

\begin{tabular}{|c|c|c|}
\hline & Incidence-based approach & Prevalence-based approach \\
\hline Description & $\begin{array}{l}\text { Estimates the economic cost of an } \\
\text { illness throughout its lifespan, } \\
\text { ranging from the initial stage to the } \\
\text { patient's complete recovery (or } \\
\text { death) }\end{array}$ & $\begin{array}{l}\text { Estimates the economic cost of an } \\
\text { illness during a certain period of time } \\
\text { by taking into account the costs } \\
\text { generated by both new and existing } \\
\text { patients }\end{array}$ \\
\hline Pros & $\begin{array}{l}\text { Allows the researcher to consider not } \\
\text { only the current cost but also the } \\
\text { future cost of an illness and the } \\
\text { sequela it causes and thereby } \\
\text { estimate the economic losses } \\
\text { incurred both in the present and the } \\
\text { future }\end{array}$ & $\begin{array}{l}\text { Better suited to estimating the } \\
\text { current cost of an illness } \\
\text { Allows the researcher to consider } \\
\text { both new and existing patients at } \\
\text { given point(s) in time }\end{array}$ \\
\hline Cons & $\begin{array}{l}\text { Makes it difficult for the researcher } \\
\text { to consider existing patients that } \\
\text { have already been afflicted with the } \\
\text { given illness } \\
\text { - Not applicable to illnesses that, at } \\
\text { present, have high prevalence and } \\
\text { low incidence rates }\end{array}$ & $\begin{array}{l}\text { Makes it difficult for the researcher } \\
\text { to estimate the total economic cost of } \\
\text { an illness throughout its entire } \\
\text { lifespan } \\
\text { - The researcher may not find patients } \\
\text { suffering from the given illness if the } \\
\text { illness lasts for relatively short spans } \\
\text { of time, despite its high incidence } \\
\text { rate }\end{array}$ \\
\hline
\end{tabular}

Table 1.

Comparison of approaches to estimating the socioeconomic costs of illnesses.

\subsection{Data selection}

COI studies can also be divided into top-down and bottom-up studies, depending on how the data used were obtained $[4,5]$.

\subsubsection{Top-down studies}

Top-down COI studies make use of data concerning the entire given population, including the entire range of diseases affecting that population on the national level, and then separate the diseases one by one to estimate their individual costs. In Korea, the most favored source of data for such studies is the billing information kept by the NHIS. Billing data provide a convenient glimpse into the total socioeconomic costs of illnesses in the given society. However, the vast scope of these data can easily lead researchers to include in their estimates expenses and costs that are not directly related to the given illness (e.g., costs of prescriptions or medical tests due to sub-diseases).

\subsubsection{Bottom-up studies}

Bottom-up COI studies review all relevant individual illnesses and then estimate the total socioeconomic cost of these illnesses for the given nation. These studies use the medical records of individual patients to estimate the costs for individual patients and then expand those estimates to arrive at the total cost for the entire group of patients affected. While this method affords relatively greater accuracy in estimation than the top-down method, it is, realistically, quite difficult to estimate the national socioeconomic cost due to the sheer volume and complexity of the data on individual patients. There may also be regional disparities in the availability and use of healthcare services, meaning that the resulting data may fail to represent the entire given society. 


\subsection{Value assessment}

In general, there are two ways to evaluate and estimate the indirect socioeconomic costs of illnesses (namely, losses of labor and productivity). These are the human capital approach and the willingness-to-pay (WTP) approach $[6,7]$.

\subsubsection{Human capital approach}

The human capital approach is the most commonly used method for estimating the value of human life and the costs of illnesses. Viewing humans as productive actors, this approach estimates the current value of a human life as the discounted future expected income.

In estimating the socioeconomic costs of illnesses, this approach posits patients as productive actors and applies specific discount rates to the income they would have earned through their labor in order to estimate their losses of working hours and resulting losses in productivity. This method equates the costs of death and illnesses to the losses of future total income that patients could have earned had they remained healthy. This approach's focus on the losses of labor productivity caused by individuals' illnesses reveals the opportunity costs of illnesses and death.

This approach is favored because the data it requires for estimating costs are relatively readily available and the outcomes of the analysis are relatively less influenced by the researcher's bias or subjective interpretation. Moreover, this approach translates the direct costs (e.g., costs of healthcare service) and indirect costs (e.g., losses of productivity) incurred by illnesses into losses of future income, estimated on the basis of the patients' current income level. However, this approach may be discriminatory, in effect, against certain underproductive groups, such as students, housewives, and seniors. Some also criticize the approach for its implied ethic, i.e., that the value of human life can be measured on the basis of a person's ability to earn income. Finally, the approach also runs the risk of underestimating the intangible costs of illnesses, such as declines in quality of life and psychological suffering.

The human capital approach is the approach most commonly taken by the majority of studies. Compared to the WTP approach, the human capital approach is less time-consuming, more cost-effective, and better suited to ensuring the objectivity of analysis results, as it excludes the researcher's bias. Most importantly, it clearly quantifies losses of productivity due to illnesses based on patients' income levels.

\subsubsection{Willingness-to-pay approach}

Also known as the contingent valuation method, the WTP approach estimates the economic value of something that is not easily converted into a monetary sum by surveying how much people would be willing to pay for it. COI studies adopting this approach ask survey participants how much they would be willing to pay to maintain or improve their health. This approach acknowledges the very commonsensical assumption that people's preferences for things that are not easily monetized can be used to estimate the economic values of those things. However, as this approach requires people to estimate the economic values of things that they are not used to monetizing, the answers given by survey participants may not be a reliable measure of the true value of those things. The questions used to survey people's willingness to pay can be either open-ended or close-ended. Open-ended questions ask participants to state the maximum amounts of money they would be willing to pay, while close-ended questions provide a few options from which participants 
may choose. Close-ended questions can be further divided into questions that apply bidding games and that use the dichotomous choice method. Questions using bidding games identify the maximum amounts people would be willing to pay by presenting them with a series of specific amounts of money and asking them whether they would be willing to pay such amounts. Questions that use the dichotomous choice method, on the other hand, present participants with two options of monetary sums at each time and proceed to the next pair of options depending on which of the preceding options the participants chose. The dichotomous choice method imposes relatively less cognitive burden on participants in deciding the economic values of certain things and allows them to arrive at a decision even in the absence of in-depth knowledge of the market situation. However, the answers that participants choose through this method may be merely the amounts of money they view as acceptable to pay, and not the maximum amounts of money they would be willing to pay. In applying this method, it is also difficult for the researcher to decide the proper intervals between the figures to be presented, meaning that it may take quite a long time for the researcher to identify the final amount of money that participants would actually be willing to pay.

The table below provides a summary of the differences between the human capital approach and the WTP approach (Table 2).

\subsection{Perspectives of analysis}

The conclusions of analyses on the costs of illnesses may be dramatically different depending on which perspective the researchers chose to adopt. Since first attempted and defined, COI studies have been a popular topic of research and

\begin{tabular}{|c|c|c|}
\hline & Human capital approach & WTP approach \\
\hline Description & $\begin{array}{l}\text { - Assesses the value of one's current } \\
\text { life in terms of one's discounted } \\
\text { future expected income } \\
\text { - Regards humans as productive } \\
\text { actors and estimates the costs of } \\
\text { illnesses as losses of working hours } \\
\text { or productivity }\end{array}$ & $\begin{array}{l}\text { - Surveys people on how much they } \\
\text { would be willing to pay for certain } \\
\text { things } \\
\text { - Estimates the costs of illnesses based } \\
\text { on how much individuals would be } \\
\text { willing to pay to maintain or improve } \\
\text { their health }\end{array}$ \\
\hline Pros & $\begin{array}{l}\text { - Ease of accessing required data. } \\
\text { Ease of quantifying losses of } \\
\text { productivity caused by illnesses } \\
\text { based on patients' income levels } \\
\text { - Results less influenced by personal } \\
\text { bias }\end{array}$ & $\begin{array}{l}\text { - Able to measure the values of even } \\
\text { things not easily monetized } \\
\text { - Uses people's tacit preferences for } \\
\text { certain things to estimate the } \\
\text { economic values of those things } \\
\text { - Capable of counting even intangible } \\
\text { costs, such as quality of life and } \\
\text { psychological suffering }\end{array}$ \\
\hline Cons & $\begin{array}{l}\text { - Discriminatory against } \\
\text { underproductive groups, such as } \\
\text { students, housewives, seniors, etc. } \\
\text { - Minimizes human life by measuring } \\
\text { it solely on the basis of individuals' } \\
\text { ability to earn income } \\
\text { - Incapable of measuring intangible } \\
\text { costs of illnesses, e.g., declines in } \\
\text { quality of life and psychological } \\
\text { suffering }\end{array}$ & $\begin{array}{l}\text { - Decides the values of things solely on } \\
\text { the basis of people's subjective } \\
\text { preferences } \\
\text { - Participants may have difficulty } \\
\text { monetizing things that they usually } \\
\text { do not monetize, meaning that their } \\
\text { answers may be less than reliable as a } \\
\text { result }\end{array}$ \\
\hline
\end{tabular}

Table 2.

Comparison of approaches to estimating the costs of illnesses. 
debate among many researchers worldwide. Analyses in the established literature today are largely guided by three perspectives: namely, the payer perspective, the patient perspective, and the societal perspective [8-11].

\subsubsection{Payer perspective}

The payer perspective focuses on the costs of illnesses that are paid by insurers and not patients. In South Korea, these costs are the costs covered by the NHI or the healthcare costs confirmed by the Health Insurance Review and Assessment Service (HIRA). These covered costs can be either narrowly construed as only the amounts paid by the insurer or more broadly construed as including the amounts of copayments made by patients as well. Taking the broad meaning would thus require the estimation of the healthcare costs confirmed by the HIRA, which encompass both the costs paid by the insurer and the copayments made by patients.

\subsubsection{Patient perspective}

The patient perspective requires the researcher to analyze and estimate the costs paid by patients due to given illnesses. These costs include the direct healthcare and non-healthcare costs and indirect costs. The direct healthcare costs include the copayments made by patients, the non-covered costs, and the costs of informal medical services, while the direct non-healthcare costs include the expenses patients have to pay in order to receive medical services, such as transportation expenses. Finally, the indirect costs include the costs incurred by patients in terms of time and the costs of caregiving.

\subsubsection{Societal perspective}

The societal perspective leads to the estimation of the costs estimated from both the payer and patient perspectives and the losses of societal productivity caused by the given diseases. In other words, the costs estimated based on this perspective include the costs of lost labor and productivity due to patients taking leaves of absence or dying prematurely. These costs may also encompass the costs of declines in quality of life and the psychological suffering of patients.

The table below summarizes the differences among these perspectives (Table 3).

\subsection{Components of costs}

Existing studies that embrace the societal perspective generally posit several specific components of the costs subject to analysis, including direct costs, indirect costs, and intangible costs $[8,11-13]$.

\subsubsection{Direct costs}

Direct costs refer to the amounts of money spent directly on treating or managing a given illness or more specifically, the amounts of money spent at medical institutions for the treatment and management of such illness. These costs can be further broken down into direct healthcare costs and direct non-healthcare costs. The direct healthcare costs include the costs of outpatient and/or hospitalization services and purchasing medications (including prescribed medications) to treat the given illness. Furthermore, it includes the costs incurred by outpatients and 
Methodology of Estimating Socioeconomic Burden of Disease Using National Health Insurance... DOI: http://dx.doi.org/10.5772/intechopen.89895

\begin{tabular}{|c|c|c|c|c|c|}
\hline \multirow[t]{2}{*}{ Type } & \multirow[t]{2}{*}{ Category } & \multirow{2}{*}{$\begin{array}{l}\text { Components of } \\
\text { cost }\end{array}$} & \multicolumn{3}{|c|}{ Perspective } \\
\hline & & & $\begin{array}{c}\text { Payer } \\
\text { perspective }\end{array}$ & $\begin{array}{c}\text { Patient } \\
\text { perspective }\end{array}$ & $\begin{array}{c}\text { Societal } \\
\text { perspective }\end{array}$ \\
\hline \multirow[t]{5}{*}{ Direct } & \multirow[t]{3}{*}{ Healthcare costs } & Covered cost & $\checkmark$ & & $\checkmark$ \\
\hline & & Copayment & & $\checkmark$ & $\checkmark$ \\
\hline & & $\begin{array}{l}\text { Non-covered } \\
\text { cost }\end{array}$ & & $\checkmark$ & $\checkmark$ \\
\hline & \multirow[t]{2}{*}{$\begin{array}{l}\text { Non-healthcare } \\
\text { costs }\end{array}$} & $\begin{array}{c}\text { Cost of } \\
\text { transportation }\end{array}$ & & $\checkmark$ & $\checkmark$ \\
\hline & & $\begin{array}{c}\text { Cost of } \\
\text { caregiving }\end{array}$ & & $\checkmark$ & $\checkmark$ \\
\hline \multirow[t]{3}{*}{ Indirect } & \multirow{3}{*}{$\begin{array}{l}\text { Losses of } \\
\text { productivity }\end{array}$} & Outpatients & & & $\checkmark$ \\
\hline & & $\begin{array}{c}\text { Hospitalized } \\
\text { patients }\end{array}$ & & & $\checkmark$ \\
\hline & & $\begin{array}{l}\text { Premature } \\
\text { deaths }\end{array}$ & & & $\checkmark$ \\
\hline Intangible & \multicolumn{2}{|c|}{$\begin{array}{l}\text { Declines in quality of life, } \\
\text { psychological suffering, etc. }\end{array}$} & & & $\checkmark$ \\
\hline
\end{tabular}

Table 3.

Costs estimated based on different perspectives.

hospitalized patients alike due to disease, encompassing covered costs paid by insurer, copayments paid by patients, non-covered costs, and prescription costs.

The direct non-healthcare costs refer to the expenses paid by patients to visit and use the services of medical institutions, such as the costs of transportation and caregiving.

\subsubsection{Indirect costs}

Indirect costs refer to the losses of labor and productivity that are incurred in addition to the tangible (financial) costs of an illness. Examples include the amounts of time taken off (paid) work to go to medical institutions and the loss of future expected income, not only of patients but also of their family members or other loved ones who are compelled to care for them. The latter example may also be expressed as the opportunity costs of being ill, including the losses of working hours and leisure time.

The indirect costs, or losses of productivity, are estimated by defining the number of hospitalization days as the number of working days lost and the amounts of time spent for outpatient visits, as losses of working time. The losses of future income are due to the premature deaths of patients.

\subsubsection{Intangible costs}

The intangible costs represent the decline in the quality of life and psychological suffering of patients and loved ones. However, it is notoriously difficult to define and quantify these costs with precision (Drummond et al., 2005). Due to the scarcity of related data and the difficulty of quantification, researchers often forgo estimating these costs (Table 4). 


\begin{tabular}{|c|c|c|c|c|}
\hline Type & Category & Costs & & Definition \\
\hline \multirow[t]{8}{*}{ Direct } & \multirow[t]{6}{*}{$\begin{array}{l}\text { Healthcare } \\
\text { costs }\end{array}$} & \multirow[t]{3}{*}{$\begin{array}{l}\text { Medical } \\
\text { institutions }\end{array}$} & $\begin{array}{l}\text { Covered } \\
\text { cost }\end{array}$ & $\begin{array}{l}\text { Portion of cost confirmed by the HIRA and paid } \\
\text { by insurers }\end{array}$ \\
\hline & & & Copayment & $\begin{array}{l}\text { Portion of cost confirmed by the HIRA and paid } \\
\text { by patients }\end{array}$ \\
\hline & & & $\begin{array}{l}\text { Non- } \\
\text { covered cost }\end{array}$ & $\begin{array}{l}\text { Cost paid by patients and not confirmed by the } \\
\text { HIRA }\end{array}$ \\
\hline & & \multirow[t]{3}{*}{ Pharmacies } & $\begin{array}{l}\text { Covered } \\
\text { prescription } \\
\text { cost }\end{array}$ & Cost of prescription drugs paid by insurers \\
\hline & & & $\begin{array}{l}\text { Prescription } \\
\text { copayment }\end{array}$ & Cost of prescription drugs paid by patients \\
\hline & & & $\begin{array}{l}\text { OTC drug } \\
\text { cost }\end{array}$ & Cost of purchasing over-the-counter drugs \\
\hline & \multirow{2}{*}{$\begin{array}{l}\text { Non- } \\
\text { healthcare } \\
\text { costs }\end{array}$} & \multicolumn{2}{|c|}{ Cost of transportation } & $\begin{array}{l}\text { Cost of traveling to and from medical } \\
\text { institutions }\end{array}$ \\
\hline & & \multicolumn{2}{|c|}{ Cost of caregiving } & $\begin{array}{l}\text { Cost of hiring professional caregivers or } \\
\text { opportunity cost incurred by family members in } \\
\text { providing care }\end{array}$ \\
\hline \multirow[t]{3}{*}{ Indirect } & $\begin{array}{l}\text { Losses of } \\
\text { productivity }\end{array}$ & \multicolumn{2}{|l|}{ Outpatients } & $\begin{array}{l}\text { Loss of working hours due to visiting medical } \\
\text { institutions as outpatients }\end{array}$ \\
\hline & & \multicolumn{2}{|c|}{ Hospitalized patients } & Loss of working hours due to hospitalization \\
\hline & & \multicolumn{2}{|c|}{ Premature deaths } & Losses of productivity due to death of patients \\
\hline Intangible & \multicolumn{3}{|c|}{$\begin{array}{l}\text { Declines in quality of life, psychological } \\
\text { suffering, etc. }\end{array}$} & $\begin{array}{l}\text { Cost associated with declining quality of life and } \\
\text { psychological suffering }\end{array}$ \\
\hline
\end{tabular}

Table 4 .

Cost components and definitions.

\section{Example of COI research using NHI data}

In this section, we present example of estimating cost-of-illness research using NHI data. This example titled "Socioeconomic Cost of Allergies" estimates the socioeconomic costs associated with allergic diseases using NHI data in South Korea [14]. In South Korea, all citizens are compulsory subscribers to the NHI scheme, which is a type of social insurance, and all medical institutions or health professionals are required to submit claim data to the NHI to charge the bill for the medical services. In other words, the NHI has medical information on around 50 million South Koreans. We hope this example will be useful for readers to conduct cost-of-illness studies.

\subsection{Study design and cost components}

The present example adopts the prevalence-based approach, because it is important to take into account both new and existing patients suffering from allergic diseases during certain periods. As well, this example employs the human capital approach as the value assessment method, because it clearly quantifies losses 
of productivity due to illness based on patients' income levels. Moreover, it is better suited to ensuring the objectivity of analysis results, as it excludes the researcher's bias. As for perspective, this study adopts the societal perspective and estimates both the direct costs paid by the insurer and patients and society-wide losses of productivity.

As the purpose of this study is to estimate the entire scope of the socioeconomic costs generated by allergic diseases in South Korea, this study estimates both the direct and indirect costs. The direct costs are divided into healthcare and nonhealthcare costs, as in previous studies that adopted the societal perspective. The indirect costs involve losses of productivity. More specifically, the direct healthcare costs include the costs incurred by outpatients and hospitalized patients, encompassing covered costs paid by insurer, copayments made by patients, noncovered costs, and prescription costs. The direct non-healthcare costs involve all expenses associated with visiting medical institutions, whether as outpatients or hospitalized patients, and receiving services for the treatment and management of allergic diseases, including the costs of transportation and caregiving. The indirect costs, or losses of productivity, are estimated by defining the number of hospitalization days as the number of working days lost and the amounts of time spent for outpatient visits, as losses of working time. The losses of future income due to the premature deaths are estimated for patients aged 15-69 (patients outside of this age bracket are excluded, as, in accordance with the law, they constitute the nonworking-age population). Due to the absence of objective data, however, intangible costs are not estimated in this example. The figure below summarizes the components of costs estimated in this study (Table 5).

\begin{tabular}{lll}
\hline Direct costs & Healthcare costs & $\frac{\text { Covered cost }}{\text { Copayment }}$ \\
\cline { 3 - 3 } & $\frac{\text { Non-covered cost }}{\text { Non-healthcare costs }}$ & Cost of medications \\
\hline Indirect costs & Cost of caregiving \\
\hline
\end{tabular}

Table 5 .

Components of estimated costs in this example.

\subsection{Data source and case definition}

To analyze the socioeconomic costs due to allergic diseases in South Korea, this study used the 2014 National Patient Sample (NPS) derived from NHI data that were collected by the HIRA. In South Korea, almost all citizens (98\% or higher) are compulsory subscribers to the NHI scheme, which is a type of social insurance, and all medical institutions are required to submit claim data to the HIRA to charge the bill for the medical services they provided when patients visited the medical institution. Consequently, the HIRA has medical information on around 50 million South Koreans. The NPS is the data of patients sampled from the large amount of claim data held by the HIRA, and it is an abridged version of claim data that contain 1-year information regarding medical treatments and prescriptions of the sampled patients. The data contain the information of about 1.4 million patients, who represent a sample of $3 \%$ of all patients. 
The NHI data is administrative data, and the prevalence rate is influenced by the case definition of disease. In other words, prevalence rates can vary dramatically depending on how the cases are defined. Most of previous studies that made use of administrative data including NHI data generally used primary diagnoses to estimate prevalence rates. This approach, however, carries the risk of either underestimating or overestimating the prevalence rates. This study therefore applied more rigorous criteria in defining prevalence. First, it identified and extracted patients whose primary and secondary diagnoses were indicated using the ICD-10 codes for allergic diseases. Of these patients, this study identified those who had been hospitalized or made at least two outpatient visits each for allergic diseases and had been prescribed drugs commonly used to treat allergic diseases (as indicated in their insurance billing records), such as nedocromil sodium, oral steroids, ventolin, and so on. Only patients meeting these rigorous criteria were admitted into this study as patients.

\subsection{Estimation methods}

The sources of data for each component of the costs estimated in this studyincluding direct and indirect costs-are as follows.

\subsubsection{Direct costs}

Direct costs refer to the amounts of spending directly related to illness and are divided into healthcare and non-healthcare costs.

Direct healthcare costs are the costs of preventing, treating, or managing illnesses by using medical institutions and include the costs of outpatient services, hospitalization, and medications (prescriptions). The majority of existing studies that estimate direct healthcare costs rely on administrative and official statistics for their estimations. As there is little controversy over the use of administrative and official statistics in estimating the direct healthcare costs of illness, this study, also, uses the NHI data to estimate the direct healthcare costs of allergic diseases.

Depending on who pays them, direct healthcare costs can be further broken down into covered costs paid by insurer, copayments made by patients, and non-covered costs also paid by patients. The formula used to estimate the direct healthcare costs is provided below.

$$
\mathrm{DHC}=\sum_{s} \sum_{y}\left[E_{i s y}(1+\alpha)+E_{o s y}(1+\beta)\right]
$$

where DHC = Direct healthcare costs, $\mathrm{s}=$ Sex, $\mathrm{y}=$ Age, $\mathrm{E}=$ Costs, $\mathrm{i}=$ Hospitalized patients, $o=$ Outpatients, $\alpha=$ Non-covered cost ratio (hospitalized patients), $\beta=$ Non-covered cost ratio (outpatients).

The direct non-healthcare costs are the costs of transportation and caregiving incurred by patients in seeking and receiving the services of medical institutions. This study draws upon the national official statistics data on transportation costs. This data include information on the costs of one-way transportation paid by outpatients and hospitalized patients and estimate the final costs of transportation based on the assumption that some patients would be accompanied by their caregivers. The costs of one-way trips were multiplied by the price-adjusted index and used to estimate the total costs of round-trip transportation. As for the cost of caregiving, this study used the average daily cost of hiring a caregiver, as suggested by the caregivers association. Defining the cost of caregiving as the opportunity cost of caregivers' time during patients' hospitalization, this study applied the average 
daily wage for caregivers as the unit cost of caregiving. This unit cost was then multiplied by the number of hospitalization days. The cost of caregiving was also estimated for outpatient visits based on the assumption that each outpatient visit takes up one-third of the caregiver's daily working hours. The formula used to estimate the direct non-healthcare costs is provided below.

$$
\mathrm{NHC}=\sum_{s} \sum_{y}\left[\left(N_{i s y}+N_{o s y}\right) \times C t \times 2\right]+\sum_{s} \sum_{y}\left[\left(L_{i s y} \times C c\right)+\frac{1}{3}\left(\left(N_{o s y} \times C_{c}\right)\right]\right.
$$

where NHC = Direct non-healthcare costs, $\mathrm{s}=$ Sex, $\mathrm{y}=$ Age, $\mathrm{N}=$ Number of visits, $\mathrm{i}=$ Inpatients, $\mathrm{o}=$ Outpatients, $\mathrm{Ct}=$ Cost of transportation, $\mathrm{L}=$ Length of stay, $\mathrm{Cc}=$ Cost of caregiving.

\subsubsection{Indirect costs}

Indirect costs do not represent actual financial costs paid but the losses of labor and productivity due to illnesses. The indirect costs represent the amounts of working time lost in order to visit and use the services of medical institutions, the loss of future income due to the premature death of patients, and the opportunity cost of caregiving. The opportunity costs so incurred include not only the amount of working time lost but also the amount of leisure time lost. This study draws upon the employment and labor statistics provided by the government in order to estimate the indirect costs. These statistics are part of the official employment and labor statistics that provide information on the average daily and monthly wages, total working hours, and employment rates by sex and age.

The losses of labor (productivity) due to the need for treatment and recovery and losses of future income due to premature death were estimated in the following manner. First, loss of labor can be understood as the opportunity cost of labor incurred by spending time hospitalized or making outpatient visits to medical institutions instead of working. These opportunity costs were thus estimated for the working-age population (ages 15-69). In the case of hospitalized patients, loss of productivity was found by multiplying the daily average wage for each age group by the number of hospitalization days. For outpatients, the daily average wage for each age group was multiplied by the number of outpatient visits made, and the result was divided by 3 (based on the assumption that outpatient visits took up one-third of each patient's daily working hours). The formula used to estimate the losses of productivity is provided below.

$$
\mathrm{PL}=\sum_{s} \sum_{y}\left[\left(N_{i s y}+\frac{1}{3} N_{o s y}\right) \times W_{s y} \times E_{s y}\right]
$$

where PL = Productivity loss, $\mathrm{s}=$ Sex, $\mathrm{y}=$ Year, $\mathrm{N}=$ Number of hospitalization days (visits), $\mathrm{i}=$ Inpatients, $\mathrm{o}=$ Outpatients, $\mathrm{W}=$ Average wage, $\mathrm{E}=$ Employment rate.

The loss of future income due to the premature death of patients represents the decrease in expected income that individuals could have earned had they lived to their full life expectancy. To estimate this loss, this study relied upon the raw data for the official statistics on causes of death provided by the government to identify the number of deaths by sex and age and then applied the death rate to the average monthly wage and number of working days for each age group. The loss of future income was again estimated for the working-age population (ages 15-69) only, applying the employment rate of each age group. In order to convert the estimated 
loss of future income into a present value, a discount rate was applied, and the sensitivity to changes in the discount rate was checked by applying additional discount rates. The formula used to estimate the loss of future income due to premature death is shown below.

$$
\mathrm{LFI}=\sum_{s} \sum_{y} \sum_{k=1}^{n}\left(N_{s y} \times \frac{Y s y(t+k) \times P s y(t+k)}{(1+r)^{k}}\right)
$$

where LFI = Loss of future income, $\mathrm{s}=$ Sex, $\mathrm{y}=$ Age, $\mathrm{k}=1,2, \ldots, \mathrm{n}$ (where " $\mathrm{n}$ " represents the difference between the life expectancy and actual average age at death for each age cohort), $t=$ Age at death, $r=$ Discount rate, Nsy $=$ Number of premature deaths associated with allergic diseases by sex and age, $\mathrm{Ysy}(\mathrm{t}+\mathrm{k})=$ Annual average income at $t+k$ by sex and age, Psy $(t+k)=$ Employment rate at $\mathrm{t}+\mathrm{k}$ by sex and age.

\title{
4. Conclusions
}

The COI study measures socioeconomic losses from certain diseases in a country. Therefore, it can provide basic information and evidence that is very important for policy prioritization and resource allocation. For these reasons, many countries are using the COI study to establish health policies. In particular, the COI study has the advantage that it is easy to understand not only policymakers but also the general public by converting national losses from diseases into monetary value.

In this chapter, we reviewed various methodologies and techniques for estimating the socioeconomic burden of disease. As well, we presented an example of COI study. We hope that this chapter will help readers better understand and use the COI study.

\section{Author details}

\author{
Hyeon-Jin Choi and Eun-Whan Lee* \\ Gyeonggi Research Institute, Suwon City, South Korea \\ *Address all correspondence to: ewlee@gri.re.kr
}

\section{IntechOpen}

(C) 2019 The Author(s). Licensee IntechOpen. This chapter is distributed under the terms of the Creative Commons Attribution License (http://creativecommons.org/licenses/ by/3.0), which permits unrestricted use, distribution, and reproduction in any medium, provided the original work is properly cited. (c) BY 
Methodology of Estimating Socioeconomic Burden of Disease Using National Health Insurance... DOI: http://dx.doi.org/10.5772/intechopen.89895

\section{References}

[1] Cooper NJ. Economic burden of rheumatic arthritis: A systematic review. Rheumatology. 2000;39:28-33

[2] Stone CE. The lifetime economic costs of rheumatoid arthritis. The Journal of Rheumatology. 1984;11: 819-827

[3] Scitovsky AA. Estimating the direct costs of illness. The Milbank Memorial Fund Quarterly. Health and Society. 1982;60:463-491

[4] Birnbaum HG, Leong SA, Oster EF, Kinchen K, Sun P. Cost of stress urinary incontinence. PharmacoEconomics. 2004;22(2):95-105

[5] Chapman KR, Mannino DM, Soriano JB, Vermeire PA, Buist AS, Thun MJ, et al. Epidemiology and costs of chronic obstructive pulmonary disease. The European Respiratory Journal. 2006;27(1):188-207

[6] Cooper BS, Rice DP. The economic cost of illness revisited. Social Security Bulletin. 1976;39(2):21-36

[7] Rice DP. Cost-of-illness studies: Fact or fiction? Lancet. 1994;344(8936):

1519-1520

[8] Rice DP. Estimating the cost of illness. American Journal of Public Health and the Nation's Health. 1967; 57(3):424-440

[9] Malek M, Chang BH, Gallagher SS, Guyer B. The cost of medical care for injuries to children. Annals of Emergency Medicine. 1991;20(9):997-1005

[10] Miller TR, Romano EO, Spicer RS. The cost of childhood unintentional injuries and the value of prevention. The Future of Children. 2000;10(1):137-163

[11] Leal J, Leungo-Fernandez R, Gray A, Petersen S, Rayner M. Economic burden of cardiovascular diseases in the enlarged European Union. European Heart Journal. 2006;27(10):1610-1619

[12] Gergen PJ. Understanding the economic burden of asthma. The Journal of Allergy and Clinical Immunology. 2001;107:s445-s448

[13] Tarricone R. Cost-of-illness analysis. What room in health economics? Health Policy. 2006;77:51-63

[14] Lee EW, Cha SH, Kim W, Choi HJ. Socioeconomic Cost of Allergies. Suwon, South Korea: Gyeonggi Research Institute; 2016 


\section{Edited by Sandeep Reddy and Aida Isabel Tavares}

As the costs and resources of delivering health services have increased over the years, the importance of evaluating health services and interventions has become essential. An evaluation provides a systematic process of assessing the efficacy and efficiency of health services, including an assessment of their impact on beneficiaries, whether it be individuals or communities. Evaluation in the health sector includes the evaluation of burden disease where human and economic costs resulting from poor health are measured.In this book, various evaluation studies are detailed, providing an excellent resource for both evaluation practitioners and academics alike. The geographical range and variety of case studies showcase how evaluation has become integral for health service planning and assessment and to assist public health policy makers decide how to use limited resources to minimize burden and inequity. This book will act as a ready resource for both workers experienced in health service evaluation and those intending to learn about burden of disease of evaluation.

\section{IntechOpen}

